\title{
Análise estabilográfica da postura ereta humana quasi-estática
}

\section{Marcos Duarte}

Escola de Educação Física e Esporte

Universidade de São Paulo 


\section{Análise estabilográfica da postura ereta humana quasi-estática}

\section{Marcos Duarte}

Escola de Educação Física e Esporte

Universidade de São Paulo

Tese apresentada à Escola de Educação Física e Esporte da Universidade de São Paulo, como requisito parcial para Concurso de Livre Docência na área de Biomecânica, junto ao Departamento de Biodinâmica do Movimento do Corpo Humano. 


\section{Sumário}

1 Introdução $\quad 8$

2 Controle postural 11

$\begin{array}{lll}2.1 & \text { Sistemas sensoriais } & 12\end{array}$

2.2 Sinergias posturais $\quad 12$

$\begin{array}{lll}2.3 & \text { Estabilometria } & 13\end{array}$

$\begin{array}{lll}2.4 & \text { Centro de gravidade e centro de pressão } & 15\end{array}$

2.5 Um modelo biomecânico simples da postura ereta 16

2.6 Determinação do centro de gravidade 18

$\begin{array}{lll}2.7 & \text { Decomposição do sinal de posturografia } & 21\end{array}$

$\begin{array}{lll}2.8 & \text { Um software para análise de dados da estabilografia } & 22\end{array}$

3 Padrões no sinal do centro de pressão durante postura ereta irrestrita de longa duração 24

$\begin{array}{lll}3.1 & \text { Introdução } & 25\end{array}$

3.2 Exemplos preliminares e terminologia $\quad 25$

$\begin{array}{lll}3.3 & \text { Modelo e algoritmo } & 27\end{array}$

3.4 Experimento 30

3.5 Dependência do reconhecimento dos padrões com os valores dos parâmetros 31

$\begin{array}{lll}3.6 & \text { Resultados } & 32\end{array}$

$\begin{array}{lll}3.7 & \text { Discussão } & 35\end{array}$

4 Análise estabilográfica da postura ereta irrestrita

$\begin{array}{lll}4.1 & \text { Introdução } & 38\end{array}$

4.2 Método $\quad 40$

$\begin{array}{lll}4.3 & \text { Análise dos dados } & 41\end{array}$

4.4 Resultados $\quad 42$

$\begin{array}{lll}4.5 & \text { Discussão } & 47\end{array}$

$\begin{array}{lll}4.6 & \text { Conclusões } & 48\end{array}$

5 Processos de correlação de longo alcance na postura ereta humana irrestrita 50

5.1 Introdução

$5.2 \quad$ Materiais e métodos $\quad 52$ 
5.3 Resultados e discussão $\quad 53$

6 Propriedades fractais da postura ereta humana 57

6.1 Introdução $\quad 58$

6.2 Materiais e métodos $\quad 58$

6.3 Resultados $\quad 59$

$\begin{array}{lll}6.4 & \text { Discussão } & 60\end{array}$

$\begin{array}{lll}6.5 & \text { Conclusão } & 61\end{array}$

7 Acurácia e velocidade de movimento durante a postura ereta 62

$\begin{array}{lll}7.1 & \text { Introdução } & 63\end{array}$

$\begin{array}{lll}7.2 & \text { Material e métodos } & 63\end{array}$

$\begin{array}{lll}7.3 & \text { Resultados e discussão } & 64\end{array}$

$8 \quad$ Informação visual, limites de estabilidade e variabilidade da postura ereta 66

$\begin{array}{lll}8.1 & \text { Introdução } & 67\end{array}$

$\begin{array}{lll}\text { 8.2 } & \text { Materiais e métodos } & 68\end{array}$

$\begin{array}{lll}8.3 & \text { Resultados } & 70\end{array}$

$\begin{array}{lll}8.4 & \text { Discussão } & 76\end{array}$

9 Conclusões gerais

10 Comentários finais $\quad 80$

11 Referências $\quad 81$ 


\section{Índice de Tabelas}

Tabela 1. Número médio de padrões de migração do COP reconhecidos pelos algoritmos (postura ereta irrestrita, 30 min, 10 sujeitos, 2 tentativas, direções a-p e m-l).

Tabela 2. Média e desvio padrão do deslocamento do COP (SD), velocidade do deslocamento do COP $(V)$, freqüência média $\left(F_{\text {média }}\right)$ do deslocamento do COP e a área do estabilograma durante postura ereta irrestrita para diferentes cargas e condições visuais $(n=5)$. Dados apresentados como média \pm desvio padrão.

Tabela 3. Média e desvio padrão do deslocamento do COP (SD), velocidade do deslocamento do COP $(V)$, freqüência média $\left(F_{\text {média }}\right)$ do deslocamento do COP e a área do estabilograma durante postura ereta irrestrita para diferentes superfícies de apoio e solados de calçados $(n=6)$. Dados apresentados como média \pm desvio padrão.

Tabela 4. Médias, desvios padrões e interações das variáveis área do estabilograma (AREA), velocidade média resultante do COP (V) e freqüencia mediana do COP (Fmed) para os seguintes alvos: neutro $(N)$, extremo anterior $(E A)$, extremo posterior $(E P)$, extremo esquerdo $(E E)$ e extremo direito $(E D)$. ANOVA medidas repetidas, teste post-hoc de Tukey. Niveis de significância: $*<0,05$; **<0,01; *** $<0,001$. 


\section{Índice de Figuras}

Figura 1. Diagrama conceitual do sistema de controle postural.

Figura 2. Três estratégias posturais usadas normalmente pelos adultos no controle da postura ereta, da esquerda para a direita: estratégia do tornozelo, do quadril e do passo. (Shummway-Cook \& Woollacott, 1995).

Figura 3. Estabilograma representativo durante postura ereta quieta (linha contínua). Nesta figura, pode-se observar o conceito de campos de força na postura: a representação da trajetória do COP $e$ os vetores de força horizontal. Note que para pequenos intervalos de tempo, vetores de força consecutivos convergem para (aproximadamente) um pólo (exemplos 1 e 2) e para longos intervalos de tempo eles convergem para diferentes pólos (Zatsiorsky \& Duarte, 2000).

Figura 4. Representação esquemática da relação entre COP e COG durante a postura ereta de um sujeito oscilando para frente e para trás. As distâncias do COP (p) e COG (g), o vetor peso $(W), o$ vetor força de reação do solo $(R)$, e vetores representativos para a velocidade $(\omega)$ e aceleração $(\alpha)$ angulares em cinco instantes diferentes são indicados (Winter, 1990).

Figura 5. Representação do modelo físico-matemático de um pêndulo invertido do corpo humano durante a postura ereta quieta para o plano sagital.

Figura 6. Trajetórias do COP, GL e da diferença entre COP e GL, $\Delta_{C O P G L}$, na direção a-p durante postura ereta quieta.

Figura 7. Trajetórias do COP, GL e força horizontal, $F$, na direção a-p durante postura ereta com oscilação forçada do tornozelo.

Figura 8. Exemplo representativo da densidade de potência espectral (PSD, power spectral density) das trajetórias COP e GL na direção a-p para postura quieta por $30 \mathrm{~s}$. PSD calculado pelo método de periodograma de Welch com resolução de 0,039 $\mathrm{Hz}$.

Figura 9. Trajetórias do COP, componentes rambling e trembling e os pontos de equilíbrio instantâneo (IEP) durante a postura ereta quieta. A figura menor representa um pêndulo simples invertido idealizando o significado das componentes do COP.

Figura 10. Janela principal do software PostTool desenvolvido para a análise do sinal do centro de pressão da estabilografia.

Figura 11. Migração do COP em duas tentativas diferentes, direção a-p versus m-l. Postura ereta de multi-região (1) e uni-região (2). O mesmo sujeito (mulher, 25 anos, 1,74 $\mathrm{m}$ de altura e 59,2 $\mathrm{kg}$ de massa) permaneceu em pé por 30 minutos duas vezes com um intervalo de uma semana.

Figura 12. Exemplo representativo de migração do COP e padrões durante a postura ereta irrestrita de longa duração. Direção a-p (homem, 26 anos, 1,85 $\mathrm{m}$ de altura e 89,1 $\mathrm{kg}$ de massa). Os picos de fidget (*) foram selecionados com um limiar de $\pm 3,0$ SD. Apenas um shift e um drift são indicados para uma melhor visualização.

Figura 13. Exemplo representativo do padrão shift e os parâmetros usados para reconhecimento.

Figura 14. Exemplo representativo do padrão fidget e os parâmetros usados para reconhecimento.

Figura 15. Exemplo representativo do padrão drift e os parâmetros usados para reconhecimento.

Figura 16. Número de padrões reconhecidos com diferentes valores limiares para os parâmetros dos algoritmos (f). (a) para shifts: 1,0; 1,5; 2,0 e 2,5 SD para diferentes janelas: 15; 30 e 60 s; máxima largura do shift fixada em $5 \mathrm{~s}$. Os dados para a largura $15 \mathrm{~s}$ foram ajustados pela equação $N_{\text {shift }}=25$ $+23 \cdot e^{-(f s-1.0) / 0.5}$. (b) para fidgets: 1,0; 2,0; 3 e 4 SD para diferentes janelas: 30, 60, and $120 \mathrm{~s}$, a largura máxima dos fidgets foi fixada em 4 s. Os dados para uma janela de 60 s foram ajustados pela 
equação $N_{\text {fidget }}=252 \cdot e^{1-f f}$. (c) para drifts: 0,$5 ; 1,0 ; 1,5$ and 2,0 SD, para diferentes comprimentos mínimos do drift: 30, 60, and $90 \mathrm{~s}$, o coeficiente de variabilidade foi fixado em 5. Os dados para uma janela de $60 \mathrm{~s}$ foram ajustados pela equação $N_{\text {drift }}=0.92+3.33 \cdot e^{-(f d-0.5) / 0.72}$. Postura ereta irrestrita, 10 sujeitos, 2 tentativas, direções a-p e $m$-l.

Figura 17. Número de shifts durante postura ereta irrestrita por 30 minutos para diferentes sujeitos e tentativas para direção a-p (a) e m-l (b). 10 sujeitos, 2 tentativas.

Figura 18. Número de fidgets durante postura ereta irrestrita por 30 minutos para diferentes sujeitos e tentativas para a direção a-p (a) e m-l (b). 10 sujeitos, 2 tentativas.

Figura 19. A distribuição de fidgets para janelas de $180 \mathrm{~s}$ em relação ao número total durante postura ereta irrestrita por 30 minutos para diferentes sujeitos e tentativas para a direção a-p (a) e m-l (b). 10 sujeitos, 2 tentativas.

Figura 20. Número de drifts durante postura ereta irrestrita por 30 minutos para diferentes sujeitos e tentativas para direção a-p (a) e m-l (b). 10 sujeitos, 2 tentativas.

Figura 21. Exemplos de dominância de padrões de shift (a), fidget (b), e um longo drift (c) em diferentes sujeitos durante postura ereta irrestrita. Sujeitos descalços sobre a superfície da plataforma de força.

Figura 22. Média e desvio padrão dos números de padrões de shifting, fidgeting e drifting por minuto durante postura ereta irrestrita em diferentes condições de carga e visão $(n=5)$. O símbolo * entre os dois pares de colunas indica um efeito da visão (ANOVA 2 fatores, $p<0,05$ ).

Figura 23. Média e desvio padrão dos números de padrões de shifting, fidgeting e drifting por minuto durante postura ereta irrestrita em diferentes condições de superficie de apoio e tipo de solado dos calçados $(n=6)$.

Figura 24. (a) Posição dos sujeitos sobre a plataforma de força e convenção dos eixos. Dois exemplos de estabilogramas durante 30 minutos de postura ereta irrestrita: (b) multi-região e (c) uni-região e série temporal representativa do COP.

Figura 25. Expoentes DFA, $\alpha$, (a) e PSA, $\beta$, (b). Linhas finas são os ajustes lineares para os dez sujeitos em ambas as direções para intervalos maiores que $10 \mathrm{~s}$ ou freqüencias menores que $10^{-1} \mathrm{~Hz}$ (indicada pela flecha tracejada). Os valores medianos são mostrados em linhas espessas. As linhas e valores dos expoentes de escala para ruído branco e ruído browniano são mostrados para comparação (linhas tracejadas).

Figura 26. Estabilogramas (esquerda) e séries temporais do COP na direção ântero-posterior (a-p) (direita) para os dados durante a postura ereta natural (1800 s, primeira linha), para 1/10 dos dados (180 s, segunda linha) e para 1/100 dos dados (18 s, terceira linha). O expoente de Hurst (H) para este exemplo é 0,34, resultando numa redução de 2,2 na escala de amplitude para cada 10 vezes de redução da escala de tempo. Ambos os eixos reais e escalonados são indicados nos gráficos de $180 \mathrm{~s}$ e de 18 s para ilustração. Note que depois de cada escalonamento (relacionado ao expoente fractal e ao periodo de tempo), os três estabilogramas e séries temporais apresentam aproximadamente as mesmas amplitudes em espaço. Para melhor claridade, nem todos os pontos são mostrados nos gráficos de $1800 \mathrm{~s}$ e $180 \mathrm{~s}$. A diferença na estrutura fina, observada para s série temporal de $18 \mathrm{~s}$ comparada às outras duas séries temporais, é devido ao fato que os deslocamentos do COP para intervalos de até $1 \mathrm{~s}$ mostram um comportamento diferente. Este comportamento é provavelmente devido às características inerciais do corpo ou a diferentes mecanismos de controle do equilibrio (conhecido como modelo de circuito aberto/fechado (ver Collins e De Luca, 1993)).

Figura 27. Gráfico R/S em escala log-log para os dados do COP de $1800 \mathrm{~s}$ do exemplo da figura anterior (ajuste para $k \equiv 10 \mathrm{~s}$ até $600 \mathrm{~s}$, inclinação $=0,34, r=0,99, p<0,00001$ ).

Figura 28. Média do tempo de movimento (TM) em função do indice de dificuldade (ID) para diferentes amplitudes de movimento (A): 3; 4,5; 6 e $9 \mathrm{~cm}$. Regressões lineares e correspondentes coeficientes de correlação (r) são apresentados para cada $A$.

Figura 29. Limites de estabilidade explorada (ELOS) versus limites de estabilidade física (PLOS) para a direção a-p (altura), direção m-l (largura) e área. Note que os valores para as áreas foram divididos por $20 \mathrm{~cm}$ para melhor claridade. $N=11$.

Figura 30. Exemplo representativo dos limites de estabilidade física (PLOS) e limites de estabilidade explorada pelo sujeito (ELOS), posição média e elipse representando 85\% da oscilação do COP nas três condições visuais, visão, sem visão e com feedback para os 13 alvos. Sujeito AS. 
Figura 31. Média da área coberta pelos deslocamentos do COP para as três condições $(V, N V, F)$ em função dos 13 alvos relativos ao ELOS (superior), média e desvio padrão para os 5 alvos na direção $m$-l (inferior esquerda) e média e desvio padrão para os 5 alvos na direção a-p (inferior direita). Valores positivos da posição dos alvos representam a direita para a direção $m$-l e a frente para a direção $a-p$.

Figura 32. Média da velocidade média resultante dos deslocamentos do COP (V COP) para as três condições $(V, N V, F)$ em função dos 13 alvos relativos ao ELOS (superior), média e desvio padrão para os 5 alvos na direção m-l (inferior esquerda) e média e desvio padrão para os 5 alvos na direção a-p (inferior direita). Valores positivos da posição dos alvos representam a direita para a direção m-l e a frente para a direção $a-p$.

Figura 33. Média da freqüência mediana dos deslocamentos do COP para as três condições $(V, N V, F)$ em função dos 13 alvos relativos ao ELOS (superior), média e desvio padrão para os 5 alvos na direção m-l (inferior esquerda) e média e desvio padrão para os 5 alvos na direção a-p (inferior direita). Valores positivos da posição dos alvos representam a direita para a direção m-l e a frente para a direção $a-p$. 


\section{Introdução}

Desde que nós humanos adotamos a postura ereta bípede, temos sido desafiados pela força de gravidade para manter o equilíbrio do corpo sobre a pequena área de suporte delimitada pelos pés. Quando permanecemos parados, não permanecemos sem movimento nós oscilamos. Somente quando a habilidade de controlar a postura ereta se deteriora, como nos idosos e em certas patologias, por exemplo, distúrbios do sistema vestibular, derrame e portadores de mal de Parkinson, é que se percebe o quão difícil e crucial esta tarefa é.

Não obstante a aparente simplicidade da tarefa, o controle da postura é um grande desafio para o corpo humano. O sistema de controle postural deve ser capaz de regular o equilíbrio em situações instáveis e por outro lado, deve ser suficientemente versátil para permitir a rápida iniciação do movimento. Talvez, a mais óbvia tarefa realizada pelo sistema de controle postural é a manutenção da postura ereta bípede, mas este sistema também atua durante o movimento do andar, por exemplo. Simplificadamente, a tarefa do sistema de controle postural é manter a projeção horizontal do centro de gravidade (COG) do individuo dentro da base de suporte definida pela área da base dos pés durante a postura ereta estática. A estabilidade é alcançada gerando-se momentos de força sobre as articulações do corpo para neutralizar o efeito da gravidade ou qualquer outra perturbação em um processo contínuo e dinâmico durante a permanência em determinada postura. Para a regulação do equilíbrio, o sistema necessita de informações sobre as posições relativas dos segmentos do corpo e da magnitude das forças atuando sobre o corpo. Para tanto, três classes de sensores podem ser utilizadas pelo corpo: somatossensorial, visual e vestibular. Estes receptores atuam de forma complexa, integrada, redundante e de maneira diferenciada para cada perturbação sobre o corpo humano. As propriedades passivas do sistema músculo-esquelético, principalmente a rigidez das estruturas biológicas, também desempenham um importante papel na manutenção do equilibrio. $O$ controle do equilibrio postural em uma pessoa é altamente afetado pela natureza da tarefa, pelas condições ambientais e pelas informações sensoriais disponíveis em função destes dois fatores anteriores e das condições da pessoa.

O presente trabalho tem como objetivo descrever pesquisas por eu conduzidas que procuraram abordar a complexa temática do controle da postura e equilibrio. A saber: (a) Sobre a análise do sinal estabilográfico e quadros de referência da postura humana, (b) Sobre a postura irrestrita de longa duração, e (c) Sobre tarefas envolvendo feedback visual do centro de pressão e o papel da informação visual no controle da postura ereta. Estas pesquisas iniciaram-se em 1997, durante meu estágio de pós-doutorado por dois anos no Departamento de Cinesiologia da 
Universidade Estadual da Pennsylvania sob a supervisão de Vladimir M. Zatsiorsky. Em sua maior parte, este trabalho sintetiza achados reportados em seis artigos publicados, um manuscrito em julgamento e um outro em preparação:

- Duarte, M., Zatsiorsky, V.M. (1999) Patterns of center of pressure migration during prolonged unconstrained standing. Motor Control, 3, 12-27.

- Zatsiorsky, V.M., Duarte, M. (1999) Instant equilibrium point and its migration in standing tasks: Rambling and trembling components of the stabilogram. Motor Control, 3, 28-38.

- Danion, F., Duarte, M., Grosjean, M. (1999) Fitts' law in human standing: the effect of scaling. Neuroscience Letters, 277, 131-133.

- Duarte, M., Zatsiorsky, V.M. (2000) On the fractal properties of natural human standing. Neuroscience Letters, 283, 173-176.

- Zatsiorsky, V.M., Duarte, M. (2000) Rambling and trembling in quiet standing. Motor Control, IN PRESS.

- Duarte, M., Zatsiorsky, V.M. (2000) Stabilographic Analysis of Prolonged Unconstrained Standing. Ergonomics. IN PRESS.

- Duarte, M., Zatsiorsky, V.M. Long-range correlations in human standing. Submetido a Physical Review E.

- Duarte, M., Zatsiorsky, V.M. Visual information, limits of variability, and variability of the human standing. Manuscrito em preparação.

A oscilação do corpo durante a postura ereta é usualmente investigada utilizando-se uma plataforma de força, um instrumento de medida sobre o qual os sujeitos permanecem em pé durante os experimentos. A variável mais comum para analisar esta oscilação é a posição do centro de pressão (COP), o ponto de aplicação da resultante das forças agindo na superficie de suporte. $O$ deslocamento do COP representa uma somatória das ações do sistema de controle postural e da força de gravidade. Devido à oscilação do corpo e às forças inerciais, a posição do COP é diferente da projeção do COG sobre a superficie de suporte; o COG indica a posição global do corpo. O presente trabalho descreve pesquisas sobre a interpretação das variáveis COP e COG e todos as outras pesquisas descritas neste trabalho se baseiam nestas duas variáveis.

Em condições de trabalho e nas atividades da vida diária, algumas pessoas permanecem em pé por longo tempo confinadas à uma pequena área na maior parte das vezes. Na postura em pé natural, as pessoas usualmente adotam posturas assimétricas e tendem a mudar a posição do corpo periodicamente enquanto mantém uma postura do corpo relativamente fixa. A contínua e lenta oscilação de baixa amplitude é comumente interrompida por mudanças posturais caracterizadas por movimentos rápidos e de grande amplitude. Há muitos estudos sobre a contínua e lenta oscilação de baixa amplitude, os quais tipicamente investigaram a postura ereta quieta, onde os sujeitos foram instruidos a ficar tão imóveis quanto possiveis em um mesmo lugar por curtos periodos. O estudo da postura ereta irrestrita de longa duração tem recebido menos atenção, particularmente, sob uma perspectiva biomecânica. Uma limitação nos estudos sobre a postura ereta humana é que tarefas com a instrução "permaneça o mais imóvel possível" são limitados a poucos minutos devido à fadiga. Ao contrário, permanecer em pé naturalmente, sem restrições, não é fadigante e pode ser reproduzido no laboratório por uma tarefa de postura ereta durante a qual a pessoa é permitida fazer qualquer movimento sem restrição alguma, exceto a de permanecer dentro da área da plataforma de força. Neste trabalho, quatro estudos sobre a postura ereta irrestrita são apresentados com o intuito de 
entender esta tarefa.

Atividades motoras mais especificas e complexas que requerem maior demanda do controle postural (no qual uma variável associada ao equilibrio postural, COP, é mostrada como feedback visual ou auditivo) têm sido aplicadas em avaliação e reabilitação do equilibrio postural com diferentes graus de sucesso. Recentemente, em colaboração com outros pesquisadores, conduzi um novo experimento para avaliação do rendimento do sistema de controle postural de adultos em uma tarefa dinâmica utilizando-se o recurso de feedback visual do equilibrio (Danion et al., 1999). Tal experimento foi o primeiro a descrever a relação entre a velocidade e acurácia de movimento em uma tarefa de equilíbrio postural, utilizando-se do paradigma proposto por Fitts e amplamente explorado para movimentos de segmentos do corpo em geral. Estes achados e pesquisas sobre o papel da informação visual no controle postural e o estudo dos limites de estabilidade são relatados aqui.

O trabalho está organizado por tópicos de pesquisa. Uma breve descrição de fundamentos gerais sobre postura e equilibrio, aspectos de neurofisiologia, biomecânica e controle motor é apresentada no capitulo dois. Em seqüência, os capitulos são organizados em função dos temas estudados. A postura ereta irrestrita de longa duração é descrita no capitulo três e então investigada em diferentes condições no capitulo quatro. Processos de correlação de longo alcance na série temporal do centro de pressão da postura ereta irrestrita de longa duração são descritos nos capítulos cinco e seis. O estudo do tempo de movimento e a acurácia do mesmo em tarefas recíprocodirecionadas utilizando o corpo inteiro é descrito no capítulo sete e o estudo dos limites de estabilidade e o papel da informação visual, no capitulo oito.

Muitas pessoas ajudaram-me de diferentes maneiras durante as pesquisas que relato e na preparação deste trabalho. Algumas delas são relações de longa data, outras conheci em função destas pesquisas, outras perdi; e com todas compartilhei bons momentos de diversão. A elas sou sinceramente grato.

Marcos Duarte mduarte@usp.br

Santos, 22 de abril de 2000. 


\section{Controle postural}

Para o cumprimento da regulação do equilíbrio, o sistema de controle postural necessita de informações sobre as posições relativas dos segmentos do corpo e da magnitude das forças atuando sobre o corpo. Para tanto, três classes de sensores podem ser utilizadas pelo corpo: somatossensorial, visual e vestibular. Estes receptores atuam de forma complexa, integrada, redundante e de maneira diferenciada para cada perturbação sobre o corpo humano (Rothwell, 1994). Um diagrama conceitual deste sistema de controle postural pode ser visto na Figura 1. Os sistemas sensoriais são representados num circuito de feedback; a integração sensorial destas diferentes informações pode ser afetada por um desejo consciente (vontade) de colocar um menor ou maior ganho em uma das fontes sensoriais, por exemplo. Mecanismos de feedforward, como, por exemplo, ajustes posturais antecipatórios, são representados por sinergias posturais. Outras sinergias posturais possíveis são as estratégias de controle postural, as quais são geralmente afetadas pelo circuito de feedback.

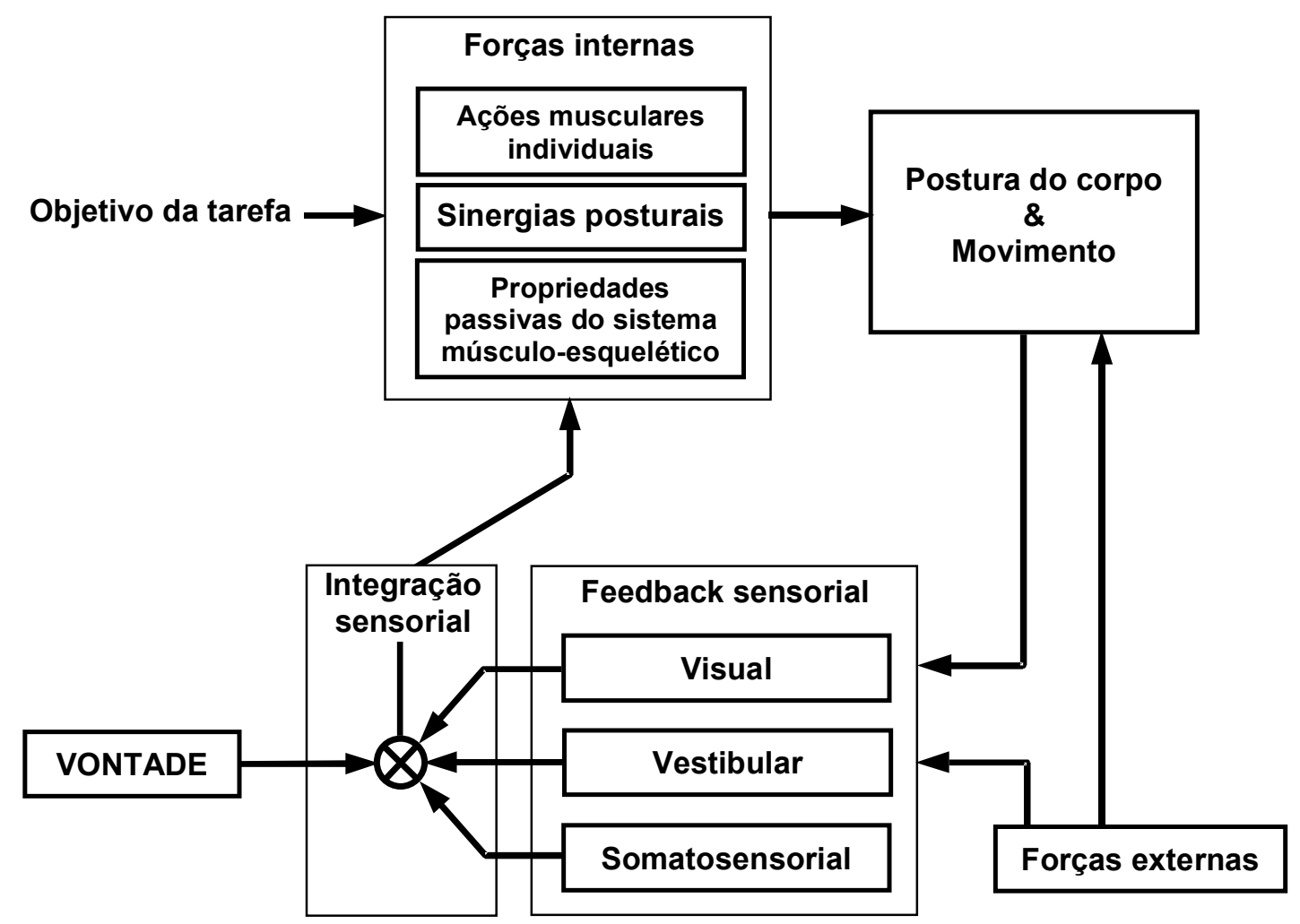

Figura 1. Diagrama conceitual do sistema de controle postural. 


\subsection{Sistemas sensoriais}

Não faz parte do escopo deste trabalho realizar uma revisão sobre os sistemas visual, vestibular e somatossensorial no corpo humano. A intenção é identificar estas estruturas e seu papel no controle postural (para uma revisão, ver Kandel et al., 1991 e Rothwell, 1994). O sistema visual fornece informações sobre a posição e movimento de um objeto no espaço (exterocepção) e a posição e movimento dos membros relativo ao ambiente e ao resto do corpo (propriocepção visual) por meio dos olhos. É o sistema sensorial que o corpo mais confia nas tarefas de manutenção da postura e de movimento (Latash, 1997) mas seu papel na manutenção da postura ereta quieta é bastante reduzido. Entre os feedbacks dos três sistemas sensoriais, os reflexos gerados pelo feedback visual são os mais lentos. Desde o clássico trabalho de Romberg, diversos estudos têm mostrado um aumento da oscilação do corpo em função da ausência de informação visual. No entanto, é conhecido que as pessoas podem apresentar um maior ou menor grau de dependência da informação visual para o controle postural (Collins \& De Luca, 1995a; Crémieux \& Mesure, 1994).

O sistema somatossensorial fornece informações sobre a posição do corpo no espaço relativo à superfície de suporte, informações da posição e velocidade relativa entre os segmentos do corpo e informações sobre as pressões agindo na interface segmento/base de suporte. O sistema de feedback somatossensorial é o mais efetivo para perturbações rápidas. Evidências clínicas sugerem que com o envelhecimento, este mecanismo de feedback torna-se mais importante na escolha das estratégias posturais (Woolacott \& Shumway-Cook, 1990). Os sensores deste sistema compreendem proprioceptores musculares (Órgão Tendinoso de Golgi e fusos musculares) e articulares e mecanoreceptores cutâneos.

O sistema vestibular fornece informações sobre a posição e movimento da cabeça em respeito à força da gravidade e forças inerciais. O sistema vestibular tem dois tipos de receptores que sentem diferentes aspectos da orientação e movimento da cabeça. Os receptores que detectam acelerações angulares são os canais semicirculares preenchidos com fluido. Certas regiões destes canais têm células sensoriais ciliares. Quando a cabeça roda, a inércia do fluido move estas células ciliares e causa a liberação de um neurotransmissor. Os canais semicirculares são particularmente efetivos na detecção de rápidas acelerações. Os receptores que detectam acelerações lineares são o utrículo e a sácula. Na parede interna destas estruturas há uma região chamada mácula com células ciliares. Estas células projetam-se em uma membrana gelatinosa, o otolito. $O$ movimento linear desta membrana gelatinosa provoca uma inclinação das células ciliares causando a liberação de um neurotransmissor.

\subsection{Sinergias posturais}

\subsubsection{Estratégias de manutenção do equilíbrio}

Tem sido reportado que durante a manutenção da postura ereta em resposta a perturbações ou durante deslocamentos voluntários do centro de gravidade, as estratégias de movimento e padrões de atividade muscular podem ser organizados em estratégia do quadril, do tornozelo e do passo (Nashner \& McCollum, 1985), como na Figura 2. Durante a tarefa de manutenção da postura ereta em situação normal, são observados padrões de movimento articular que envolvem uma combinação destas diferentes estratégias ao mesmo tempo. Apesar deste fator, o entendimento do processo de controle postural através destas estratégias é interessante e útil, por decompor movimentos complexos em estruturas mais simples. 


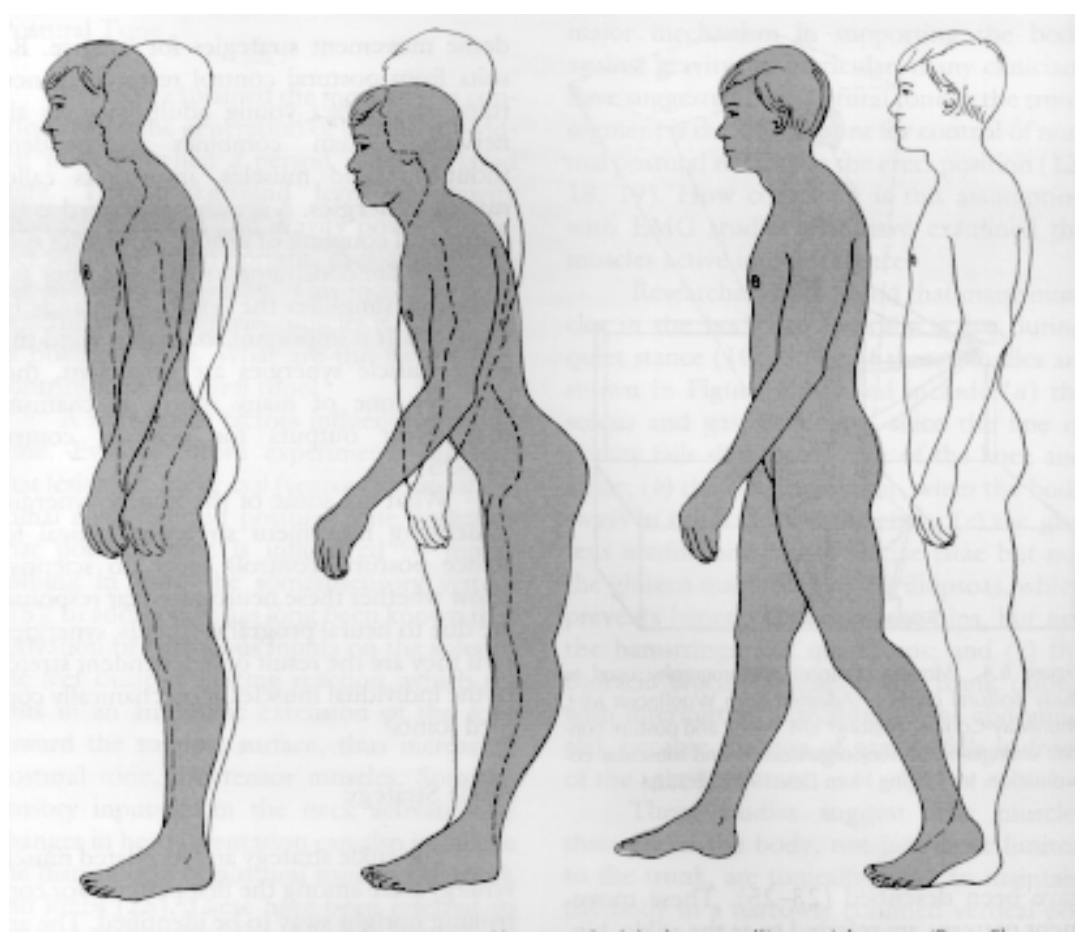

Figura 2. Três estratégias posturais usadas normalmente pelos adultos no controle da postura ereta, da esquerda para a direita: estratégia do tornozelo, do quadril e do passo. (Shummway-Cook \& Woollacott, 1995).

\subsubsection{Ajuste postural antecipatório}

Os ajustes posturais antecipatórios (APA) são ações pré-programadas, dessa forma são ajustes superestimados ou subestimados mas que buscam prever a magnitude da perturbação, necessariamente iniciados voluntariamente e desencadeados centralmente (Latash, 1997). São funções dos APA (Massion, 1998): minimizar as perturbações posturais, em termos de equilíbrio ou de orientação postural; a preparação postural para o movimento, como indicado pelo deslocamento do COG antes de um movimento da perna para início da marcha; ajudar a realização do movimento em termos de velocidade ou força, e desenvolver momentos de inércia que se opõem aos momentos intersegmentares (que podem criar instabilidades ao movimento).

\subsection{Estabilometria}

Estabilometria, também chamada estabilografia ou estatocinesiografia, é a medida e o registro da contínua oscilação do corpo humano (Terekhov, 1976a, 1976b). Ainda que mais de 100 anos se passaram desde que Romberg criou seu teste estático para medir a habilidade de manter a postura ereta, somente nas últimas décadas a quantificação mais precisa e adequada do balanço corporal tem sido implementada. $O$ desenvolvimento tecnológico das plataformas de força e o avanço em processamento de sinais tornaram possível esta melhora. A Figura 3 mostra um estabilograma (o mapeamento do COP ântero-posterior (a-p) versus o COP médio-lateral $(\mathrm{m}-\mathrm{I})$ representativo durante a postura ereta quieta. 


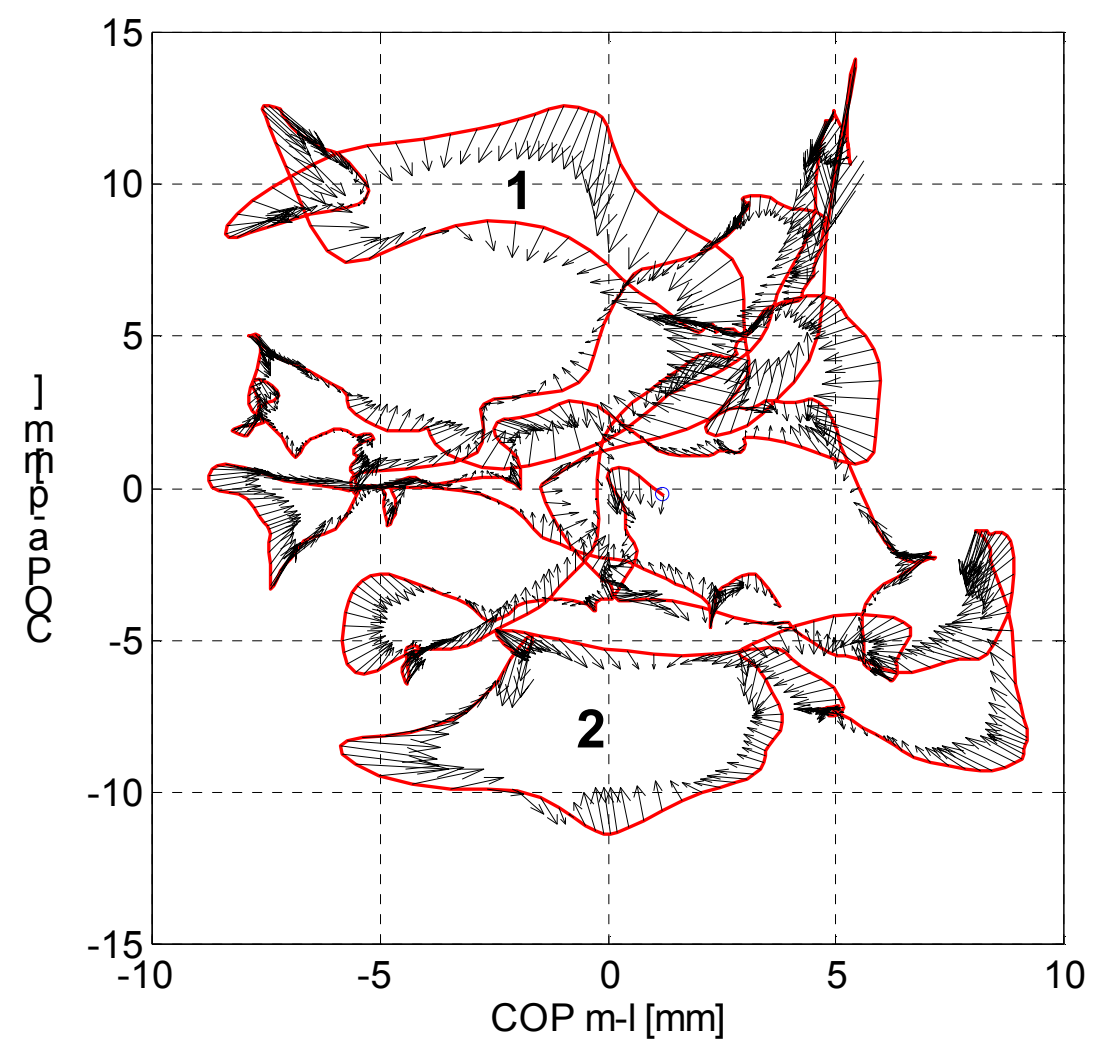

Figura 3. Estabilograma representativo durante postura ereta quieta (linha contínua). Nesta figura, pode-se observar o conceito de campos de força na postura: a representação da trajetória do COP e os vetores de força horizontal. Note que para pequenos intervalos de tempo, vetores de força consecutivos convergem para (aproximadamente) um pólo (exemplos 1 e 2) e para longos intervalos de tempo eles convergem para diferentes pólos (Zatsiorsky \& Duarte, 2000).

Uma grande variedade de modelos e métodos matemáticos tem sido empregados para analisar os dados estabilográficos (para uma revisão, ver Prieto et al., 1993; Hufschimidt et al., 1980; Winter et al., 1990). Dentre estes métodos, pode-se destacar:

(a) Parâmetros de estatística simples (Murray et al., 1975; Paulus et al., 1984);

(b) variações e áreas de migração do COP (Hasan et al., 1990; Riach \& Starkes, 1993; Starkes et al., 1992; Slobounov \& Newell, 1994);

(c) velocidade de migração do COP (Hasan et al., 1990; Starkes et al., 1992; Riach \& Starkes, 1994);

(d) comprimento do caminho viajado pelo COP (Norre et al. 1987a, b);

(e) funções de transferência (Peeters et al., 1985);

(f) características espectrais (Bensel \& Dzendolet, 1968; Aggashyan et al., 1973a, b; Soames et al., 1976; Peeters et al., 1985; Yoneda \& Tokumasu, 1986; Williams et al., 1997);

(g) análises de autocorrelação e autoregressão (Bräuer and Seidel, 1981; Takata et al., 1983a, b; Tokumasu et al., 1983);

(h) medidas de tempo-até-contato (Riccio, 1993; Slobounov et al., 1997); 
(i) análise espectral evolucionária (Schumann et al., 1995);

(j) dimensões fractais (Firsov \& Rosenblum, 1990; Prieto et al., 1992);

(k) análise no plano de fases (Ryley et al., 1995);

(I) coeficientes de Grassberger-Procaccia para estudo da dimensionalidade de processos caóticos (Collins \& De Luca, 1993, 1994; Newell et al., 1993) e

(m) análise de difusão do estabilograma (Roy et al., 1987; Collins \& De Luca, 1995a,b; Riley et al., 1997, Newell et al., 1997; Lauk et al., 1998).

Todos estes métodos têm sido utilizados para extrair o máximo possível de informações do sinal da estabilografia. Em conjunto à trajetória do COP, a trajetória do COG também tem sido utilizada na análise da postura humana. A seguir, são descritas as características destas duas trajetórias.

\subsection{Centro de gravidade e centro de pressão}

O COP é o ponto de aplicação da resultante das forças verticais atuando na superfície de suporte, e representa um resultado coletivo do sistema de controle postural e da força de gravidade. Há uma certa confusão com a utilização das grandezas COG e COP no estudo do controle postural (Gurfinkel, 1973; Winter, 1990; King \& Zatsiorsky, 1997). O COG é o centro das forças gravitacionais agindo sobre todos os segmentos do corpo humano, se move como se a força gravitacional sobre todo o corpo agisse apenas neste ponto e é um conceito análogo ao centro de massa. Ele pode ser calculado a partir da média ponderada dos COG de cada segmento do corpo em uma dada posição (instante). A posição do COG é uma medida de deslocamento e é totalmente independente da velocidade ou aceleração total do corpo ou de seus segmentos (Goldstein, 1980; Winter, 1990). O COP também é uma medida de deslocamento e é dependente do COG. Ele expressa a localização do vetor resultante da força de reação do solo em uma plataforma de força. Este vetor é igual e oposto à média ponderada da localização de todas as forças que agem na plataforma de força, como a força peso e as forças internas (musculares e articulares) transmitidas ao chão (Winter, 1990). Por conseguinte, a oscilação do COG é a grandeza que realmente indica o balanço do corpo, e a grandeza COP é na verdade a resposta neuromuscular ao balanço do COG como representado na Figura 4. Estas duas grandezas expressam conceitos diferentes, mas em situações específicas, como na postura ereta estática, podem apresentar significados semelhantes (Gurfinkel, 1973). As diferenças entre o COG e o COP são devidas a efeitos dinâmicos e quanto menor as freqüências de oscilação do corpo, menores serão as características dinâmicas na posição de equilíbrio. Para freqüências de até $0,2 \mathrm{~Hz}$, cerca de $10 \%$ da oscilação do COP não representa a oscilação do COG, mas sim acelerações de segmentos corporais, e para 0,5 Hz este número já é cerca de $50 \%$ (Gurfinkel, 1973). O conteúdo do espectro de densidade de potência do sinal do estabilograma para uma pessoa normal na postura ereta está na faixa de 0 a $2 \mathrm{~Hz}$ (Hayes, 1982), com a maior parte do conteúdo até $0,5 \mathrm{~Hz}$. 


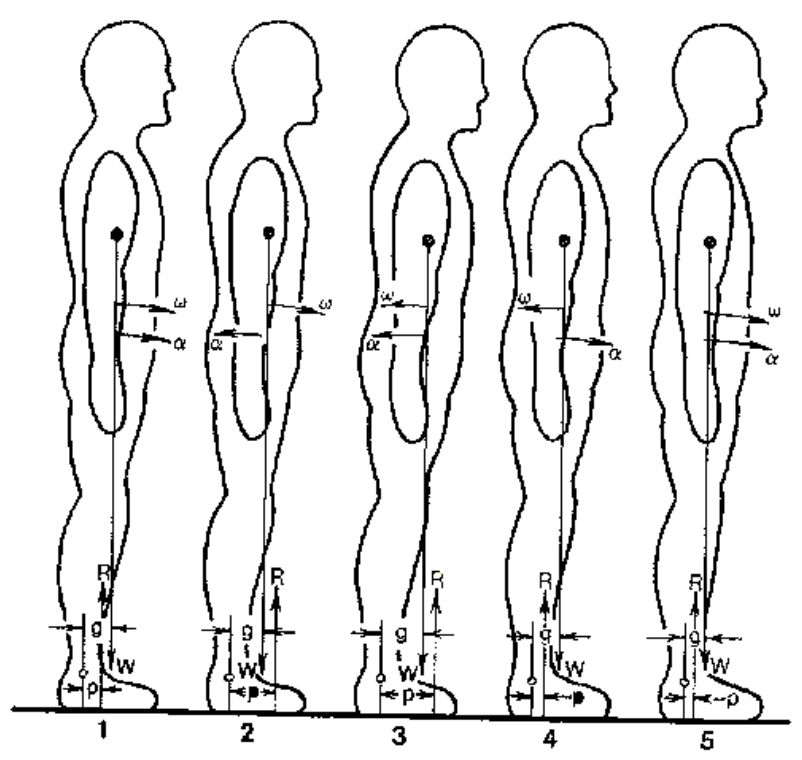

Figura 4. Representação esquemática da relação entre COP e COG durante a postura ereta de um sujeito oscilando para frente e para trás. As distâncias do COP (p) e COG $(g)$, o vetor peso $(W)$, o vetor força de reação do solo $(R)$, e vetores representativos para a velocidade $(\omega)$ e aceleração $(\alpha)$ angulares em cinco instantes diferentes são indicados (Winter, 1990).

\subsection{Um modelo biomecânico simples da postura ereta}

O sistema músculo-esquelético humano é um mecanismo articulado ativo extremamente complexo com cerca de 244 graus de liberdade e cerca de 650 geradores individuais de força, os músculos. A modelagem exata da dinâmica deste sistema transcende a capacidade científica e tecnológica atual. Apesar desta complexidade grandiosa, as características principais da dinâmica do sistema músculo-esquelético humano durante a postura ereta quieta podem ser elegantemente capturadas por um simples modelo físico matemático de um pêndulo invertido com segmentos rígidos articulados por juntas do tipo dobradiça. Nesta abordagem simplificada, os músculos de cada segmento são agrupados como atuadores de torque em cada junta. O modelo pode ser desenvolvido para mover-se em uma, duas ou três dimensões e ter um ou vários segmentos em movimento com as equações descritas pelo formalismo Newtoniano ou Lagrangeano. A seguir, é descrito um modelo de um pêndulo simples para representar a dinâmica do sistema músculo-esquelético humano no plano sagital de uma forma bastante simplificada com o intuito de mostrar os conceitos básicos da modelagem físico-matemática.

Considere o corpo no plano sagital representado por dois segmentos rígidos; os pés e o resto do corpo, sendo que os pés encontram-se fixos ao chão e o resto do corpo comporta-se como um segmento rígido articulado no pé por uma articulação tipo dobradiça, conforme a Figura 5. 


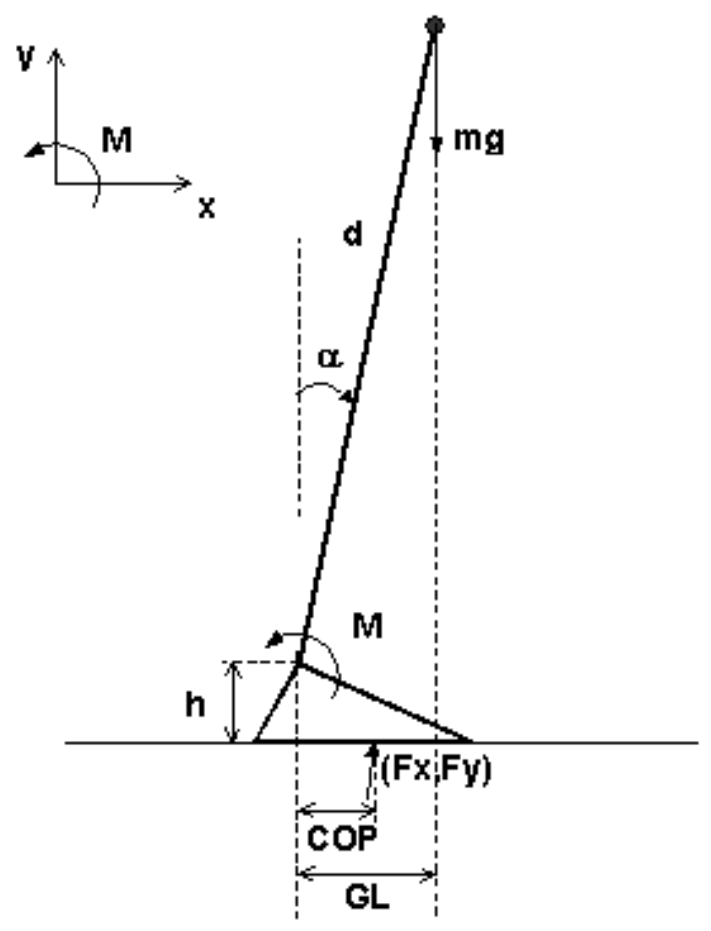

Onde:

d é o comprimento do pêndulo, dado pela distância do tornozelo até o COG do corpo;

m é a massa do corpo;

$\alpha$ é o ângulo entre a vertical e o corpo;

h é a altura da articulação do tornozelo;

Fx, Fy são as forças na direção a-p e na direção vertical respectivamente;

COP é a posição do COP na direção a-p;

GL é a posição da projeção horizontal do COG na direção a-p;

M é o torque resultante no tornozelo para a manutenção da postura ereta.

Figura 5. Representação do modelo fisico-matemático de um pêndulo invertido do corpo humano durante a postura ereta quieta para o plano sagital.

O torque atuante no tornozelo para este pêndulo simples invertido é dado pela clássica equação diferencial:

$$
M-m g d \operatorname{sen} \alpha=-I \frac{d^{2} \alpha}{d t^{2}}
$$

onde l é o momento de inércia do corpo em torno da articulação do tornozelo. l é dado por $\mathrm{cmd}^{2}$, onde $c$ é um fator de forma. Para toda a massa concentrada a uma distância $d, c=1$, de uma haste de comprimento $d$ e massa $m c$ é 1,33. O fator de forma para o corpo humano aproxima-se ao de uma haste.

Esta equação pode ser linearizada para pequenas variações angulares: $\alpha<1 \rightarrow \operatorname{sen} \alpha \approx \alpha$, e por sua vez $\alpha$ pode ser expressa como $\alpha \approx x / d$, onde $x$ é o deslocamento na direção $x(a-p)$ do COG (GL). A equação então pode ser reescrita como:

$$
M=-c m d \frac{d^{2} G L}{d t^{2}}+m g G L
$$

Por outro lado, o torque no tornozelo pode também ser calculado a partir da equação de movimento para o segmento pé. Quando é desprezado o peso do pé e forças inerciais tem-se que $F y \approx m g$, e o torque será:

$$
M=C O P m g+h F x
$$

Finalmente, a aceleração do COG na direção a-p pode ser calculada a partir da força na direção a-p e da massa do corpo:

$$
\frac{d^{2} G L}{d t^{2}}=\frac{F x}{m}
$$


Combinando-se as equações anteriores pode-se chegar a uma expressão que engloba as variáveis antropométricas $m, L, h, I$, as da plataforma de força $F x, F y, C O P$ e a variável $G L$ :

$$
\begin{aligned}
& C O P m g+h F x=-c d F x+m g G L \\
& C O P-G L=-(c d+h) \frac{F x}{m g}
\end{aligned}
$$

As variáveis $c, d, h$ são constantes; esta equação final expressa a relação fundamental entre as posições do $C O P$ e da $G L$ em relação a $F x$ : a diferença $C O P-G L$ é negativamente correlacionada com $F x$; e quando $F x$ é nula $C O P$ e $G L$ coincidem. Este fato tem sido a base de um algoritmo para a estimação da $G L$ a partir do $C O P$ e de $F x$ e é descrito a seguir.

\subsection{Determinação do centro de gravidade}

As componentes mais importantes da grandeza centro de gravidade em estudos de posturografia são as componentes horizontais (nas direções a-p e m-l) que é conhecida como linha de gravidade (GL, gravity line). Diferentes métodos tem sido propostos para o cálculo do centro de gravidade ou da linha de gravidade:

Método cinemático: as posições dos segmentos corporais são medidas e o COG do corpo é determinado a partir do uso destas posições e do conhecimento dos parâmetros inerciais do corpo como posição do COG em cada segmento e sua respectiva massa (Murray et al., 1967; Spaepen et al., 1979; Koozekanani \& Duerk, 1985; Riley et al., 1990; Eng \& Winter, 1993; Hasan et al., 1996; Winter et al., 1998). O método cinemático pode ser reduzido a monitorar o movimento de apenas uma marca sobre o corpo, assumindo que o movimento desta marca é representativo do movimento do COG global. Tipicamente esta marca é posicionada sobre a coluna vertebral próximo aos quadris (Murray et al., 1975; Shimba, 1984; Gard \& Childress, 1997). Os obstáculos ao uso do método cinemático são que os parâmetros inerciais dos segmentos corporais apresentam consideráveis erros (modelos antropométricos do corpo apresentam grandes erros) e que o método é muito complexo e trabalhoso, já que requer o uso da cinemetria. Para a minimização do erro, essencialmente sistemático, ou a análise desconsidera este erro, ou restrições externas (como a média do sinal da GL deve coincidir com a média do COP), ou a GL estimada pelo método cinético é utilizada para aumentar a acurácia da GL pelo método cinemático.

Método cinético: da mecânica clássica, o COG pode ser encontrado por dois diferentes modos. No primeiro, a força horizontal dividida pela massa (aceleração horizontal) é integrada duas vezes e a GL é determinada (Spaepen et al., 1977; Levin \& Mizrahi, 1996; King \& Zatsiorsky, 1997; Crowe et al., 1993; Kingma et al., 1995; Shimba, 1984; Eng \& Winter, 1993). No segundo, como a taxa de mudança de momento angular do centro de gravidade em relação ao tempo é igual ao torque total do sistema, o valor do centro de gravidade pode ser encontrado (Shimba, 1984; King \& Zatsiorsky, 1997). O principal problema deste método é como achar a posição e velocidade inicial do corpo na dupla integração. Se estas constantes não são achadas, é considerado apenas o deslocamento líquido do COG e que apresenta uma velocidade média nula (Eng \& Winter, 1993).

Método de filtragem: Um filtro passa baixa é aplicado no COP (Caron et al., 1997). Este método é provavelmente o mais simples e rápido. Basea-se, no fato que o COG apresenta freqüências menores que o COP que oscila em torno do COG. Entretanto, falta a este médodo a fundamentação fisiológica por negligenciar mudanças que possam afetar o COP e não o COG. 
Sobre o método de integração dupla, uma outra variante é considerar que as posições horizontais do COP e do COG coincidem quando a força horizontal resultante agindo sobre o corpo é zero. As posições do COP nestes instantes (que são conhecidas) podem ser usadas para determinar as constantes de integração (King \& Zatsiorsky, 1997). Deste modo, o COG é calculado para os dados entre dois instantes consecutivos de força nula. King e Zatsiorsky usaram somente o primeiro valor da posição do COP (como a posição inicial do COG) para determinar o COG entre dois instantes consecutivos de força nula. Porque são necessárias duas constantes neste método, a outra constante (a velocidade inicial do $C O G$ ) foi determinada por iteração numérica para garantir que a posição final do COG coincidisse com a próxima posição do COP no instante de força nula. Os instantes de força nula foram achados por aproximação definindo-se um valor de limiar abaixo do qual a força horizontal era considerada nula. Os métodos de iteração e limiar não são acurados nem eficientes e podem ser altamente dependentes de parâmetros artificiais como o valor de limiar, freqüência de amostragem e o passo da iteração.

Desenvolvi uma variante do método de dupla integração entre os instantes de força nula onde ambas as constantes de integração são determinadas analiticamente a partir dos dados do COP e os instantes de força nula são achados por interpolação (Zatsiorsky \& Duarte, 2000). Recapitulando, a aceleração horizontal do corpo é dada por $\ddot{x}(t)=F_{x}(t) / M$, onde $M$ é a massa corporal. A posição horizontal do corpo, a linha de gravidade (GL), pode ser achada por integração dupla da equação acima. A tarefa é achar as duas constantes de integração.

O primeiro estágio é determinar as posições do COP nos instantes quando $F_{\text {hor }}=0$, os pontos de equilíbrio instantâneo (IEP, instant equilibrium points). Durante a postura ereta, quando o corpo humano está num IEP, o COP coincide com GL (para uma prova ver King \& Zatsiorsky, 1997, Zatsiorsky \& King, 1998, cf. Levin \& Mizrahi, 1996) e com o ponto de referência de equilíbrio (Zatsiorsky \& Duarte, 1999). Tecnicamente, os instantes quando $F_{\text {hor }}$ muda o sinal de positivo (negativo) para negativo (positivo) foram selecionados e então, os instantes quando $F_{\text {hor }}=0$ foram estimados por interpolação linear local da série temporal da $F_{\text {hor }}$. Finalmente, as posições do COP nestes instantes (IEP) foram determinados por interpolação por spline da série temporal do COP.

Dado dois consecutivos IEP, $t_{0} / F_{\text {hor }}=0$ e $t_{f} F_{\text {hor }}=0$, como as posições do COP e do COG coincidem, a primeira constante de integração é $x\left(t_{0}\right)=x_{C O P}\left(t_{0}\right)$. A segunda constante, a velocidade inicial, pode ser determinada por:

$$
v\left(t_{0}\right)=\frac{x_{C O P}\left(t_{f}\right)-x_{C O P}\left(t_{0}\right)-\sum_{t_{0}}^{t_{f}} \Delta t \sum_{t_{0}}^{t_{f}} \frac{F_{x}(t)}{M} \Delta t}{\left(t_{f}-t_{0}\right)}
$$

Finalmente, GL é estimada por:

$$
x(t)=x_{C O P}\left(t_{0}\right)+v\left(t_{0}\right)\left(t-t_{0}\right)+\sum_{t_{0}}^{t} \Delta t \sum_{t_{0}}^{t} \frac{F_{x}(t)}{M} \Delta t
$$

Este método pode ser aplicado para cada dois instantes consecutivos de força nula ou para o dado como um todo em um passo. Neste último caso, somente a primeira e a última posição do COP nos instantes de força nula são usadas para achar as duas constantes de integração. A vantagem de integrar a força para cada dois instantes consecutivos de força nula é que possíveis erros da integração numérica não são propagados para o resto dos dados; sendo um método bastante robusto para calcular o COG a partir do COP. 
Na Figura 6 e Figura 7 são mostrados exemplos de trajetórias de força horizontal, COP e GL (obtida utilizando-se o algoritmo citado) na direção a-p durante postura ereta quieta e com oscilação forçada do tornozelo. Pode-se observar que nos instantes em que COP e GL coincidem, a força horizontal é zero e que o COP e GL estão em fase e COP e Força estão em antifase.

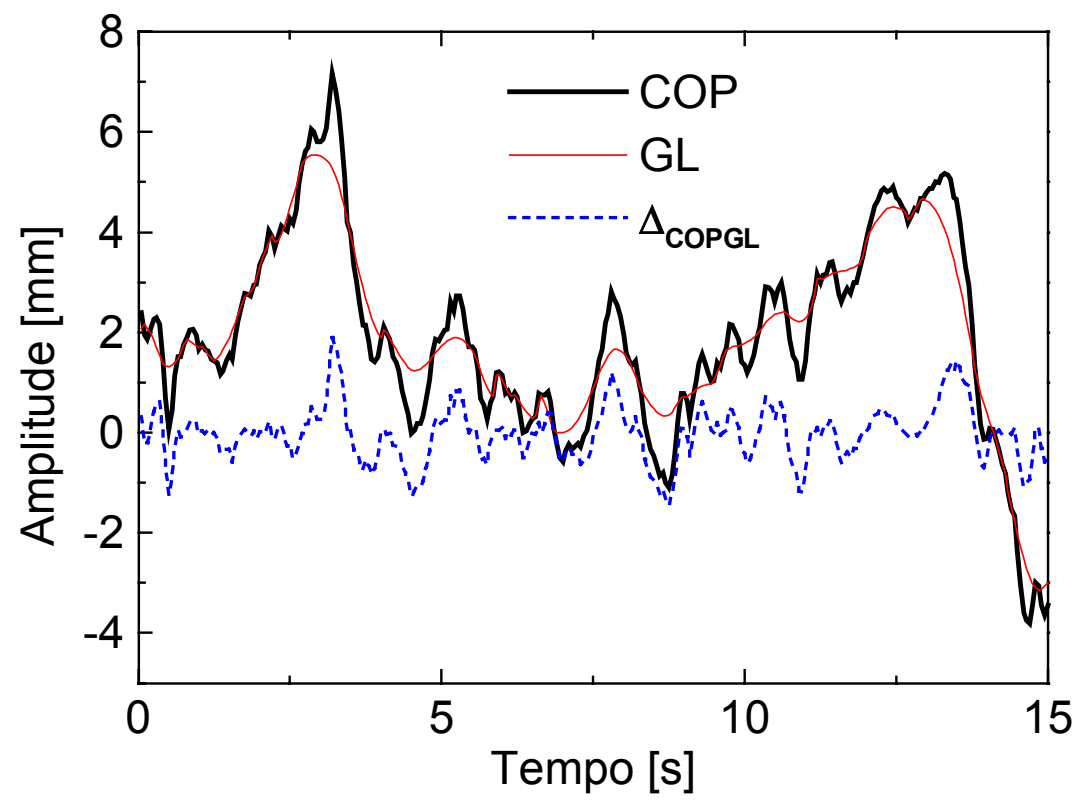

Figura 6. Trajetórias do COP, GL e da diferença entre COP e GL, $\Delta_{C O P G L}$, na direção a-p durante postura ereta quieta.

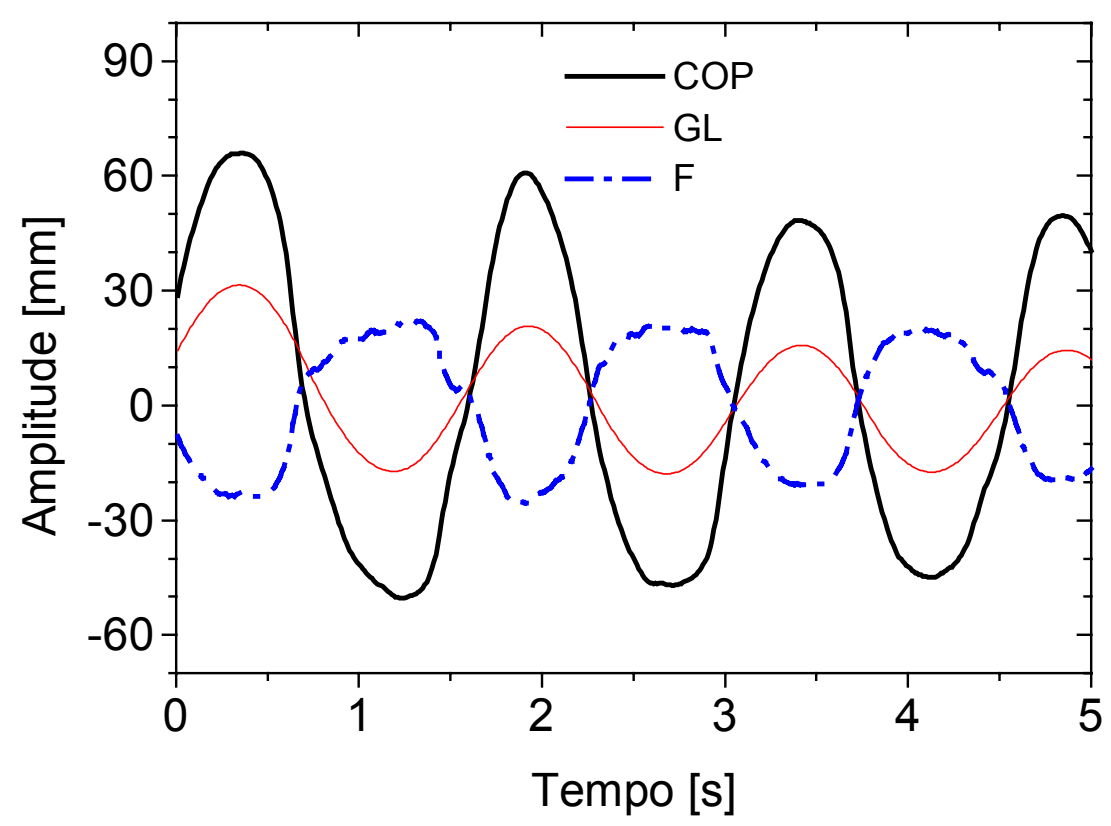

Figura 7. Trajetórias do COP, GL e força horizontal, $F$, na direção a-p durante postura ereta com oscilação forçada do tornozelo.

A Figura 8 mostra um exemplo do comportamento das trajetórias COP e GL no domínio de freqüências, evidenciando o conteúdo de freqüências mais altos na trajetória do COP. 


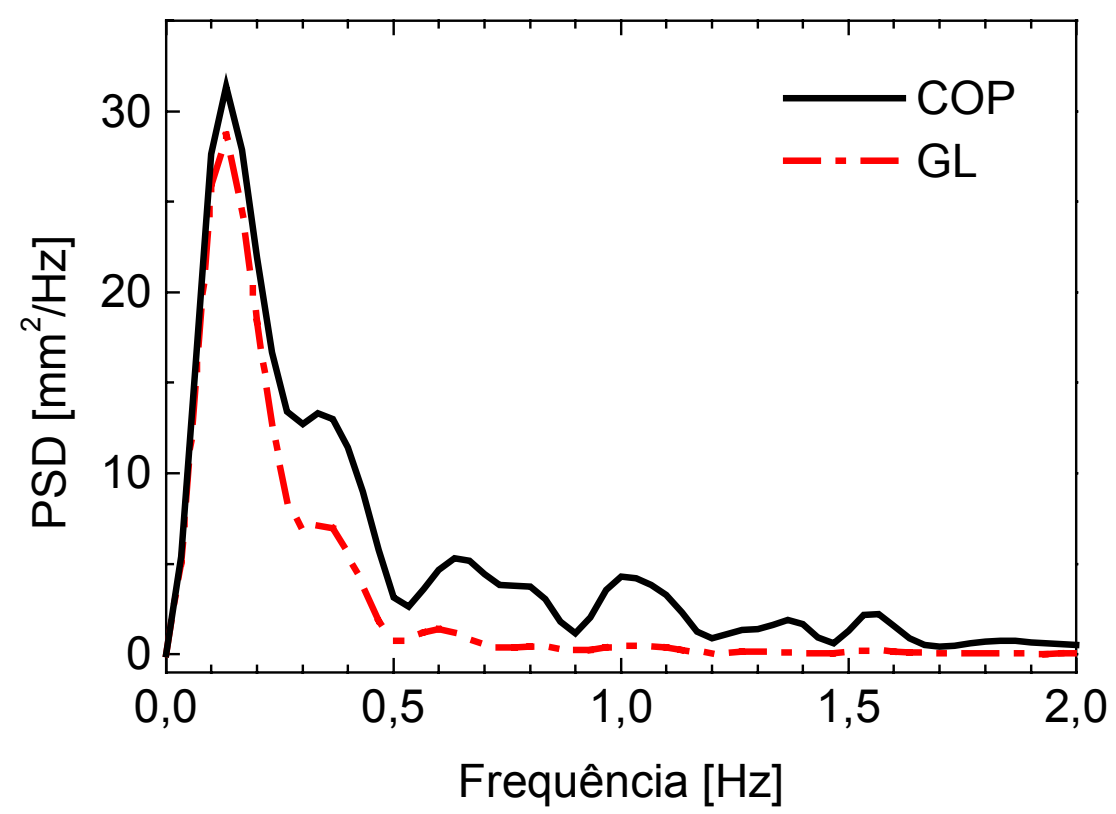

Figura 8. Exemplo representativo da densidade de potência espectral (PSD, power spectral density) das trajetórias COP e GL na direção a-p para postura quieta por $30 \mathrm{~s}$. PSD calculado pelo método de periodograma de Welch com resolução de 0,039 $\mathrm{Hz}$.

\subsection{Decomposição do sinal de posturografia}

Um método de decomposição do estabilograma em duas componentes, chamadas rambling e trembling, foi desenvolvido (Zatsiorsky \& Duarte, 1999, 2000). A componente rambling revela o movimento de um ponto de referência móvel (um ponto atrator) com respeito ao qual o equilíbrio do corpo é mantido instantaneamente. A componente trembling reflete a oscilação do corpo em torno da trajetória do ponto de referência. Estas duas componentes são representadas esquematicamente na Figura 9. Os conceitos de ponto de equilíbrio instantâneo (IEP) e trajetória discreta do IEP foram introduzidos. A trajetória rambling foi computada por interpolação da trajetória discreta do IEP com funções spline cúbicas. A trajetória trembling foi calculada como a diferença entre a trajetória rambling a trajetória do centro de pressão (COP). Valores instantâneos da trajetória trembling são negativamente correlacionados com os valores da força de reação do solo horizontal sem defasagem, $r=-0,85 \pm 0,13$. Isto sugere que trembling é fortemente influenciado pela força restaurativa que é proporcional à magnitude do desvio do COP em relação à trajetória rambling e age sem defasagem. Um incremento da posição relativa do COP por unidade de força restauradora, em $\mathrm{mm} / \mathrm{N}$, foi em média $1,4 \pm 0,4$. A variabilidade do rambling é aproximadamente três vezes maior que a variabilidade do trembling. 


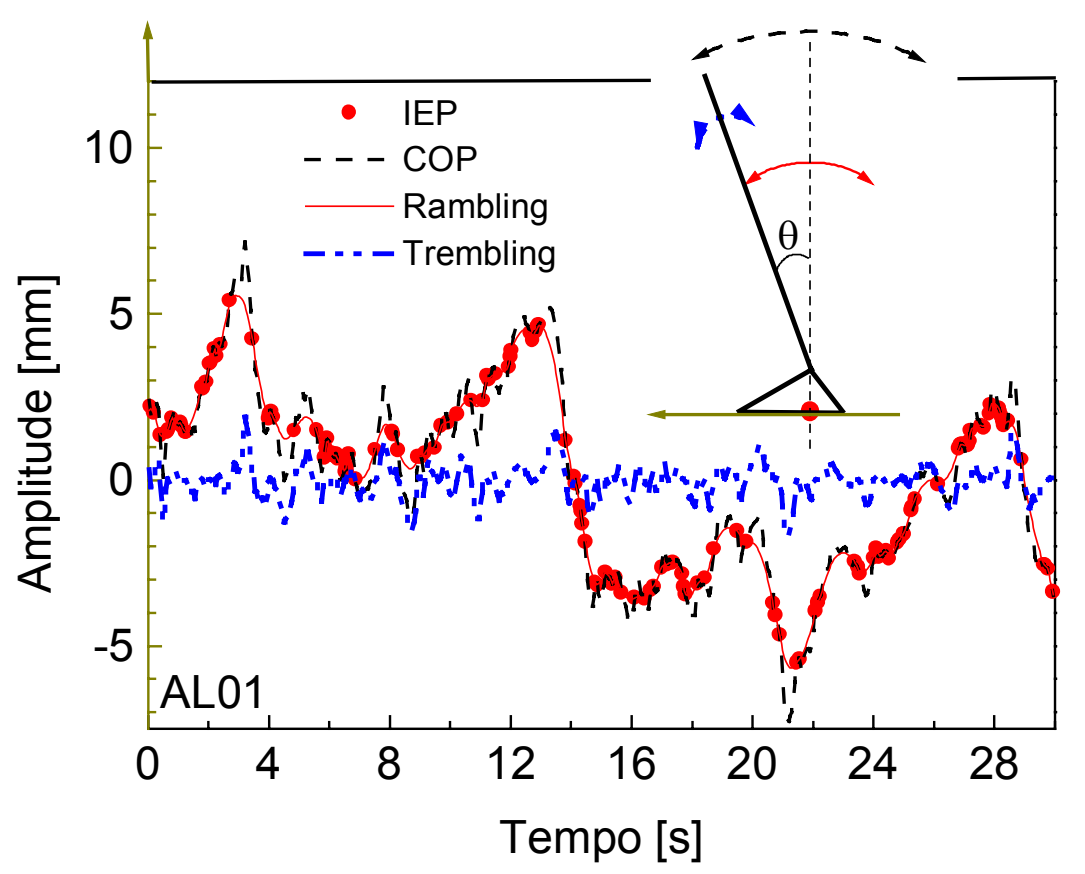

Figura 9. Trajetórias do COP, componentes rambling e trembling e os pontos de equilibrio instantâneo (IEP) durante a postura ereta quieta. A figura menor representa um pêndulo simples invertido idealizando o significado das componentes do COP.

\subsection{Um software para análise de dados da estabilografia}

Desenvolvi um programa para análise de dados da estabilografia, denominado PostTool. Tecnicamente, o programa consiste de uma série de códigos implementados em um ambiente de programação, o software Matlab 5.3 para Windows (Mathworks, Inc. Natick, MA, EUA). Uma interface gráfica para o usuário (GUI, graphical user interface) foi implementada para permitir uma operação amigável ao usuário; a janela principal deste programa é mostrada na Figura 10. O uso de uma GUI elimina a necessidade do usuário entender a linguagem de programação do Matlab para o uso dos códigos. A principal vantagem de desenvolver os algoritmos em Matlab é que o código inteiro é aberto e o usuário pode implementar ou modificar o programa segundo suas necessidades rapidamente. Por exemplo, seguindo os códigos do programa, alguém poderia facilmente adicionar um outro botão representando uma função específica do usuário.

Os códigos desenvolvidos implementam as seguintes funções:

1. Estatística básica: cálculo da média, desvio padrão, velocidade média do COP, área do estabilograma, freqüências média e mediana

2. Análise dos padrões do COP durante postura ereta irrestrita de longa duração

3. Estimação da linha de gravidade

4. Análise da difusão do estabilograma pelo método de random walk

5. Decomposição do estabilograma nas componentes rambling e trembling. 


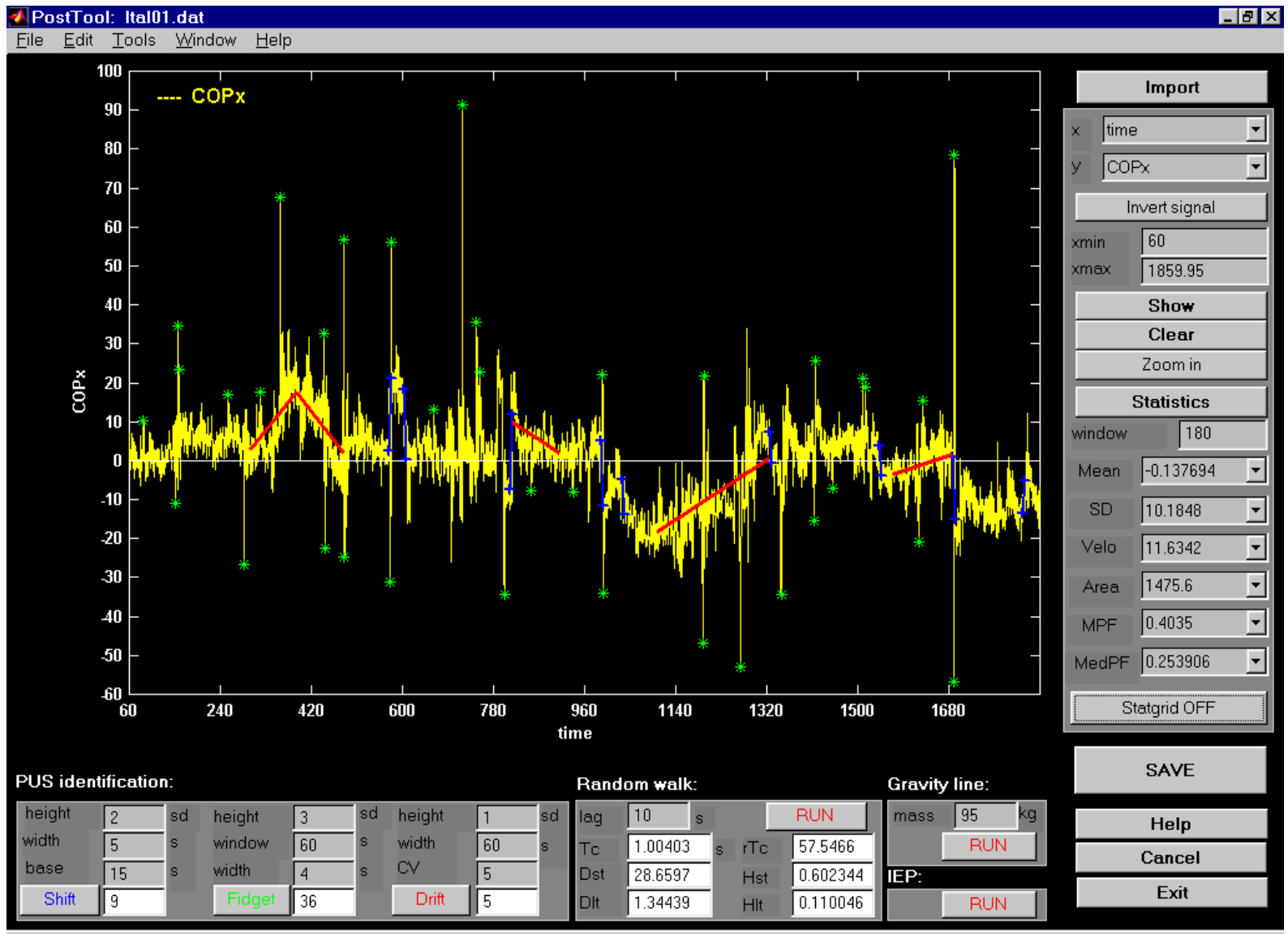

Figura 10. Janela principal do software PostTool desenvolvido para a análise do sinal do centro de pressão da estabilografia.

O programa PostTool foi utilizado em vários dos estudos reportados neste trabalho, principalmente para visualização e análises preliminares dos sinais. Atualmente, ele também tem sido utilizado pelo grupo do Dr. Li da Walsh University, Ohio, EUA, para análise dos dados de postura irrestrita de longa duração em casos clínicos. 


\section{Padrões no sinal do centro de pressão durante postura ereta irrestrita de longa duração}

A postura ereta irrestrita de longa duração foi estudada em 10 sujeitos saudáveis. Os métodos usuais utilizados em análise estabilográfica assumem que a migração do centro de pressão (COP) é aleatória, isto é não estruturada. Este estudo é baseado na idéia oposta e mostra que durante a postura ereta irrestrita de longa duração padrões específicos e consistentes da migração do COP existem e podem ser reconhecidos por meio de um algoritmo computacional. Três padrões de migração foram encontrados: (1) shifting, um deslocamento rápido da posição do COP de uma região para outra; (2) fidgeting, um rápido e grande deslocamento e retorno do COP para aproximadamente a mesma posição; e (3) drifting, um lento e contínuo deslocamento da posição média do COP. Um software foi escrito e valores default para certos parâmetros foram escolhidos para o reconhecimento dos padrões de migração do COP mencionados.

Para 30 min de postura ereta irrestrita de longa duração os seguintes padrões foram identificados: shifting foi observado em média a cada $316 \pm 292$ s na direção ântero-posterior (a-p) com uma amplitude média do shift de $17 \pm 15 \mathrm{~mm}$ e a cada $199 \pm 148 \mathrm{~s}$ na direção médiolateral (m-l) com uma amplitude média do shift de $22 \pm 38 \mathrm{~mm}$. Os intervalos de tempo para fidgeting foram $59 \pm 15 \mathrm{~s}$ na direção a-p (amplitude média do fidget de $35 \pm 20 \mathrm{~mm}$ ) e $49 \pm 16 \mathrm{~s} \mathrm{na}$ direção m-l (amplitude média do fidget de $32 \pm 36 \mathrm{~mm}$ ). O intervalo médio entre drifts foi $319 \pm 173 \mathrm{~s}$ na direção a-p (amplitude média do drift de $16 \pm 8 \mathrm{~mm}$ ) e $529 \pm 333 \mathrm{~s}$ na direção $\mathrm{m}-\mathrm{l}$ (amplitude média do drift de $12 \pm 7 \mathrm{~mm}$ ). 


\subsection{Introdução}

A medição do COP durante a postura ereta não perturbada, também chamada estabilografia estática, tem sido um objeto de intensa pesquisa nas últimas seis décadas (Hellebrandt, 1938; Thomas \& Whitney, 1959; Bensel \& Dzendolet, 1968; Nashner, 1981; Winter et al., 1990; Collins \& De Luca, 1993). O presente estudo difere dos outros estudos de posturografia em dois aspectos: (1) o tipo de tarefa motora e (2) o método de análise dos dados posturográficos.

Comumente em estudos de posturografia estática, os sujeitos são solicitados a ficarem quietos em pé por um período de 20 a $90 \mathrm{~s}$ (para uma revisão, ver Kapteyn et al., 1983 e Prieto et al., 1993). No entanto, durante atividades da vida diária, as pessoas geralmente não ficam em pé quietas. Neste estudo, nós tentamos imitar a postura ereta natural e nós estudamos a postura ereta irrestrita de longa duração. Nos experimentos nenhuma instrução específica foi dada aos sujeitos sobre como ficar em pé e os sujeitos foram permitidos mudarem suas posturas como quisessem.

Prévios estudos sobre postura ereta de longa duração realizados com a instrução "permaneça o mais imóvel possível" pesquisaram principalmente as reações fisiológicas do corpo à esta tarefa (para uma revisão, ver Rys \& Konz, 1994).

Como descrito no capítulo anterior, uma grande variedade de métodos tem sido empregados para analisar os dados estabilográficos. Todos os métodos são baseados numa idéia comum: que a migração do COP é não estruturada. O presente estudo é baseado na idéia oposta para a análise da postura ereta irrestrita de longa duração.

O principal objetivo deste estudo é mostrar que durante a postura ereta irrestrita de longa duração, padrões específicos e consistentes da migração do COP existem e podem ser reconhecidos por um algoritmo computacional. Os objetivos são: (1) descrever tais padrões; (2) desenvolver um algoritmo para detecção; (3) especificar os parâmetros para detecção no algoritmo e sugerir um procedimento de classificação padrão; e (4) apresentar estatística descritiva dos padrões de migração do COP durante postura ereta irrestrita de longa duração.

\subsection{Exemplos preliminares e terminologia}

Quando a migração do COP é mapeada no plano a-p versus m-I, dois padrões típicos podem ser observados: postura ereta de multi-região e de uni-região, como mostrado na Figura 11. Na postura ereta de multi-região, os sujeitos tendem a mudar a posição média do COP várias vezes durante a tentativa. Estas regiões podem ser chamadas de domínios de atração do COP. 


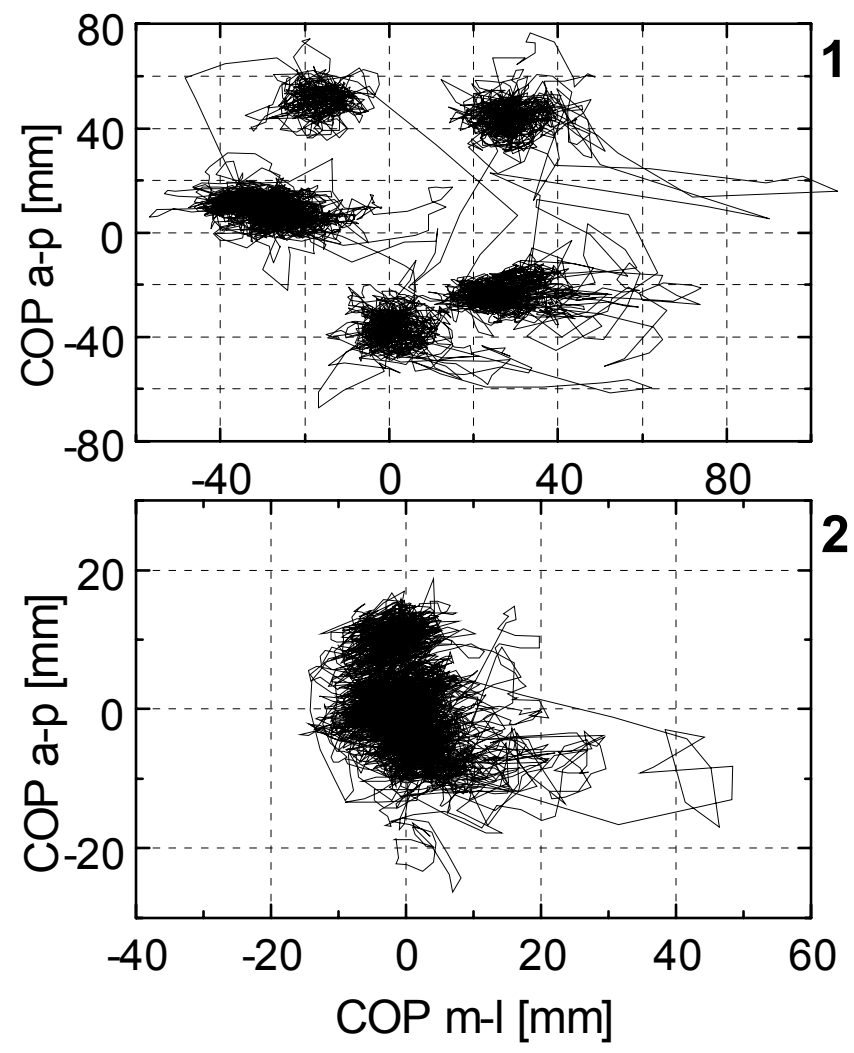

Figura 11. Migração do COP em duas tentativas diferentes, direção a-p versus m-l. Postura ereta de multi-região (1) e uni-região (2). O mesmo sujeito (mulher, 25 anos, $1,74 \mathrm{~m}$ de altura e 59,2 $\mathrm{kg}$ de massa) permaneceu em pé por 30 minutos duas vezes com um intervalo de uma semana.

Quando os dados do COP são apresentados como séries temporais, os seguintes três padrões são identificáveis (ver Figura 12):

1. Shifting (tipo degrau): um rápido deslocamento da posição média do COP de uma região à outra.

2. Fidgeting (tipo pulso): um rápido e grande deslocamento do COP e retorno para aproximadamente a mesma posição.

3. Drifting (tipo rampa): um contínuo e lento deslocamento da posição média do COP (tendência linear ou não linear).

Se uma tentativa é consideravelmente longa, em geral os três padrões estão presentes. Em adição a estes padrões, naturalmente observa-se a característica oscilação do COP de baixa amplitude refletindo a contínua perturbação da postura ereta e sua regulação. 


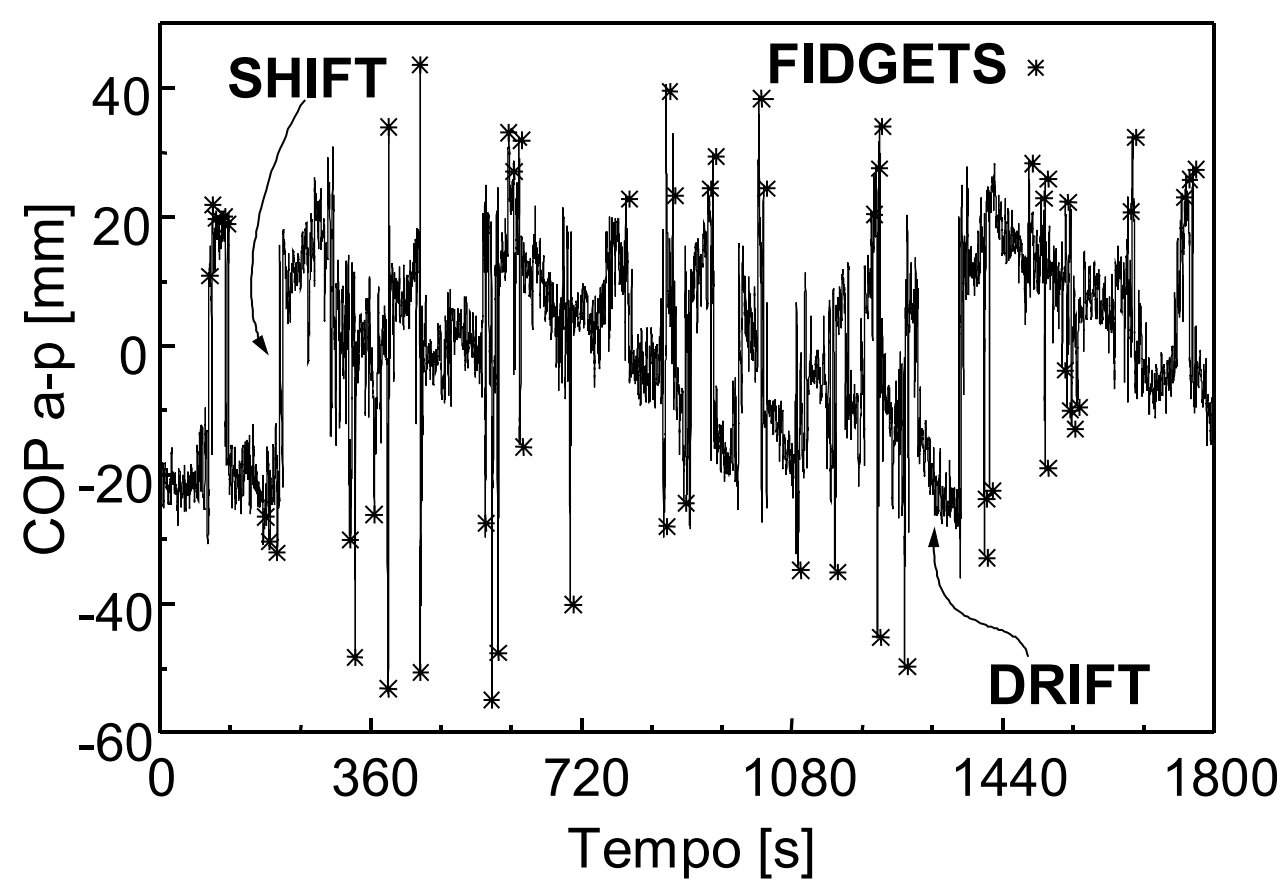

Figura 12. Exemplo representativo de migração do COP e padrões durante a postura ereta irrestrita de longa duração. Direção a-p (homem, 26 anos, 1,85 m de altura e 89,1 kg de massa). Os picos de fidget (*) foram selecionados com um limiar de $\pm 3,0$ SD. Apenas um shift e um drift são indicados para uma melhor visualização.

\subsection{Modelo e algoritmo}

Códigos foram escritos por eu utilizando o software Matlab (Matlab 5.3, MathWorks Inc., Natick, MA, EUA) com uma interface gráfica ao usuário onde os parâmetros para identificação dos padrões do COP podem ser especificados. A interface ao usuário permite selecionar e plotar os dados e a identificação dos padrões baseados em critérios objetivos. Os algoritmos para reconhecimento dos padrões são descritos a seguir.

(1) Shifting: a detecção foi feita comparando os valores médios de duas janelas consecutivas móveis. A seguinte seqüência foi empregada:

1a. Os valores médios, $\bar{x}_{W 1}, \bar{x}_{W 2}$, e desvios padrões, $S D_{W 1}$ e $S D_{W 2}$, para duas janelas consecutivas móveis, $W_{1}$ and $W_{2}$, separadas pelo período $W_{S}$ foram computados.

1b. Duas janelas consecutivas satisfazendo a equação abaixo foi classificada como um shift.

$$
\left|\frac{\bar{x}_{W 1}-\bar{x}_{W 2}}{\sqrt{S D_{W 1}^{2}+S D_{W 2}^{2}}}\right| \geq f_{\text {shift }}
$$

A amplitude do shift é definida como $\left|\bar{x}_{W 1}-\bar{x}_{W 2}\right|$. Por conseguinte, a identificação do padrão shift depende dos seguintes parâmetros: (a) o valor limiar da amplitude do shift $\left(f_{\text {shift, }}\right.$ em unidades de $S D_{W_{1}}+S D_{W_{2}}$ ), (b) o comprimento das janelas temporais, $W_{1}$ e $W_{2}$, e (c) o período separando as duas janelas consecutivas, $W_{S}$, como representado na Figura 13. 


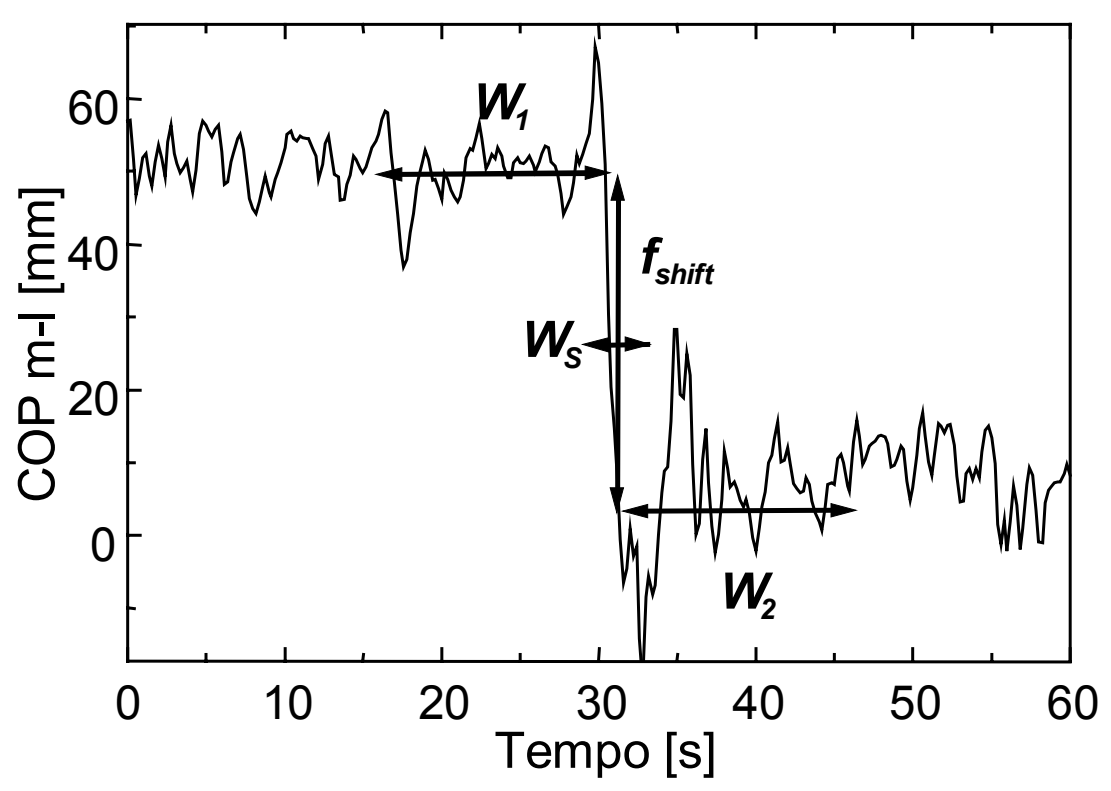

Figura 13. Exemplo representativo do padrão shift e os parâmetros usados para reconhecimento.

(2) Fidgeting: a detecção foi feita comparando-se o valor de pico com o valor médio de uma janela centrada em torno do pico. A seguinte seqüência foi empregada:

2a. Os dados entre dois shifts consecutivos foram selecionados e todos os picos positivos e negativos, $\boldsymbol{x}_{\boldsymbol{F}}$, com uma largura estimada, $W_{F}, \leq 4 \mathrm{~s}$, foram achados. A largura do fidget foi estimada como a largura total à meia altura (uma medida conhecida em processamento de sinais como full width at half maximum, FWHM).

2b. Uma janela móvel centrada em $\boldsymbol{x}_{F}$ com um comprimento $W$ foi usada e o valor médio do COP nesta janela, $\bar{x}_{W}$, e seu desvio padrão, $S D_{W}$, foram computados.

2c. Qualquer pico satisfazendo a equação abaixo foi classificado como um fidget.

$$
\left|\frac{x_{F}-\bar{x}_{W}}{S D_{W}}\right| \geq f_{\text {fidget }}
$$

A amplitude do fidget é definida como $\left|x_{F}-\bar{x}_{W}\right|$. De acordo com a equação acima, o reconhecimento de fidgets depende dos seguintes parâmetros: (a) o valor limiar da amplitude do fidget ( $f_{\text {fidget }}$, em unidades de $S D_{W}$ ), (b) o comprimento da janela temporal, $W$, e (c) a máxima largura do fidget, $W_{F}$, como representado na Figura 14. 


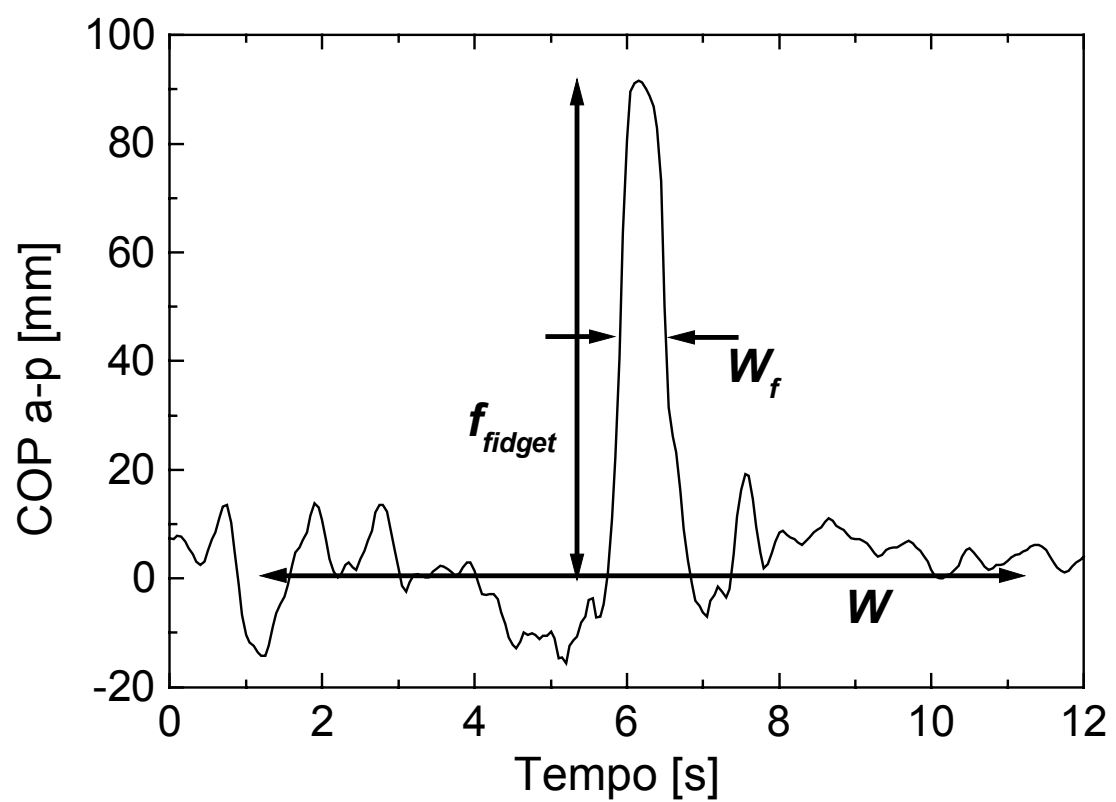

Figura 14. Exemplo representativo do padrão fidget e os parâmetros usados para reconhecimento.

(3) Drifting: a detecção pretendeu quantificar qualquer tendência nos dados experimentais. A identificação dos drifts foi realizada da seguinte maneira:

3a. Os dados entre dois shifts consecutivos foram selecionados e filtrados com um filtro passa baixa com uma freqüência de corte $F_{C}=1 / 2 W_{D}$, onde $W_{D}$ é a mínima largura do drift que se pretende identificar. Este procedimento preserva somente a componente de baixa freqüência (drift) nos dados.

3b. Valores máximos e mínimos locais foram determinados, $X_{\text {MAX }}$ e $X_{\text {MIN }}$.

3c. A diferença entre quaisquer dois consecutivos máximos and mínimos locais localizados a uma distância maior que $W_{D}$ foi determinada.

3d. esta diferença foi comparada com um valor de limiar pré-selecionado $f_{\text {drift }}$ (em unidades de $S D_{W}$ ). Se a diferença excedia $f_{\text {dritt, }}$ o próximo passo foi feito.

3e. O coeficiente de variação dos dados, $C V=\sum_{i=1}^{n}\left(S D_{i} /\left|\bar{X}_{i}\right|\right)$, foi calculado, onde $S D_{i}$ e $\left|\bar{X}_{i}\right|$ são respectivamente o desvio padrão e o valor médio absoluto da diferença entre o dado cru $i$ e o dado filtrado i. O CV foi calculado sobre o intervalo entre consecutivos máximos e mínimos locais.

3f. Se o CV é menor que um valor pré-selecionado, $C V_{\text {drift, }}$ e se os consecutivos máximos e mínimos satisfazem a equação abaixo, o padrão de migração do COP foi classificado como um drift.

$$
\left|\frac{X_{M A X}-X_{M I N}}{S D_{w}}\right| \geq f_{D R I F T}
$$

A amplitude do drift é definida como $\left|x_{\max }-x_{\text {min }}\right|$. Por conseguinte, o reconhecimento de um drift depende de (a) o valor limiar da amplitude do drift ( $f_{\text {drift, }}$ em unidades de $\left.S D_{w}\right)$ (b) o mínimo 
comprimento de um drift, $W_{D}$, que também determina a freqüência de corte, $F_{C}$, e (c) o valor máximo do coeficiente of variação, $C V_{\text {drift, }}$ como representado na Figura 15.

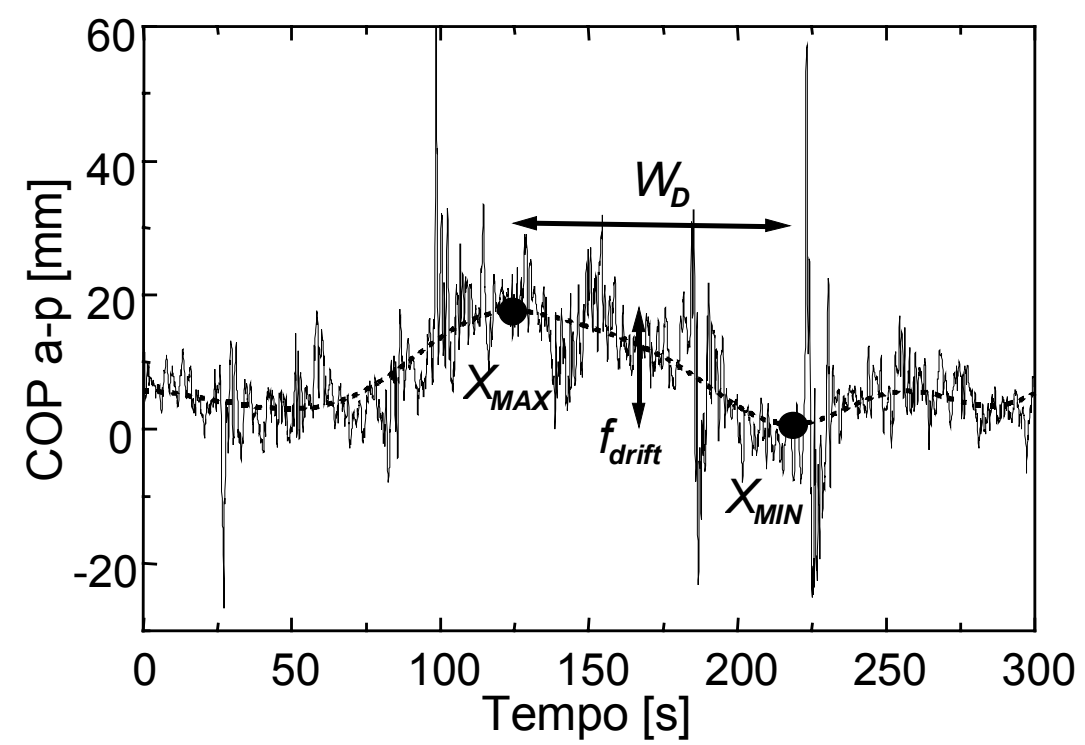

Figura 15. Exemplo representativo do padrão drift e os parâmetros usados para reconhecimento.

\subsection{Experimento}

Dez sujeitos saudáveis (oito homens e duas mulheres) participaram deste estudo. A idade média do grupo era de $28 \pm 5$ anos, estatura média de $1,79 \pm 0,09 \mathrm{~m}$ e massa corporal média de $78 \pm 14 \mathrm{~kg}$. Nenhum dos sujeitos tinha histórico de desordem postural ou no sistema músculoesquelético.

Os sujeitos permaneceram em pé numa postura ereta sobre uma plataforma de força de $40 \times 90 \mathrm{~cm}^{2}$ (modelo 4090S Bertec Inc., Worthington, OH, EUA), de superfície dura. O protocolo de testes consistiu das seguintes tentativas: 1) postura ereta quieta por $40 \mathrm{~s}, 2$ ) postura ereta irrestrita por 31 minutos, e 3) postura ereta quieta por $40 \mathrm{~s}$ (idêntica a primeira tentativa). Houve um minuto de intervalo entre as tentativas. O mesmo protocolo de testes foi aplicado uma semana mais tarde. Durante os testes, os sujeitos calçavam meias e estavam de olhos abertos. Inicialmente, os sujeitos foram instruídos a ficarem em pé com os pés separados por uma largura confortável (aproximadamente a largura dos ombros) e com os braços ao lado do corpo. Na primeira e terceira tentativas, os sujeitos foram solicitados a manterem a mesma posição durante a aquisição. $\mathrm{Na}$ segunda tentativa, quando os sujeitos foram permitidos a mudar livremente suas posturas em qualquer instante, não houve instrução específica de como permanecer em pé além de não pisar fora da plataforma de força. Os experimentos foram realizados em uma sala silenciosa de $8 \times 6 \mathrm{~m}^{2} \mathrm{com}$ a plataforma de força posicionada no meio. Somente os resultados da tarefa de postura ereta irrestrita são reportados aqui.

Os dados foram adquiridos em freqüência de amostragem de $20 \mathrm{~Hz}$ utilizando-se um computador pessoal (modelo P5-100, Gateway 2000, Inc., N. Sioux City, EUA) com um cartão A/D de 12 bits (modelo AT-MIO-64E-3, National Instruments Corporation, Dallas, TX, EUA) controlado por um código especial escrito no software LabView (LabView 4.1, National Instruments Corporation, Dallas, 
TX, EUA). Os dados foram analisados com os códigos em Matlab previamente descrito. Alguns sujeitos também foram filmados para documentação qualitativa do experimento.

O primeiro minuto dos dados de postura ereta irrestrita não foi considerado porque foi o tempo dado aos sujeitos para se habituarem com a tarefa. A análise foi feita para ambas as direções a-p e m-I. A análise dos dados foi realizada em dois estágios. No primeiro estágio, os valores dos parâmetros dos algoritmos para identificação dos padrões foram variados. É descrita a seguir a dependência dos resultados do reconhecimento com tais parâmetros. Então, certos valores default foram selecionados e a análise principal foi realizada. Uma análise de variância (ANOVA) para medidas repetidas e com um fator e nível de significância de 0,05 foi aplicada sobre o número de padrões para determinar os efeitos das duas diferentes tentativas e da duração da tentativa.

\subsection{Dependência do reconhecimento dos padrões com os valores dos parâmetros}

Os parâmetros que definem a sensitividade do reconhecimento dos três padrões de migração do COP podem, em princípio, ser escolhidos pelo pesquisador. Evidentemente, os valores escolhidos irão afetar os resultados obtidos. É quase impossível evitar subjetividade na escolha dos parâmetros. A análise que se segue foi realizada para explorar a influência dos valores dos parâmetros sobre o reconhecimento dos padrões.

Shifts: O reconhecimento de shifts depende de (a) o limiar de shift $\left(f_{\text {shift }}\right.$, em unidades de $S D_{W 1}+$ $S D_{W_{2}}$ ), (b) o comprimento das janelas temporais, $W_{1}$ e $W_{2}$, e (c) o período separando as duas janelas consecutivas, $W_{S}$; onde o limiar de shift é o parâmetro mais importante. Dois parâmetros foram alterados de uma maneira sistemática, o limiar de shift $( \pm 1,0 ; \pm 1,5 ; \pm 2,0 ;$ e $\pm 2,5$ SD) e o comprimento da janela (15; 30 ; e $60 \mathrm{~s})$. A máxima duração do shift, $W_{S}$, foi fixada em $5,0 \mathrm{~s}$. Os resultados são apresentados na Figura 16a. No estudo principal, os seguintes valores foram adotados como default: (a) valor limiar de $\pm 2 \mathrm{SD}$, (b) comprimento da janela de $15 \mathrm{~s}$, e (c) máxima duração do shift de 5,0 s.

Fidgets: O reconhecimento de fidgets depende de (a) o limiar de fidget $\left(f_{\text {fidget }}\right.$, em unidades de $\left.S D_{W}\right)$, (b) o comprimento da janela temporal, $W$, e (c) a máxima duração do fidget, $W_{F}$; onde o limiar de fidget é o parâmetro mais importante. Dois parâmetros foram alterados de uma maneira sistemática, o limiar de fidget ( $\pm 1,0 ; \pm 2,0 ; \pm 3,0$; e $\pm 4,0 \mathrm{SD}$ ) e o comprimento da janela (30; 60; e $120 \mathrm{~s}$ ). A máxima duração do fidget, $W_{F}$, foi fixada em 4,0 s. Os resultados são apresentados na Figura 16b. No estudo principal, os seguintes valores foram adotados como default: (a) um valor limiar de \pm 3 SD, (b) um comprimento da janela de $60 \mathrm{~s}$, e (c) uma máxima duração do fidget de 4,0 s.

Drifts: O reconhecimento de drifts depende de (a) o limiar de drift ( $f_{\text {drift, }}$ em unidades de $S D_{W}$ ), (b) o comprimento mínimo de um drift, $W_{D}$, que também determina a freqüência de corte, $F_{C}$, e (c) o valor máximo do coeficiente de variação, $C V_{\text {drift; }}$ onde o limiar de drift é o parâmetro mais importante. Dois parâmetros foram alterados de uma maneira sistemática, o limiar de drift $( \pm 0,5 ; \pm 1,0 ; \pm 1,5$; e $\pm 2,0$ SD) e o comprimento da janela (30; 60; e 90 s. O valor máximo do coeficiente de variação foi fixado em 5,0 . Os resultados são apresentados na Figura 16c. No estudo principal, onde os parâmetros foram fixados, os seguintes valores foram adotados como default: (a) um valor limiar de \pm 1 SD, (b) um comprimento da janela de $60 \mathrm{~s}$, e (c) o máximo coeficiente de variação de 5,0. 


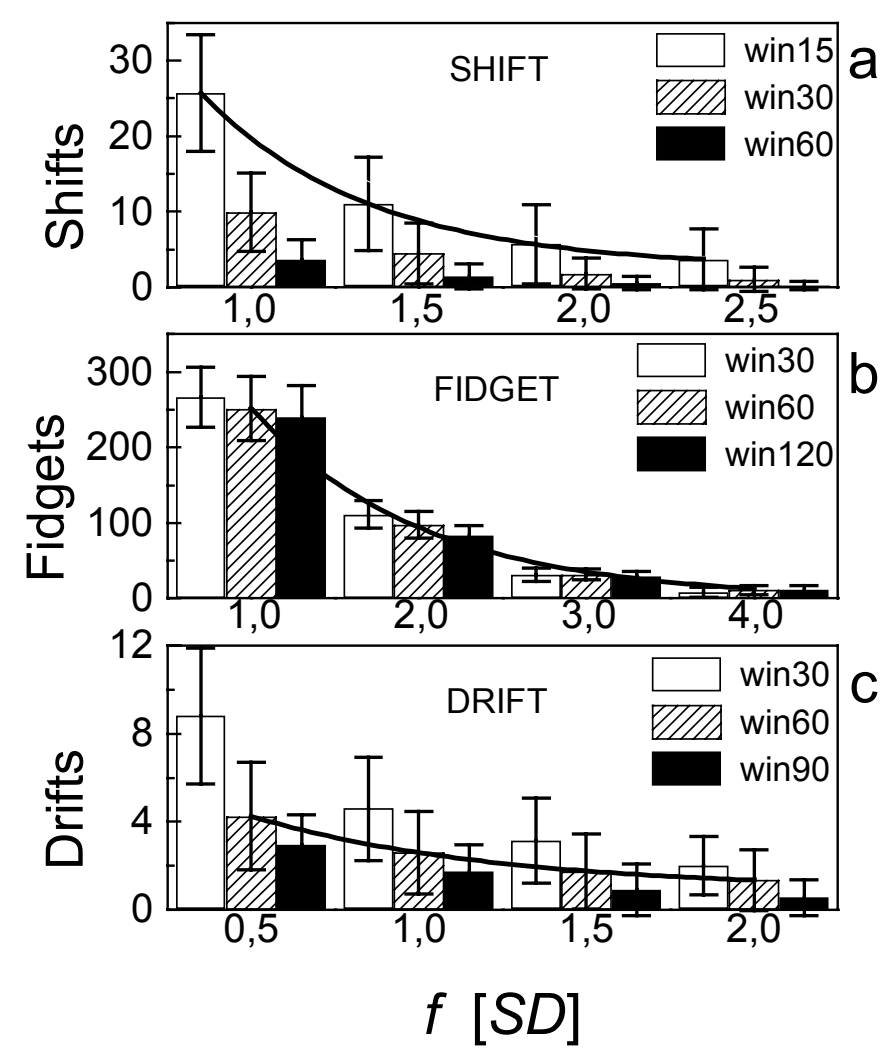

Figura 16. Número de padrões reconhecidos com diferentes valores limiares para os parâmetros dos algoritmos (f). (a) para shifts: 1,0; 1,5; 2,0 e 2,5 SD para diferentes janelas: 15; 30 e $60 \mathrm{~s}$; máxima largura do shift fixada em $5 \mathrm{~s}$. Os dados para a largura $15 \mathrm{~s}$ foram ajustados pela equação $N_{\text {shift }}=25+23 \cdot e^{-(f s-1.0) / 0.5}$. (b) para fidgets: 1,0; 2,0; 3 e 4 SD para diferentes janelas: 30, 60, and $120 \mathrm{~s}$, a largura máxima dos fidgets foi fixada em $4 \mathrm{~s}$. Os dados para uma janela de $60 \mathrm{~s}$ foram ajustados pela equação $N_{\text {fidget }}=252 \cdot e^{1-f f}$. (c) para drifts: 0,$5 ; 1,0 ; 1,5$ and $2,0 \mathrm{SD}$, para diferentes comprimentos mínimos do drift: 30,60 , and $90 \mathrm{~s}$, o coeficiente de variabilidade foi fixado em 5 . Os dados para uma janela de 60 s foram ajustados pela equação $N_{d r i f t}=0.92+3.33 \cdot e^{-(f d-}$ ${ }_{0.5) / 0.72}$. Postura ereta irrestrita, 10 sujeitos, 2 tentativas, direções a-p e m-l.

\subsection{Resultados}

Os algoritmos desenvolvidos reconheceram todos os três padrões do COP em todos os sujeitos e em quase todas as tentativas. Os dados médios são apresentados na Tabela 1.

Um rápido deslocamento da posição média do COP de uma região a outra (shift) aconteceu em média a cada $316 \pm 292 \mathrm{~s}$ na direção a-p (variando de $82 \mathrm{~s}$ a $1800 \mathrm{~s}$ ) com uma amplitude média do shift de 2,6 $\pm 0,9 \mathrm{SD}(17 \pm 15 \mathrm{~mm})$. Na direção $\mathrm{m}-\mathrm{I}$, um shift ocorreu em média a cada $199 \pm 148 \mathrm{~s}$ (variando de $75 \mathrm{~s}$ a $>1800 \mathrm{~s}$ ) com uma amplitude média do shift de 4,3 $\pm 3,9 \mathrm{SD}$ $(22 \pm 38 \mathrm{~mm}$ ) (Figura 17). A diferença entre o número de shifts na direção a-p e m-I não foi significante, $F(3 ; 36)=1,55, p>0,05$. Os dados foram reprodutíveis entre as tentativas; o número de shifts foi similar na primeira e segunda tentativas, $F(1 ; 18)=0,17 ; p>0,05$ para a direção a-p, e $F(1 ; 18)=1,22 ; p>0,05$ para a direção $\mathrm{m}$-I. Os shifts foram observados tanto na postura ereta em uni-região como em multiregião. A única diferença foi na amplitude do amplitude: houve 3 tentativas de multi-região, com uma

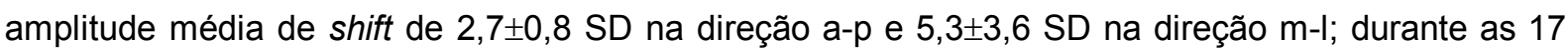

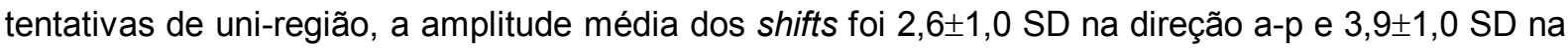
direção m-I. A amplitude dos shifts foi maior na direção $m-I$ que na direção a-p. 
Tabela 1. Número médio de padrões de migração do COP reconhecidos pelos algoritmos (postura ereta irrestrita, 30 min, 10 sujeitos, 2 tentativas, direções a-p e m-l).

\begin{tabular}{ccc}
\hline VARIÁVEL & DIREÇÃO a-p & DIREÇÃO m-I \\
\hline SHIFT [shifts/30 min] & $6 \pm 5$ & $9 \pm 7$ \\
Amplitude média [SD] & $2,6 \pm 0,9$ & $4,3 \pm 3,9$ \\
Amplitude média [mm] & $17 \pm 15$ & $22 \pm 38$ \\
\hline FIDGET [fidgets/30 min] & $30 \pm 8$ & $36 \pm 12$ \\
Amplitude média [SD] & $4 \pm 1$ & $4,4 \pm 1,5$ \\
Amplitude média [mm] & $35 \pm 20$ & $32 \pm 36$ \\
\hline DRIFT [drifts/30 min] & $6 \pm 3$ & $3 \pm 2$ \\
Amplitude média [SD] & $2,5 \pm 1,6$ & $1,8 \pm 1,1$ \\
Amplitude média [mm] & $16 \pm 8$ & $12 \pm 7$ \\
Duração média [s] & $178 \pm 199$ & $165 \pm 187$ \\
\hline
\end{tabular}

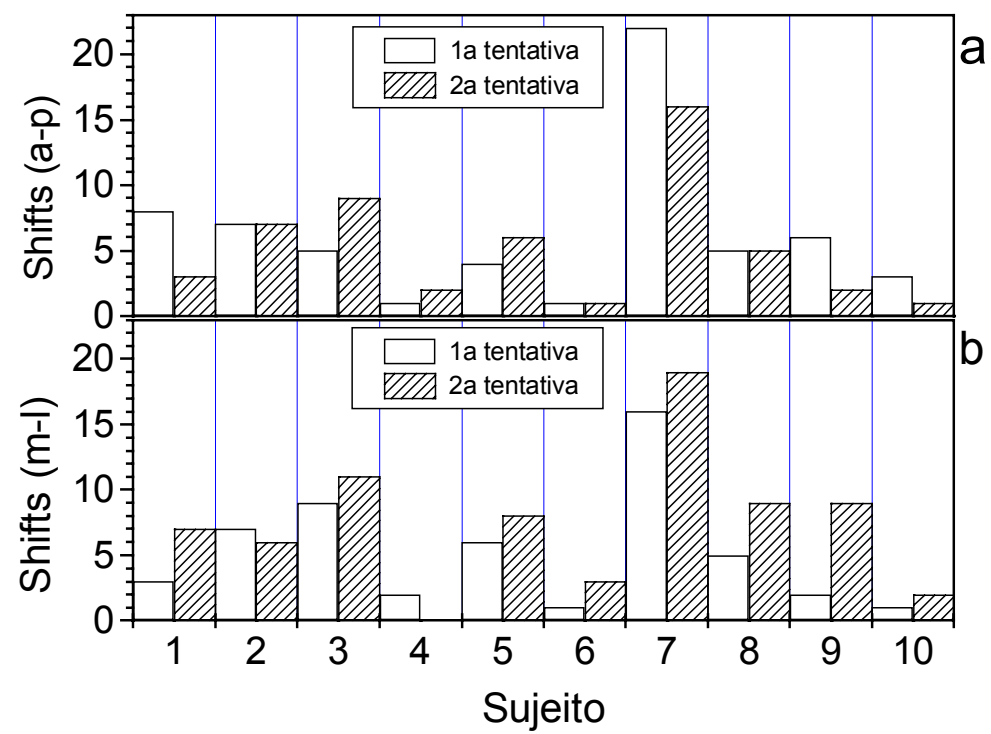

Figura 17. Número de shifts durante postura ereta irrestrita por 30 minutos para diferentes sujeitos e tentativas para direção a-p (a) e m-l (b). 10 sujeitos, 2 tentativas.

Um rápido e grande deslocamento e retorno do COP para aproximadamente a mesma posição (fidget) ocorreu em média a cada $59 \pm 15$ s na direção a-p (variando de 41 s a 112 s) com uma amplitude média do fidget de $4 \pm 1$ SD $(35 \pm 20 \mathrm{~mm})$. Na direção $\mathrm{m}-\mathrm{l}$, os fidgets ocorreram em média a cada $49 \pm 16 \mathrm{~s}$ (variando de $31 \mathrm{~s}$ a $106 \mathrm{~s}$ ) com uma amplitude média do fidget de 4,4 $\pm 1,5 \mathrm{SD}(32 \pm 36$ $\mathrm{mm}$ ). Os dados foram reprodutíveis entre as duas tentativas (Figura 18). A maioria dos fidgets foram realizados na direção oblíqua. Por causa disto, o número de fidgets nas duas direções foi muito similar, na média 30 e 36 fidgets para os $30 \mathrm{~min}$ da tentativa, respectivamente. Esta diferença não foi estatisticamente significante, $\mathrm{F}(3 ; 36)=1,73 ; p>0,05$. 


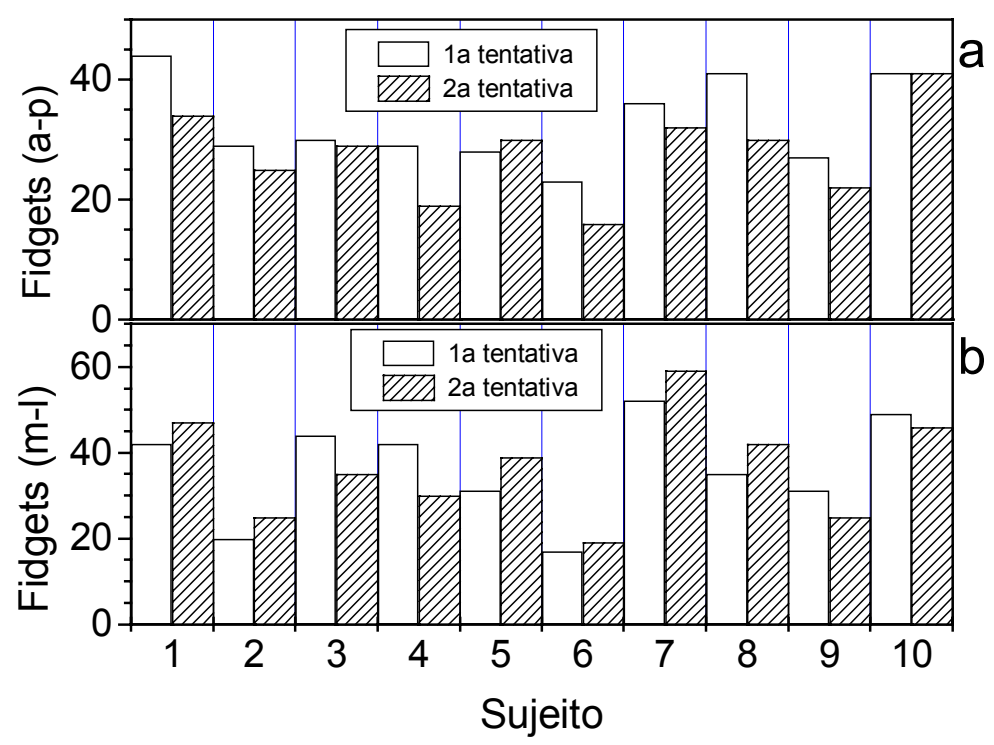

Figura 18. Número de fidgets durante postura ereta irrestrita por 30 minutos para diferentes sujeitos e tentativas para a direção a-p (a) e m-l (b). 10 sujeitos, 2 tentativas.

Não houve nenhuma concentração observável de fidgets durante o período da tentativa nem para a direção a-p $F_{(9 ; 190)}=0,73 ; p>0,05$, ou para a direção $m-I, F_{(9 ; 190)}=1,50 ; p>0,05$. (Figura 19).

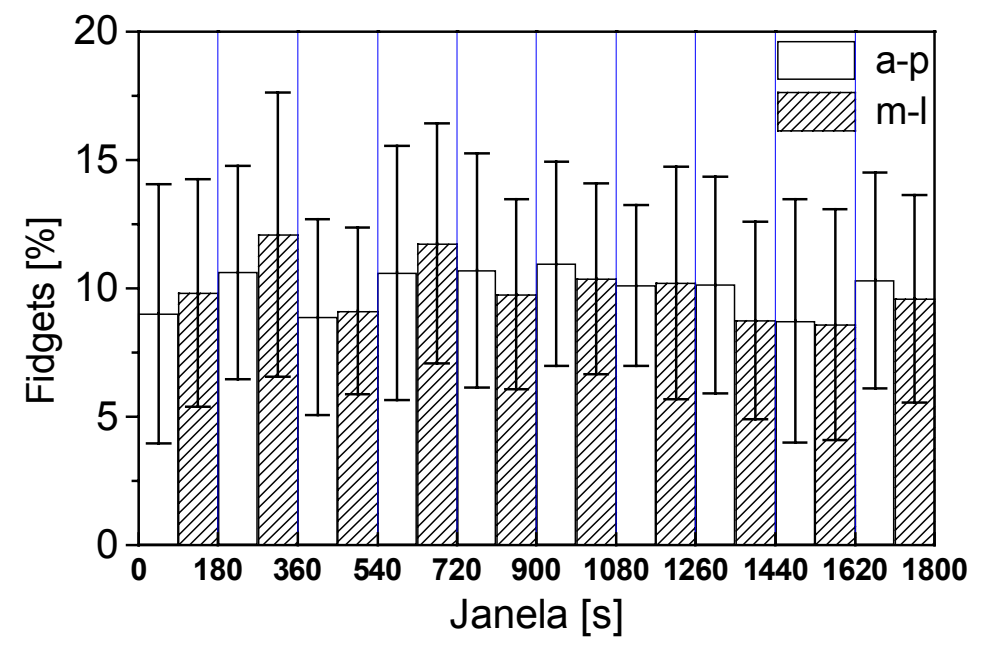

Figura 19. A distribuição de fidgets para janelas de $180 \mathrm{~s}$ em relação ao número total durante postura ereta irrestrita por 30 minutos para diferentes sujeitos e tentativas para a direção a-p (a) e m-l (b). 10 sujeitos, 2 tentativas.

Um deslocamento lento e contínuo da posição média do COP (drift) ocorreu em média na direção a-p a cada $319 \pm 173 \mathrm{~s}$ (variando de $150 \mathrm{~s}$ a >1800 s) com uma amplitude média do drift de $2,5 \pm 1,6 \mathrm{SD}(16 \pm 8 \mathrm{~mm})$ e uma duração média do drift de 178 $\pm 199 \mathrm{~s}$. Na direção $\mathrm{m}-\mathrm{I}$, o intervalo entre drifts foi em média igual a $529 \pm 333 \mathrm{~s}$ (variando de $225 \mathrm{~s}$ a $>1800 \mathrm{~s}$ ) com uma amplitude média do drift de $1,8 \pm 1,1 \mathrm{SD}(12 \pm 7 \mathrm{~mm})$ e uma duração média de $165 \pm 187 \mathrm{~s}$ (Figura 20). Os dados foram reprodutíveis entre as duas tentativas. Não houve diferença entre as duas tentativas nem para a direção a-p, $F(1 ; 18)=0,13 ; p>0,05$, nem para a direção $m-I F(1 ; 18)=4,13 ; p>0,05$.

Comparado ao número de fidgets, os números de shifts e drifts variaram substancial- 
mente entre os sujeitos (Figura 17 e Figura 20), com a variação de 0 a 22 shifts e 0 a 12 drifts.

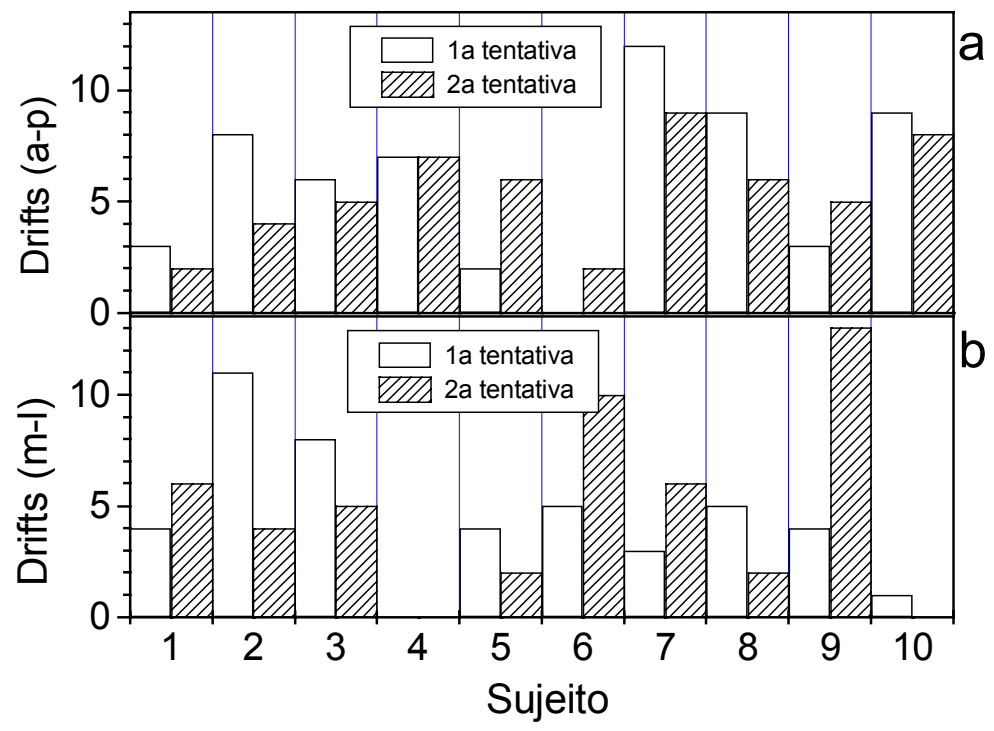

Figura 20. Número de drifts durante postura ereta irrestrita por 30 minutos para diferentes sujeitos e tentativas para direção a-p (a) e m-l (b). 10 sujeitos, 2 tentativas.

\subsection{Discussão}

O principal achado deste estudo foi a existência de três padrões de migração do COP durante a postura ereta irrestrita de longa duração. Tais padrões, shifts, fidgets, e drifts existem e podem ser reconhecidos por algoritmos computacionais apropriados.

Atualmente, pouco é conhecido sobre este fenômeno. A observação qualitativa dos sujeitos revelou que os três padrões resultam de vários movimentos dos segmentos corporais ou do corpo como um todo. Os movimentos mais comuns foram com os braços, cabeça, tronco e redistribuição do peso de uma perna para a outra.

O termo 'fidgeting' já foi usado por outros pesquisadores para descrever qualquer mudança postural sem especificar o tipo de movimento. Bhatnager et al. $(1984,1985)$ reportaram que durante a tarefa de sentar por um longo tempo, a freqüência de mudanças posturais ('fidgeting') aumentou mais de $50 \%$ nas três horas de observação. Alexander (1992) usou o termo 'fidgeting' para designar as mudanças posturais durante a postura ereta. Ele sugeriu a hipótese de que um objetivo de produzir fidgeting é mudar a pressão na cartilagem articular.

No presente estudo, o termo 'fidgeting' foi conotado em um sentido mais específico; não é qualquer deslocamento do COP, mas um rápido desvio e retorno do COP a sua posição inicial. Entre os padrões identificados, o fidgeting é o padrão mais freqüente de migração do COP. Visto que o COP retorna à aproximadamente a mesma posição, os fidgets não são mudam a posição média do COP. É plausível considerar que fidgeting serve para redistribuir a pressão nas articulações, para rebombear o líquido sinovial da cartilagem e aliviar a pressão local na sola dos pés. Quando os sujeitos reportaram o que sentiram durante a postura ereta irrestrita por 30 minutos, a queixa mais freqüente era sobre o desconforto nos pés. Uma possível razão para esta queixa pode ser a fadiga dos receptores de pressão na sola dos pés. O fidget pode ser a resposta a este desconforto. Se fidgets são inspirados por necessidades de mudança temporal na pressão da cartilagem articular ou 
da constante pressão nas solas dos pés não é sabido até este momento. Outros motivos, como acúmulo de sangue nas pernas, podem ser sugeridos.

Em contraste ao fidgeting, o shifting e drifting representam duas estratégias usadas pelo sistema nervoso para mudar a posição média do COP por longos períodos. O shifting é uma mudança mais dramática e permanente da posição do COP; tipicamente, o shifting é resultado da redistribuição do peso sobre uma perna para a outra ou mesmo um passo, ou ambos. As rápidas transições de um spot para outro na postura ereta de multi-região (Figura 11) estão relacionadas a este padrão. A existência de shifting e drifting ajusta-se bem à hipótese de Lestienne e Gurfinkel (1988). Estes autores sugeriram que o sistema de controle motor responsável pela manutenção do equilíbrio é um sistema hierárquico de dois níveis. O nível superior ("conservativo") determina um quadro de referência para o equilíbrio, com respeito ao qual o equilíbrio é mantido. O nível inferior ("operativo") mantém o equilíbrio em torno desta pré-determinada referência. Esta hipótese foi apoiada pelos experimentos de Gurfinkel et al. (1995). Nestes experimentos, a superfície de suporte rodava lentamente. Foi observado que por algum tempo os sujeitos mantinham a orientação fixa do corpo em relação à superfície (a vertical percebida) em vez da vertical real. Lestienne e Gurfinkel (1988) e também Gurfinkel et al. (1995) não abordaram em seus estudos uma possível migração do ponto de referência durante a postura ereta natural. $O$ presente estudo sugere que tal migração existe. No cenário desta hipótese, shifting e drifting podem ser considerados dois padrões diferentes da migração do ponto de referência.

A razão para uma lenta mudança da posição do COP, drifting, não é clara. Visto que durante drifting o COP muda sua posição média muito lentamente, certamente este padrão não é uma solução efetiva e espontânea para evitar desconforto ou prevenir uma queda. Talvez drifting simplesmente indique que o sistema nervoso não é sensível a pequenas mudanças da posição do COP. Durante drifting, o corpo não somente migra como um todo; mas também oscila em torno de um ponto de referênica móvel. Somente quando os pequenos deslocamentos acumulam e excedem um certo nível, o sistema nervoso corrige a posição média do corpo. A amplitude média do drifting foi de $16 \mathrm{~mm}$ para a direção a-p e $12 \mathrm{~mm}$ para a direção $\mathrm{m}-\mathrm{I}$ para uma duração média de três minutos, resultando numa velocidade média de drifting de $0,23 \mathrm{~mm} / \mathrm{s}$. Usando um modelo de pêndulo invertido simples, o deslocamento angular médio do corpo durante drifting foi estimado em $0,8^{0}$. Gurfinkel et al. (1995) reportaram que quando a plataforma de força girava $1,5^{\circ}$ lentamente $(f=0,006 \mathrm{~Hz})$, o centro de gravidade mantinha sua posição média em torno de ponto de referência que se movia lentamente (por conseguinte, a linha vertical da gravidade não era usada como referência absoluta). Nossos dados estão em bom acordo com estes achados. Nossos dados sugerem que durante a postura ereta natural, o ponto de referência migra. Note que fidgeting foi observado também durante drifting, indicando que estes dois processos servem a diferentes propósitos. 


\section{Análise estabilográfica da postura ereta irrestrita}

A postura ereta natural é caracterizada por mudanças posturais e diferentes hipóteses tem sido propostas para explicar estas mudanças. Neste estudo, quatro hipóteses foram investigadas quantificando-se o número de mudanças posturais nos dados do centro de pressão durante postura irrestrita de longa duração em diferentes condições experimentais, investigando os efeitos de uma carga mecânica, diferentes condições visuais e diferentes tipos de superficie de suporte e solado do calçado. Os sujeitos ficaram em pé por 30 minutos sem nenhuma instrução além de não pisar fora da plataforma. Não houve nenhum efeito significativo sobre o número de padrões do centro de pressão associados às mudanças posturais devido à carga, visão, superfície e calçado durante a postura ereta; na média, foram observados aproximadamente dois padrões do centro de pressão por minuto em todas as condições. A análise dos dados do centro de pressão pelos parâmetros estatísticos usuais (desvio padrão, velocidade e freqüência do deslocamento do centro de pressão e área do estabilograma) também não mostrou nenhum efeito das diferentes condições. 


\subsection{Introdução}

Em condições de trabalho bem como nas atividades da vida diária, algumas pessoas permanecem em pé por longo tempo, na maior parte das vezes, confinadas a uma pequena área. $\mathrm{Na}$ postura em pé natural, as pessoas usualmente adotam posturas assimétricas e tendem a mudar a posição do corpo periodicamente enquanto mantém uma postura do corpo relativamente fixa (Bridger 1991, Whistance et al. 1995). A contínua e lenta oscilação de baixa amplitude é comumente interrompida por mudanças posturais caracterizadas por movimentos rápidos e de grande amplitude. Há muitos estudos na literatura sobre a contínua e lenta oscilação de baixa amplitude, os quais tipicamente investigaram a postura ereta quieta, onde os sujeitos foram instruídos a ficar tão imóveis quanto possíveis num mesmo lugar por curtos períodos. O estudo da postura ereta irrestrita de longa duração tem recebido menos atenção, particularmente sob uma perspectiva biomecânica.

A importância das mudanças posturais durante a postura ereta irrestrita de longa duração foi citada previamente por Mosher (1913), apud Zacharkow (1988), e por Carlsöö (1961), apud Whistance et al. (1995), que salientaram a importância de deslocarem o peso corporal de lado a lado para um melhor conforto. Uma hipótese declara que tais mudanças posturais diminuem a acumulação de sangue venoso nas extremidades inferiores, a qual tem sido apontada como a principal fonte de desconforto durante a postura ereta (Brantingham et al., 1970; Kim et al., 1994; Zhang et al., 1991). Cavanagh et al. (1987) identificaram grandes movimentos do corpo como a principal estratégia para evitar a oclusão do fluxo sanguíneo em algumas regiões da sola dos pés causada pela contínua pressão estática durante a postura ereta. Alexander (1992) apresentou a hipótese de que o propósito das mudanças posturais, as quais ele chamou fidgeting, é aliviar a pressão nas articulações por meio do rebombeamento do fluido cartilaginoso. A relevância das mudanças posturais também tem sido reconhecida para a tarefa do sentar (Bhatnager et al., 1985) e para o dormir deitado (Keane, 1979).

Sob uma abordagem ecológica/psicológica, as mudanças posturais podem também ser interpretadas como mecanismos para explorar e colher informações do ambiente, principalmente por meio do sistema sensório visual. De acordo com este ponto de vista, a postura ereta natural é mais do que uma pura tarefa mecânica, a postura ereta também envolve interação com o ambiente que poderia ser mediada pelas mudanças posturais.

A postura ereta irrestrita por alguns minutos até poucas horas tem sido caracterizada na literatura por uma grande variedade de medidas. Estes critérios incluem atividade eletromiográfica, pressão venosa, batimento cardíaco, critério de conforto subjetivo, parâmetros da estabilografia, cinemática de segmentos corporais, mudanças nas dimensões corporais e temperatura da pele (Brantingham et al., 1970, Zhang et al., 1991, Kim et al., 1994, Rys \& Konz 1994, Madeleine et al., 1998, Duarte \& Zatsiorsky, 1999). Entre os métodos empregados, a análise cinemática da postura ereta (análise de vídeo) e a estabilografia são os utilizados para quantificar as mudanças posturais.

A medida da posição do centro de pressão (COP) durante a postura ereta, chamada estabilometria ou posturografia, tem sido por décadas a principal ferramenta biomecânica para o entendimento do equilíbrio corporal. O COP é o ponto de aplicação da resultante das forças verticais agindo sobre a superfície de suporte, e representa o resultado combinado do sistema de controle postural e da força de gravidade. Costumeiramente, a posturografia é dividida em análise estática e dinâmica. A posturografia estática preocupa-se com a postura quieta não perturbada, quando o sujeito tenta ficar imóvel (Hellebrandt, 1938, Thomas \& Whitney, 1959, Gurfinkel et al., 1974, Winter, 1995). Na posturografia dinâmica, uma perturbação é aplicada e a resposta do sujeito a esta 
perturbação é estudada (para uma revisão sobre posturografia dinâmica, ver Johansson e Magnusson 1991). Uma comparação e aplicações da posturografia estática e dinâmica são discutidas por Baloh et al. (1994), Furman et al. (1993), Horak (1997). Nem posturografia estática ou dinâmica parecem ser apropriadas para descrever a postura ereta natural, já que a primeira não permite mudanças posturais e a última utiliza de pertubações externas conhecidas. Em adição, nenhum dos métodos quantifica as mudanças posturais durante a postura ereta irrestrita. Poucos estudos tem se preocupado com uma análise posturográfica da postura ereta irrestrita.

Duarte e Zatsiorsky (1999) mediram a posição do COP durante a postura ereta irrestrita em adultos saudáveis e observaram padrões que foram associados com as mudanças posturais dos sujeitos (descritos no capítulo anterior). Algoritmos computacionais para detecção automática de tais padrões foram desenvolvidos e uma análise estatística destes resultados foi realizada.

No presente trabalho, as mudanças posturais durante a postura ereta irrestrita foram investigadas em diferentes condições medindo os padrões do COP. Primeiramente, o efeito de uma carga (isto é, suportando uma carga) foi estudado para explorar as diferentes hipóteses sugeridas na literatura para explicar os fatores causadores das mudanças posturais para responder a questão "por que as pessoas repetidamente mudam suas posturas corporais?" Com a adição de uma carga externa, a pressão na cartilagem articular dos membros inferiores e na sola dos pés aumentaria. Se a principal razão para as mudanças posturais é rebombear o fluido cartilaginoso, como proposto por Alexander (1992), o número de mudanças posturais deveria aumentar com a adição de carga. Se as razões para mudanças posturais são somente diminuir o acúmulo de sangue venoso nas extremidades inferiores e permitir uma circulação momentânea de sangue através de algumas regiões da sola dos pés, o número de mudanças posturais não iria variar durante a postura ereta com carga. A pressão na sola dos pés durante a portura ereta sem carga já é grande suficiente para ocluir a circulação de sangue nesta região (Cavanagh et al., 1987). A primeira hipótese deste estudo foi que o número de mudanças posturais não iria variar com a adição de carga.

O segundo objetivo deste estudo foi investigar o papel da visão durante a postura ereta irrestrita. Se os movimentos durante a postura ereta natural fossem realizados para explorar o ambiente por meio do sistema sensório visual (Riccio \& McDonald, 1998), se esperaria menos mudanças posturais se a informação visual fosse removida. A ausência de visão, resultaria em um pequeno aumento na instabilidade postural, resultando em um aumento da atividade muscular nas estremidades inferiores para manter a estabilidade postural. Este aumento na atividade muscular iria diminuir o acúmulo de sangue venoso nas extremidades inferiores, e consequentemente, haveria uma menor necessidade de mudanças posturais. Então, a segunda hipótese foi que a ausência de visão levaria a um menor número de mudanças posturais.

Os terceiro e quarto objetivos foram investigar os efeitos da rigidez da superfície de suporte e da sola do calçado sobre o comportamento da postura ereta irrestrita. Madeleine et al. (1998) reportaram um aumento no deslocamento do COP durante a postura ereta em um superfície dura quando comparado a ficar em pé sobre um tapete anti-fadiga (uma superfície macia). No entanto, Zhang et al. (1991) não encontraram diferença alguma no desvio padrão do deslocamento do COP entre ficar em pé numa superfície dura ou macia; eles também não encontraram nenhum efeito da interface pés/chão no número de mudanças posturais durante a postura ereta por até uma hora. Um raciocínio físico prediria que haveria um aumento da oscilação do corpo em superfície macia devido à instabilidade mecânica e que por conseguinte, um aumento da oscilação do COP. Este aumento na instabilidade aumentaria a atividade muscular e então as mudanças posturais não seriam tão necessárias, levando a uma diminuição do número de mudanças posturais com uma 
superfície macia. A variação e desvio padrão do deslocamento do COP não medem somente o aumento do deslocamento do COP devido à instabilidade mecânica de uma superfície macia, mas também o efeito das mudanças posturais. Então, o aumento na variação do deslocamento do COP em uma superfície dura reportado por Madeleine e colaboradores poderia ser devido às mudanças posturais e não devido à instabilidade mecânica. As terceira e quarta hipóteses foram que o uso de superfícies macias e calçados com solado macio iriam diminuir o número de mudanças posturais durante a postura ereta irrestrita

$\mathrm{Na}$ literatura, análises do deslocamento do COP durante postura ereta irrestrita são limitadas a dois estudos, cada um reportando um único parâmetro: desvio padrão dos dados do COP (Zhang et al., 1991) e variação dos dados do COP (Madeleine et al., 1998). Ambos estudos investigaram o efeito do tipo de superfície na postura ereta irrestrita. No presente trabalho, em adição às investigações sobre as mudanças posturais usando a análise dos padrões do COP, uma detalhada caracterização dos dados do COP também foi realizada. Neste sentido, medidas de desvio padrão, velocidade e freqüência média do deslocamento do COP e área do estabilograma são reportadas. Uma caracterização mais completa do deslocamento do COP durante postura ereta irrestrita contribuirá para um melhor entendimento dos efeitos dos diferentes fatores investigados aqui sobre a postura ereta.

\subsection{Método}

Este estudo foi conduzido usando uma plataforma de força de $40 \times 90 \mathrm{~cm}^{2}(4090 \mathrm{~S}$, Bertec, $\mathrm{OH}, \mathrm{EUA}$ ) com uma superfície metálica (ferro, considerada uma superfície dura). A plataforma de força mediu os três componentes da força, $F x, F y$ e $F z$, e as três componentes do torque, $M x, M y$ e $M z$ ( $x, y$ e $z$ são as direções ântero-posterior, médio-lateral e vertical, respectivamente). A posição do COP é dada por COPx $=(-h \cdot F x-M y) / F z$ e COPy $=(-h \cdot F y+M x) / F z$, onde $h$ é a altura do material, por exemplo um tapete, sobre a plataforma de força. O dado do COP é uma posição (duas coordenadas) na superfície da plataforma. Estas duas coordenadas são identificadas em relação à orientação do sujeito: direção ântero-posterior (a-p) e direção médio-lateral (m-l).

Os sujeitos realizaram a tarefa de postura ereta irrestrita por 31 minutos. O primeiro minuto dos dados foi excluido da análise porque foi considerado o tempo dado aos sujeitos para se acomodarem à tarefa. Aos sujeitos foram permitidos mudar a postura livremente a qualquer momento; não houve nenhuma instrução específica sobre como ficar em pé exceto não pisar fora da plataforma de força. Os experimentos foram realizados em uma sala sem barulho $\left(8 \times 6 \mathrm{~m}^{2}\right)$ com a plataforma posicionada no meio. Durante a tarefa de postura ereta irrestrita, o sujeito podia se comunicar ocasionalmente com o pesquisador que estava sentado em frente ao sujeito a uma distância de cerca de $2 \mathrm{~m}$. Todos os sujeitos participaram voluntariamente deste estudo e eram saudáveis sem nenhuma doença física ou mental. Antes dos experimentos, eles assinaram um termo de consentimento aprovado pelo Escritório de Regulamentação de Consentimentos da Universidade Estadual da Pennsylvania.

Cinco sujeitos participaram dos experimentos onde foram investigados os efeitos de carga e visão; os sujeitos apresentavam (média \pm desvio padrão) $21 \pm 2$ anos, altura de 1,81 $\pm 0,02 \mathrm{~m}$ e massa de $79 \pm 9 \mathrm{~kg}$. Cada um dos sujeitos realizou a tarefa de postura ereta irrestrita em quatro condições diferentes, cada condição em um dia diferente no mesmo horário. As quatro condições foram: 1) sem carga e olhos abertos (chamada normal), 2) com uma carga de $32 \mathrm{~kg}$ e olhos abertos, 3) sem carga e visão totalmente obstruída, e 4) com uma carga de $32 \mathrm{~kg}$ e visão totalmente 
obstruída. Todas as tarefas foram realizadas sobre a superfície da plataforma de força e descalços, a seqüência das tarefas foi pseudo randomizada entre os sujeitos. A carga foi aplicada usando-se um cinto de chumbo em volta da cintura.

No experimento onde os efeitos da superfície e da sola do calçado foram investigadas, seis sujeitos participaram deste estudo: os sujeitos apresentavam (média \pm desvio padrão) $28 \pm 12$ anos, estatura de $1,65 \pm 0,09 \mathrm{~m}$ e massa de $58 \pm 11 \mathrm{~kg}$. Cada um dos sujeitos realizou a tarefa de postura ereta irrestrita em quatro condições diferentes, cada condição em um dia diferente no mesmo horário. As quatro condições foram: 1) calçado de solado duro e superfície do chão dura, 2) calçado de solado macio e superfície dura, 3) calçado de solado duro em superfície macia e 4) calçado de solado macio em superfície macia. A seqüência das tarefas foi pseudo randomizada entre os sujeitos. Os calçados de solado macio foram calçados esportivos confortáveis dos próprios sujeitos sem salto. Os calçados de solado duro também pertenciam aos sujeitos e eram calçados sociais sem salto. A superfície dura usada foi a própria superfície da plataforma de força e a superfície macia foi um tapete comercial anti-fadiga (ERGOMAT USA, Inc., TX, EUA) feito de poliuretano com uma compressibilidade de $35 \mathrm{~kg}$ para uma compressão de $3 \mathrm{~mm}$ com uma prova de $105 \mathrm{~mm}$ de diâmetro. A posição do COP foi calculada levando-se em conta a altura do tapete utilizando-se as fórmulas citadas. Antes das análises, os sinais do COP foram filtrados com um filtro passa-baixa Butterworth de quarta ordem, atraso de fase zero e freqüência de corte de $8 \mathrm{~Hz}$ já que a maioria da potência do sinal está abaixo de $2 \mathrm{~Hz}$ (ver Winter (1995) para uma revisão sobre este tópico).

\subsection{Análise dos dados}

\subsubsection{Análise dos padrões nos dados do COP}

Os padrões shifting, fidgeting e drifting foram identificados utilizando-se o algoritmo descrito no capítulo anterior. Os padrões foram primeiro determinados separadamente para as direções a-p e m-I utilizando-se os mesmos critérios. Os padrões aparecendo simultaneamente nas duas direções foram identificados e contados como um único padrão. A análise que se segue é sobre o número total de padrões. Os números de shifts e fidgets foram também examinados como uma função do tempo dividindo a tarefa de 30 minutos em dez segmentos sem sobreposição com uma largura de 3 minutos. Os seguintes valores foram adotados para os parâmetros de reconhecimento dos padrões shift, fidget ou drift respectivamente: uma amplitude de shift mínima de 2 SD, uma largura máxima de shift de $5 \mathrm{~s}$, uma janela base de $15 \mathrm{~s}$; uma mínima amplitude de fidget de $3 \mathrm{SD}$, uma máxima largura de fidget de $4 \mathrm{~s}$, e uma janela base de $60 \mathrm{~s}$; uma amplitude mínima do drift de 1 $\mathrm{SD}$, uma largura mínima do drift de $60 \mathrm{~s}$. Estes valores foram similares aos valores usados na literatura (Duarte \& Zatsiorsky, 1999).

\subsubsection{Análise de parâmetros convencionais nos dados do COP}

Um dos objetivos deste estudo foi fornecer uma caracterização detalhada dos deslocamentos do COP. Neste sentido, foram selecionados quatro dos mais comuns parâmetros utilizados em estabilografia: o desvio padrão (SD) dos dados (Murray et al., 1975), a velocidade do deslocamento do COP, a área do estabilograma e a freqüência média do deslocamento do COP. A velocidade $(\mathrm{V})$ do deslocamento do COP foi determinada dividindo-se a excursão total do COP pelo período total dos dados, 30 minutos, (Riach \& Starkes, 1994). A área do estabilograma (a curva do deslocamento do COP na direção a-p versus o deslocamento do COP na direção $\mathrm{m}-\mathrm{I}$ ) foi calculada usando-se o método de área da elipse; os eixos principais da elipse foram determinados pela análise 
de componentes principais (Oliveira et al., 1994). Parâmetros no domínio de freqüências têm sido usados na literatura para ganhar um melhor entendimento das características temporais da estabilidade postural (Bensel e Dzendolet, 1968, Williams et al., 1997). Neste estudo, a freqüência média $\left(F_{\text {média }}\right)$ do deslocamento do COP foi calculada a partir da densidade de potência espectral do deslocamento do COP, a qual foi estimada usando-se método de periodograma de Welch com uma resolução de 0,039 Hz (Matlab software, MathWorks, Inc., 1996).

$\mathrm{Na}$ análise destes parâmetros convencionais, os dados para as direções a-p e m-l foram analisados separadamente - um procedimento usual já que os deslocamentos do COP para diferentes direções são pobremente correlacionados.

\subsubsection{Análise estatística}

Um ANOVA $2 \times 2$ para medidas repetidas com nível de significância de 0,05 foi empregado para determinar os efeitos das variáveis carga e visão no primeiro experimento e os efeitos das variáveis superfície e calçado no segundo experimento.

\subsection{Resultados}

\subsubsection{Padrões dos deslocamentos do COP}

Os três padrões do deslocamento do COP foram observados nos comportamentos dos sujeitos nos experimentos. No entanto, padrões individuais predominaram em diferentes sujeitos, como mostrado na Figura 21. Diferentes sujeitos 'preferem' usar shifting, fidgeting ou drifting durante a postura ereta, indicando diferentes estratégias de mudanças posturais durante a postura ereta irrestrita. Uma oscilação de freqüência muito baixa com um período aproximado de 30 minutos pode ser vista na Figura 21(c). Isto é uma indicação de correlação de longo alcance ou um processo de longa memória (grandes flutuações em adição a pequenas flutuações) nos dados do COP durante postura ereta irrestrita. Devido à correlação de longo alcance, os dados separados por grandes intervalos de tempo são dependentes. Este fenômeno é descrito nos próximos dois capítulos. 


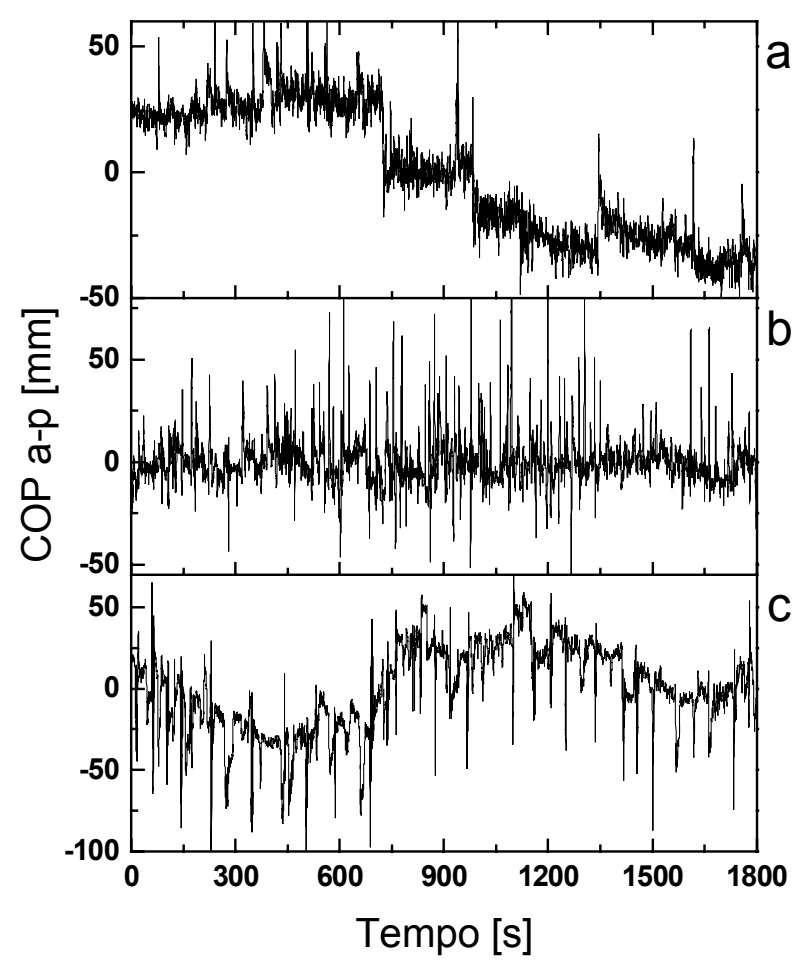

Figura 21. Exemplos de dominância de padrões de shift (a), fidget (b), e um longo drift (c) em diferentes sujeitos durante postura ereta irrestrita. Sujeitos descalços sobre a superfície da plataforma de força.

\subsubsection{Efeitos do uso de uma carga e obstrução da visão sobre postura ereta irrestrita}

Os resultados da análise dos padrões do COP durante os 30 minutos de postura ereta irrestrita são mostrados na Figura 22. A análise de variância mostrou um único efeito estatisticamente significante que foi o efeito da interação entre visão e carga para o número de fidgets $(F(1 ; 4)=14,69$; $p<0,05)$. Na condição de visão obstruida, houve uma aumento do número de fidgets quando o sujeito usava uma carga, enquanto que na condição de olhos abertos, houve uma pequena diminuição do número de fidgets quando os sujeitos usavam a carga, como pode ser visto na Figura 22.

Fidgeting foi o padrão mais freqüente, seguido por shifting (cerca de duas a tres vezes menos freqüente) e então por drifting (cerca de seis vezes menos freqüente que fidgeting). O número total de padrões do COP por minuto foi de quase 2 padrões/minuto, variando menos que $15 \%$ entre as diferentes condições.

A análise da dependência temporal dos padrões fidgeting e shifting durante os dez segmentos de 3 minutos cada mostrou que o número de padrões de COP variou entre os segmentos mas sem alguma tendência definida. 


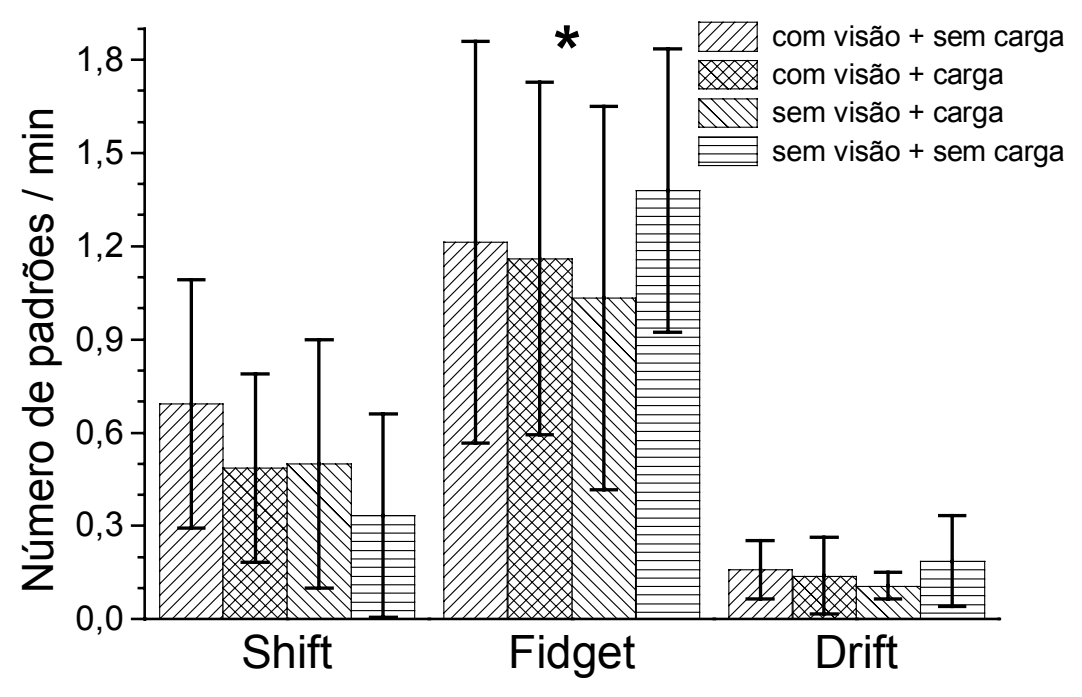

Figura 22. Média e desvio padrão dos números de padrões de shifting, fidgeting e drifting por minuto durante postura ereta irrestrita em diferentes condições de carga e visão $(n=5)$. O símbolo * entre os dois pares de colunas indica um efeito da visão (ANOVA 2 fatores, $p<0,05$ ).

Os resultados para os quatro parâmetros - desvio padrão, velocidade do deslocamento, freqûencia média, e área do estabilograma são mostrados na Tabela 2. A análise de variância mostrou apenas um efeito estatisticamente significante, o efeito da visão na freqüência média, $F_{\text {média, }}$ do deslocamento do COP na direção a-p $(F(1,4)=10,97, p<0,05)$. 
Tabela 2. Média e desvio padrão do deslocamento do COP (SD), velocidade do deslocamento do COP $(V)$, freqüência média $\left(F_{\text {média }}\right)$ do deslocamento do COP e a área do estabilograma durante postura ereta irrestrita para diferentes cargas $e$ condições visuais (n=5). Dados apresentados como média \pm desvio padrão.

\begin{tabular}{llcc}
\hline \multicolumn{1}{c}{ Variável } & Tarefa & \multicolumn{2}{c}{ Direção } \\
\hline SD [cm] & & ântero-posterior & médio-lateral \\
& com visão+sem carga & $2,0 \pm 0,8$ & $2,3 \pm 1,3$ \\
& com visão+com carga & $1,4 \pm 0,6$ & $1,8 \pm 1,4$ \\
& sem visão+sem carga & $1,7 \pm 0,9$ & $2,3 \pm 2,2$ \\
& sem visão+com carga & $2,0 \pm 1,2$ & $2,6 \pm 2,1$ \\
\hline $\mathrm{V}[\mathrm{cm} / \mathrm{s}]$ & com visão+sem carga & $1,4 \pm 0,3$ & $1,3 \pm 0,4$ \\
& com visão+com carga & $1,2 \pm 0,2$ & $0,9 \pm 0,4$ \\
& sem visão+sem carga & $1,4 \pm 0,3$ & $1,2 \pm 0,4$ \\
& sem visão+com carga & $1,7 \pm 0,5$ & $1,5 \pm 0,9$ \\
\hline $\mathrm{F}_{\text {média }}[\mathrm{Hz}]$ & com visão+sem carga & $0,26 \pm 0,03$ & $0,28 \pm 0,06$ \\
& com visão+com carga & $0,27 \pm 0,03$ & $0,29 \pm 0,04$ \\
& sem visão+sem carga & $0,34 \pm 0,05$ & $0,33 \pm 0,12$ \\
& sem visão+com carga & $0,33 \pm 0,10$ & $0,31 \pm 0,11$ \\
\hline Área $\left[\mathrm{cm}^{2}\right]$ & com visão+sem carga & \multicolumn{2}{c}{$55 \pm 34$} \\
& com visão+com carga & \multicolumn{2}{c}{$40 \pm 38$} \\
& sem visão+sem carga & \multicolumn{2}{c}{$61 \pm 81$} \\
& sem visão+com carga & \multicolumn{2}{c}{} \\
\hline
\end{tabular}

\subsubsection{Efeitos da superfície e tipo de calçado sobre a postura ereta irrestrita}

Os resultados da análise dos padrões do COP durante os 30 minutos de postura ereta irrestrita são mostrados na Figura 23. Os resultados do ANOVA para o número de padrões não indicou nenhuma diferença estatística entre as quatro condições. De novo, fidgeting foi o padrão mais freqüente, seguido por shifting (cerca de duas a tres vezes menos freqüente) e então por drifting (cerca de sete vezes menos freqüente que fidgeting). Similarmente aos resultados da carga e visão, o número total de padrões do COP por minuto foi de quase 2 padrões/minuto, variando menos que $15 \%$ entre as diferentes condições. 


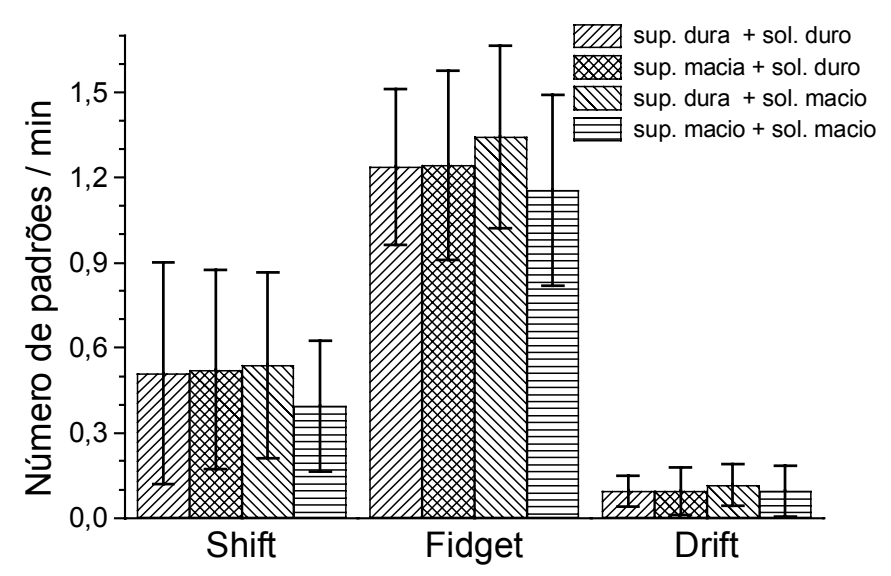

Figura 23. Média e desvio padrão dos números de padrões de shifting, fidgeting e drifting por minuto durante postura ereta irrestrita em diferentes condições de superfície de apoio e tipo de solado dos calçados $(n=6)$.

De novo, não houve uma tendência sistemática na dependência temporal do número de padrões do COP em função da duração da tarefa.

Os resultados para os quatro parâmetros - desvio padrão, velocidade do deslocamento, freqûencia média, e área do estabilograma são mostrados na Tabela 3.

Tabela 3. Média e desvio padrão do deslocamento do COP (SD), velocidade do

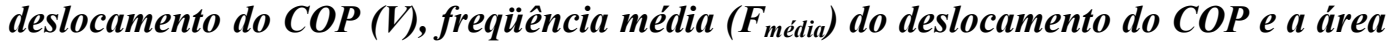
do estabilograma durante postura ereta irrestrita para diferentes superficies de apoio $e$ solados de calçados $(n=6)$. Dados apresentados como média \pm desvio padrão.

\begin{tabular}{cccc}
\hline Variável & Tarefa & \multicolumn{2}{c}{ Direção } \\
\hline & & ântero-posterior & médio-lateral \\
\hline DP [cm] & sup. dura+sol. duro & $1,8 \pm 0,8$ & $2,0 \pm 1,1$ \\
& sup. macia+sol. duro & $1,9 \pm 0,8$ & $1,7 \pm 0,9$ \\
& sup. dura+sol. macio & $1,7 \pm 0,7$ & $1,9 \pm 1,0$ \\
& sup. macia+sol. macio & $1,7 \pm 0,8$ & $2,3 \pm 1,4$ \\
\hline V [cm/s] & sup. dura+sol. duro & $1,8 \pm 1,3$ & $1,2 \pm 0,4$ \\
& sup. Macia+sol. duro & $1,9 \pm 1,6$ & $1,2 \pm 0,4$ \\
& sup. dura+sol. macio & $1,9 \pm 1,3$ & $1,2 \pm 0,3$ \\
& sup. macia+sol. macio & $1,8 \pm 1,3$ & $1,3 \pm 0,6$ \\
\hline$F_{\text {média }}[\mathrm{Hz}]$ & sup. dura+sol. duro & $0,33 \pm 0,10$ & $0,35 \pm 0,09$ \\
& sup. macia+sol. duro & $0,31 \pm 0,09$ & $0,38 \pm 0,13$ \\
& sup. dura+sol. macio & $0,34 \pm 0,12$ & $0,36 \pm 0,09$ \\
& sup. macia+sol. macio & $0,35 \pm 0,10$ & $0,37 \pm 0,12$ \\
\hline Área $\left[\mathrm{cm}^{2}\right]$ & sup. dura+sol. duro & \multicolumn{3}{c}{$43 \pm 31$} \\
& sup. macia+sol. duro & \multicolumn{2}{c}{$41 \pm 30$} \\
& sup. dura+sol. macio & \multicolumn{2}{c}{$39 \pm 27$} \\
& sup. macia+sol. macio & $50 \pm 36$ \\
\hline
\end{tabular}

Além da quantificação do número total de padrões por tentativa, a amplitude de cada padrão, como previamente definida, também foi analisada. A amplitude média para cada padrão não 
dependeu da carga, visão, superfície e calçado.

\subsection{Discussão}

\subsubsection{Efeitos do uso de carga e obstrução da visão sobre a postura ereta irrestrita}

A adição de carga não afetou significativamente a ocorrência de diferentes padrões do COP. Os fidgets, os padrões mais freqüentes, evidentemente não são produzidos para mudar a posição do COP ou a projeção do centro de gravidade do corpo sobre a base de suporte (linha da gravidade). Ainda que não medimos a linha de gravidade, para baixas freqüências de deslocamento, abaixo de $0,2 \mathrm{~Hz}$, a posição do COP corresponde aproximadamente à linha de gravidade.

A acumulação venosa nas extremidades inferiores em vez da fadiga muscular tem sido apontada como a principal causa de disconforto durante a postura ereta por longa duração (Brantingham et al., 1970, Basmajian, 1979, Kim et al., 1994, Madeleine et al., 1998). Movimentos do corpo são creditados a aumentarem a atividade de bombeamento venoso (Brantingham et al. 1970, Madeleine et al., 1998). Nossos resultados corroboram este ponto de vista. Eles sugerem que o principal papel do fidgeting é aumentar a atividade de bombeamento venoso e permitir a momentânea circulação de sangue na sola dos pés como proposto por Cavanagh et al. (1987) que reportou que o pico de pressão nos pés durante a postura ereta é de aproximadamente $137 \mathrm{kPa}$. A pressão sistólica normal é de $17 \mathrm{kPa}$. Então, durante a postura ereta normal, os vasos já estão fechados. Fidgeting pode ser um mecanismo de liberação momentânea desta pressão para restaurar a circulação sanguinea e por conseguinte diminuir a fadiga. Um aumento na pressão (adição de carga) não aumenta a oclusão e por conseguinte não provoca adicionais fidgets. Os dados do presente estudo parecem apoiar a hipótese de oclusão do sangue. No entanto, nossa análise biomecânica é limitada para qualquer conclusão mais profunda sobre tais mecanismos.

Outra explicação para as mudanças posturais, proposta por Alexander (1992), não foi corroborada pelos achados deste estudo. Alexander sugeriu que mudanças posturais poderiam estar rebombeando fluido sinovial da articulação nas extremidades inferiores. Se fosse isto o caso, um aumento na pressão (acréscimo de carga) deveria aumentar a ocorrências destas mudanças. $O$ presente estudo mostrou que não há tal aumento do número de mudanças posturais.

Ficar com a visão obstruída por 30 minutos não alterou a ocorrência de padrões do COP na condição sem carga. Estes resultados indicam que as mudanças posturais não são influenciadas pela visão nas condições ambientais dos experimentos. Por conseguinte, o papel das mudanças posturais na interação/exploração do ambiente mediada pela visão durante a postura ereta, como pensado na abordadem ecológica/psicológica, não foi verificado. É possível que a pequena amplitude do deslocamento corporal e o constante ambiente visual do laboratório não motivaram esta exploração do ambiente. No entanto, na condição com carga e visão obstruída, foi observado um aumento dos padrões fidget. Talvez a instabilidade criada pela carga, mas a remoção da visão aumentaram as mudanças posturais para aumentar a entrada de informações proprioceptivas e por conseguinte ajudar na manutenção do equilíbrio, como pensado na hipótese ecológica. A propriocepção torna-se mais importante quando não se tem a informação visual. Por conseguinte, a hipótese de exploração não pode ser totalmente desconsiderada.

Um aumento na variabilidade (desvio padrão) e freqüência média do deslocamento do COP durante a postura ereta para ambas as direções com os olhos fechados tem sido reportado na 
literatura (Amblard et al. 1985, Diener e Dichgans 1988, Collins e De Luca 1995a). Resultados similares foram encontrados somente para a freqüência média na direção a-p. Parece que a natureza irrestrita da tarefa mascarou qualquer mudança na oscilação corporal com a visão obstruída.

\subsubsection{Efeitos da superfície e tipo de calçado na postura ereta irrestrita}

Era esperado que permanecer em pé sobre um tapete macio (um tapete anti-fadiga comercial) deveria reduzir fadiga e o número de mudanças posturais. Contrário às expectativas, a ocorrência de padrões do COP não mudou quando diferentes superfícies e calçados foram usados. Este fato está em desacordo com os benefícios divulgados comercialmente sobre as diferentes superfícies e calçados. Zhang et al. (1991), usando análise de video, analisaram 120 minutos de postura ereta irrestrita em superfícies duras e macias com calçado macios e também não reportaram nenhum efeito sobre o número de mudanças posturais.

No presente estudo, nenhuma mudança foi observada na variabilidade do deslocamento do COP quando os sujeitos permaneceram em pé em diferentes superfícies. Madeleine et al. (1998) estudaram postura ereta irrestrita por 105 minutos e reportaram um aumento na variabilidade do deslocamento do COP quando os sujeitos permaneceram em pé numa superfície dura quando comparado a permanecer em pé sobre um tapete anti-fadiga. No entanto, naquele experimento os sujeitos aplicaram forças em uma mesa e também na plataforma de força e somente a posição do COP na plataforma foi medida. Por conseguinte, os resultados do COP podem ter sido prejudicados. Em acordo com nossos resultados, Zhang et al. (1991), que analisaram o desvio padrão do deslocamento do COP, não encontraram durante os 120 minutos de postura ereta irrestrita em superfícies duras e macias com calçado macio. De novo, parece que a natureza irrestrita da tarefa mascarou qualquer mudança das oscilações corporais devido à rigidez da superfície.

\subsubsection{Comparação entre a análise de padrões do COP e a análise de vídeo de Zhang et al (1991)}

Uma detalhada análise quantitativa das mudanças posturais observadas por vídeo-tape durante 120 minutos de postura ereta irrestrita foi realizada em Zhang et al. (1991). Os autores reportaram um aumento do número de mudanças posturais com o decorrer do tempo com um número médio de pouco mais de 1 mudança postural/min. Seus resultados gráficos (Zhang et al., 1991, Figura 3) começam com cerca de 0,8 mudanças posturais/min nos primeiros $15 \mathrm{~min}$, aumentando para 1,2 mudanças posturais /min no final da primeira hora, e aumentando vagarosamente para cerca de 1,3 mudanças posturais/min nos últimos $15 \mathrm{~min}$ dos $120 \mathrm{~min}$ de postura ereta. No entanto, nenhuma tendência no número de mudanças posturais durante os 30 minutos foi encontrada no presente estudo, onde o número total de padrões do COP (a soma de shifting, fidgeting e drifting) por minuto foi pouco abaixo de 2 mudanças posturais/min para todas as condições estudadas. A diferença entre os dois estudos pode ser explicada, pelo menos em parte, por diferentes classificações de mudança postural; uma classificação visual pelo experimentador versus a escolha de uma limiar em nossa classificação estatística. Duarte e Zatsiorsky (1999) discutiram os efeitos da escolha de diferentes limiares para a identificação dos padrões. Basicamente, com limiares mais altos a técnica seria menos sensitiva às mudanças posturais. Também deveria ser mencionado que o reconhecimento de drifting é tecnicamente difícil quando utilizando o método de video já que este padrão tem um período muito longo (tipicamente alguns minutos).

\subsection{Conclus̃̃es}


A ocorrência de mudanças posturais medidas pelos padrões do COP, desvio padrão, freqüência média e velocidade do deslocamento do COP e área do do estabilograma foram invariantes com respeito ao uso de carga, obstrução da visão, rigidez da superfície de apoio e do solado do calçado.

A invariância das mudanças posturais com a adição de carga corrobora a hipótese de que mudanças posturais permitem a momentânea circulação sangüinea na sola dos pés. Em um ambiente visualmente constante, o número de mudanças posturais não foi afetado pela obstrução da visão durante a postura ereta irrestrita. Isto suporta a idéia da natureza fisiológica das mudanças posturais durante a postura. Os benefícios divulgados comercialmente dos tapetes anti-fadiga e solados de sola macia para a postura ereta irrestrita são questionáveis sob o ponto ponto de vista biomecânico, pelo menos até 30 minutos de duração da tarefa. 


\section{Processos de correlação de longo alcance na postura ereta humana irrestrita}

A trajetória do centro de pressão (COP) durante a postura ereta humana tem sido modelada com sucesso por meio de ferramentas da mecânica estatística. No entanto, certas análises são limitadas pela curta duração (menos que um minuto) de típicas séries temporais obtidas em experimentos de equilibrio e postura. Para sobrepor esta limitação, nós investigamos a postura ereta irrestrita de adultos saudáveis por um periodo de 30 minutos e estimamos as correlações de longo alcance na trajetória do COP. Dois métodos foram usados nesta estimação: análise de flutuações, (DFA, detrended fluctuation analysis) e análise de potência espectral. Ambos métodos produziram resultados similares: em particular, o exponente de escala médio $\alpha$ de correlações de longo alcance do tipo $1 / f^{\alpha}$, usando o método DFA, foi de $\alpha=1,00 \pm 0,22$ (de 0,68 a 1,47), isto é, os deslocamentos do COP durante a postura ereta irrestrita por longos periodos podem ser considerados ruido $1 / f$. 


\subsection{Introdução}

Desde que nós humanos adotamos a postura ereta bípede, temos sido desafiados para manter o equilíbrio do corpo sobre uma pequena área de suporte. Somente quando a habilidade de controlar a postura ereta deteriora, como em idosos e em certas patologias (por exemplo, distúrbios do sistema vestibular e derrame), é que se percebe o quão difícil e crucial esta tarefa é. A manutenção do balanço é uma tarefa complexa realizada pela integração de vários tipos de informação sensorial (visual, vestibular e somatossensorial) e por meio das propriedades passivas do sistema músculo-esquelético. Um recente exemplo do esforço para entender o controle postural é o estudo da adaptação à microgravidade realizado pela tripulação de uma missão espacial da NASA ${ }^{1}$.

Quando solicitados a permanecerem parados, os humanos não permanecem sem movimento - eles oscilam. Esta oscilação é usualmente registrada por uma plataforma de força, um instrumento de medida sobre o qual os sujeitos permancem em pé durante os experimentos. A variável mais comum para analisar esta oscilação é o COP. Devido à oscilação do corpo e às forças inercias, a posição do COP é diferente da projeção do centro de gravidade (COG) sobre a superfície de suporte; o COG indica a posição global do corpo. O deslocamento do COP em curtos intervalos de tempo (menos que um minuto) durante a postura quieta tem sido modelado com sucesso como um processo de random walk, interpretando a realização do sistema de controle postural como um processo estocástico em vez de determinístico (Collins \& De Luca, 1993, 1994, 1995b). Esses autores reportaram que o deslocamento do COP era persistente para intervalos de até $1 \mathrm{~s}$ (correlações positivas) e para intervalos de $1 \mathrm{~s}$ a $10 \mathrm{~s}$ era observado um comportamento de antipersistência (correlações negativas ou anti-correlações). Baseado nos limites da base de suporte durante a postura ereta quieta, os autores propuseram a hipótese de que o processo deveria saturar na região de 10 a $30 \mathrm{~s}$, isto é, nenhuma correlação de longo alcance para intervalos de tempo acima de $30 \mathrm{~s}$ era esperada durante a postura ereta quieta; mas os autores reconheceram que séries temporais mais longas eram necessárias para uma conclusão final (Collins \& De Luca, 1993).

Uma limitação nos estudos sobre a postura ereta humana é que tarefas com a instrução "permaneça o mais imóvel possível" são limitadas a poucos minutos devido à fadiga. Por outro lado, a postura ereta natural por longos períodos, mais que alguns minutos, é uma tarefa muito comum na vida diária, como permancer em pé numa fila, ou enquanto conversa com alguém. Esta postura ereta é caracterizada por mudanças repetidas da posição do corpo, que são auto-induzidas, realizadas quase que inconscientemente e geralmente não podem ser associadas a uma fonte externa de perturbação. Permanecer em pé naturalmente não é fadigante e pode ser reproduzido no laboratório por uma tarefa de postura ereta durante a qual a pessoa é permitida fazer qualquer movimento sem restrição alguma, exceto a permanecer dentro da área da plataforma de força. Esta postura ereta sem restrições em sujeitos saudáveis foi examinada por Duarte e Zatsiorsky (1999) que observaram freqüências muito baixas no deslocamento do COP durante a postura ereta irrestrita, uma assinatura típica de um processo de correlação de longo alcance ou processo de longa memória e que não fora estudado para humanos durante a postura ereta. Neste capítulo, é reportado e quantificado o fenômeno de correlação de longo alcance durante longos períodos de postura ereta irrestrita

Processos de correlação de longo alcance apresentam flutuações de períodos bastante longos como também flutuações de períodos curtos, com a dependência entre dados maior do a esperada para dados independentes. Este fenômeno tem sido observado em áreas bastante diversas

\footnotetext{
${ }^{1}$ Experimentos sobre disturbios do equilíbrio foram conduzidos na missão STS 95 do ônibus espacial da NASA, incluindo um estudo do equilíbrio em um idoso, o especialista J. F. Glenn, 77 anos de idade.
} 
da natureza. Sobre sistemas biológicos e especificamente humanos, tem sido observado nos intervalos das passadas do andar humano (Hausdorff et al., 1995), cognição humana (Gilden et al., 1995), intervalos entre movimentos rítmicos de batida (Chen et al., 1997), variabilidade do batimento cardíaco (Peng et al., 1993b, 1995) e em certas sequências de DNA (Peng et al., 1993a, 1994).

\subsection{Materiais e métodos}

Neste estudo, 10 sujeitos saudáveis $(28 \pm 5$ anos, $1,79 \pm 0,09 \mathrm{~m}$ e $78 \pm 14 \mathrm{~kg})$ permanecerem em pé numa postura ereta sem restrição sobre uma plataforma de força de $40 \times 90 \mathrm{~cm}$ por 30 min (os métodos são descritos no capítulo 3). As trajetórias do COP foram analisadas para as direções ântero-posterior (a-p) e médio-lateral $(m-l)$. Exemplos de estabilogramas (mapeamento de COP a-p versus COP m-I) e uma série temporal são mostrados na Figura 24.
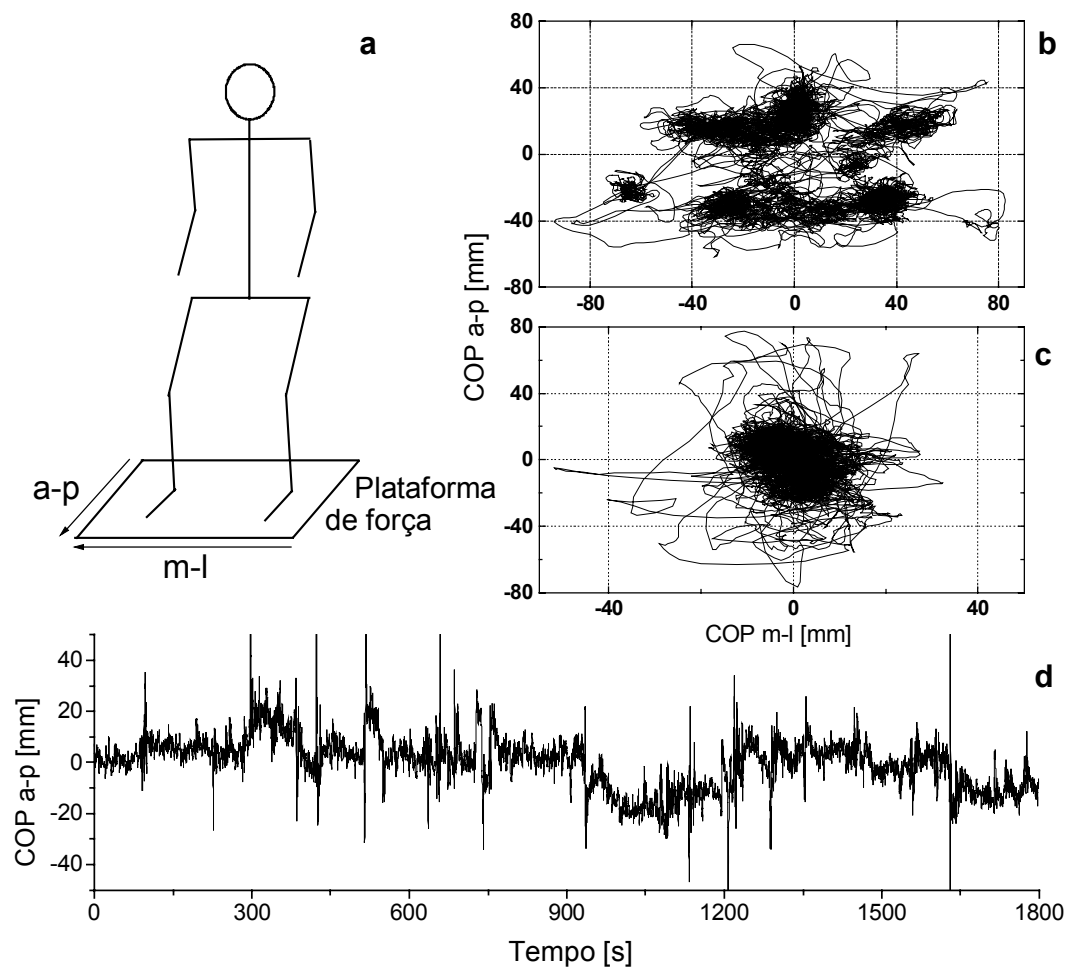

Figura 24. (a) Posição dos sujeitos sobre a plataforma de força e convenção dos eixos. Dois exemplos de estabilogramas durante 30 minutos de postura ereta irrestrita: (b) multi-região e (c) uni-região e série temporal representativa do COP.

O modelo estocástico de um ruído gaussiano fracional (ou a função integrada, um movimento browniano fracional) é um exemplo de um processo auto-similar (como um fractal) apropriado para modelar fenômenos de correlação de longo alcance. Este modelo tem sido usado com sucesso em muitos dos fenômenos citados e foi usado aqui. Vários modelos eurísticos têm sido sugeridos para estimar as correlaçãoes de longo alcance desde a clássica estatística R/S proposta por Hurst em hidrologia (para uma revisão dos métodos, ver Beran (1994)). Dois métodos foram usados aqui para estimar as correlações de longo alcance: análise de potência espectral (PSA, power spectral analysis) (Beran, 1994), realizada no domínio de freqüências, e análise de flutuações (DFA, detrended fluctuation analysis) (Peng, 1993a), realizada no domínio temporal. 
O método PSA consiste em graficar o espectro de potência de um sinal em uma escala log-log. Se o sinal apresenta correlações de longo alcance em uma região de freqüências então uma regressão linear no gráfico log-log captura a relação entre freqüência e potência do tipo $1 / f^{\beta}$ onde $f$ é a freqüência e $\beta$ é o exponente de escala. $O$ exponente $\beta$ é 0 para ruído branco, -1 para ruído $1 / f$, e -2 para ruído browniano. O método DFA é uma modificação da análise RMS de um random walk (Feder, 1988) e é menos sensitivo a possíveis não estacionariedades e ruído nos dados como no caso dos deslocamentos do COP durante a postura ereta irrestrita.

Para um processo random walk, o deslocamento líquido de um walker depois de $k$ passos é $y(k)=\sum_{i=1}^{k} u(i)$, onde $u(i)$ é um sinal de processo random walk ou movimento browniano. Usando o método DFA, o sinal integrado, $y$, de comprimento total $N$ é dividido em janelas de comprimento $\ell$; cada janela avança com um intervalo de $\ell / s$, onde $s$ é o parâmetro de sobreposição e $N /(\ell / s)$ é o número total de janelas. Para cada janela, a tendência local é estimada por um ajuste linear por mínimos quadrados, $y$, e é subtraida esta tendência da curva. A variância de cada janela do sinal sem tendência é calculada. A raiz quadrada da variância média de todos as janelas de comprimento $\ell$ é a flutuação sem tendências, $F$, do walker:

$$
F(\ell)=\sqrt{\frac{\ell / s}{N} \sum_{n=1}^{N /(\ell / s)} \frac{1}{\ell} \sum_{k=1}^{\ell}[y(k)-\hat{y}(k)]^{2}}
$$

As flutuações RMS aumentam com $\ell$, e se há uma relação linear na escala log-log de $\mathrm{F}$ com $\ell$, os dados obedecem uma função lei de potência, $F(\ell) \sim \ell^{\alpha}$, onde $\alpha$ é o exponente de escala quantificando as correlações de longo alcance. Para ruído branco, o exponente $\alpha$ é 0,5 , para ruído $1 / f$ é 1 e 1,5 para ruído Browniano. Para dados com um comprimento infinito, os exponentes $\alpha$ e $\beta$ são relacionados pela expressão $\beta=1-2 \alpha$ (Havlin et al., 1988). Correlações de longo alcance para os dados do COP foram analisadas para janelas de comprimento maior que $10 \mathrm{~s}$ e de até um terço (10 minutos) dos 30 minutos de dados. O limite inferior foi selecionado para ignorar as já reportadas correlações de curto alcance para a postura ereta quieta na região de 1 s (Collins \& De Luca, 1993, 1994, 1995b). O limite superior foi escolhido de modo a obter no mínimo três grupos independentes de dados, para aumentar o valor estatístico dos resultados.

\subsection{Resultados e discussão}

As regressões lineares ajustadas para cada tentativa na região de $10 \mathrm{~s}$ a $10 \mathrm{~min}$ representando o exponente de escala (inclinações) obtidos pelos métodos DFA e PSA são mostrados

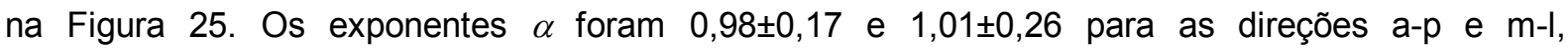
respectivamente. Os exponentes $\beta$ foram $-1,00 \pm 0,42$ e $-1,27 \pm 0,63$ para as direções a-p e $\mathrm{m}-\mathrm{I}$, respectivamente. Estes resultados satisfazem a relação $\beta=1-2 \alpha$ e indicam a presença de correlações de longo alcance não triviais. Já que os valores foram menores que os valores para o movimento browniano, as correlações são na verdade anti-correlações (correlações negativas).

A variabilidade de $\alpha$ (expressada pelo desvio padrão médio) foi cerca de 2,5 vezes menor que a variabilidade de $\beta$. Como esperado, isto indica que o método DFA produziu resultados mais robustos e que foram menos sensíveis a não estacionariedades e ruídos. $O$ valor médio de $\alpha$ para os dados do COP nas direções a-p e $\mathrm{m}$-I foi $1,00 \pm 0,22(0,68$ a 1,47), o que é equivalente ao valor $\alpha=1$ para ruído $1 / f$, como mostrado na Figura 25. A variação reportada para os exponentes de escala pode sugerir que a observação de correlações de longo alcance não são somente uma verificação da universalidade do ruído $1 / f$ na natureza mas sim um fenômeno manifestando-se 
diferentemente em sujeitos adultos saudáveis.
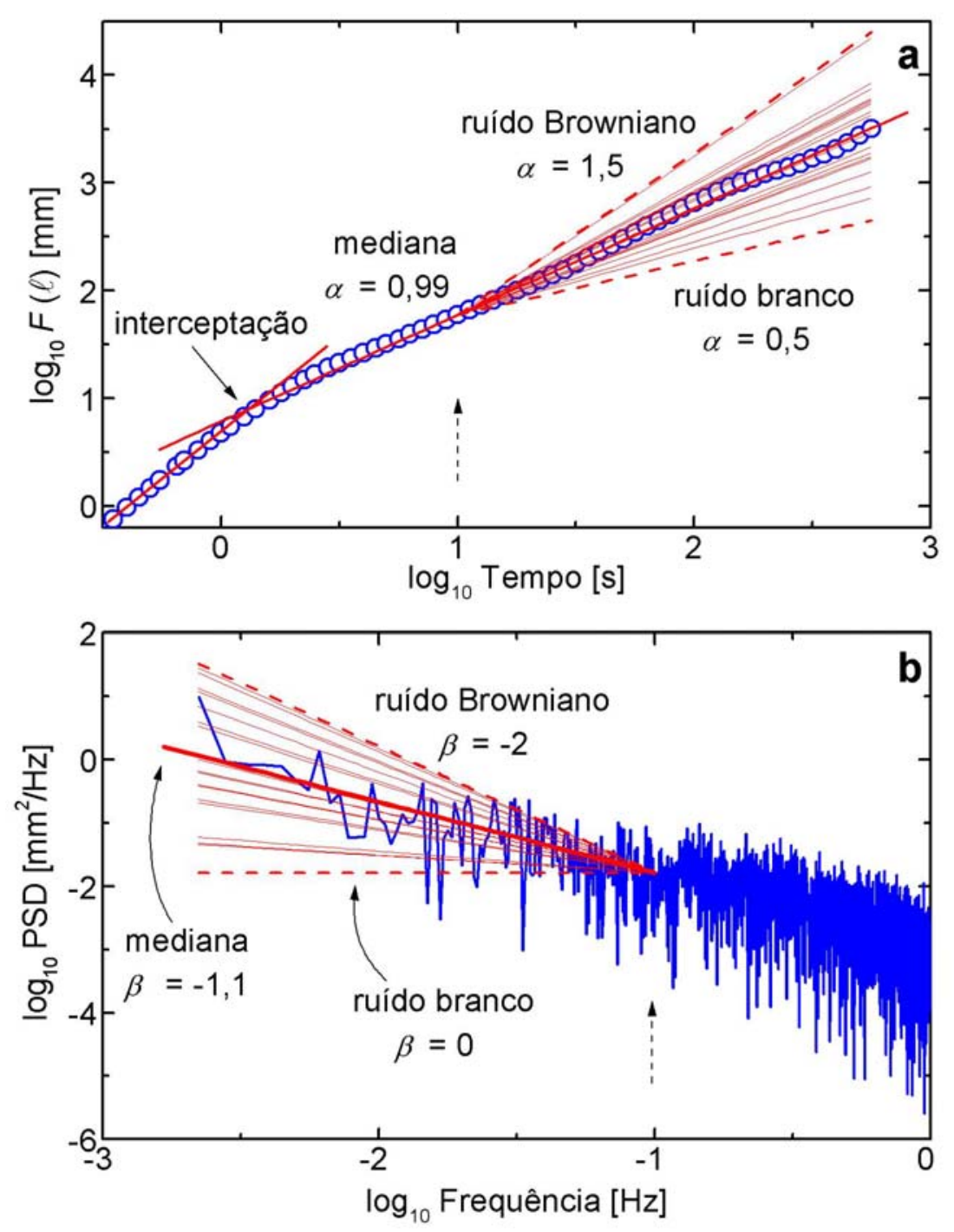

Figura 25. Expoentes DFA, $\alpha$, (a) e PSA, $\beta$, (b). Linhas finas são os ajustes lineares para os dez sujeitos em ambas as direções para intervalos maiores que $10 \mathrm{~s}$ ou freqüências menores que $10^{-1} \mathrm{~Hz}$ (indicada pela flecha tracejada). Os valores medianos são mostrados em linhas espessas. As linhas e valores dos expoentes de escala para ruído branco e ruído browniano são mostrados para comparação (linhas tracejadas).

Para determinar a significância estatística dos resultados, um teste surrogate foi realizado (Theiler et al., 1992). Para isso, 10 novos sinais foram criados por embaralhando aleatório do sinal original; os sinais criados tinham a mesma média e variância do sinal original mas não mais deveriam apresentar correlações de longo alcance, indicado por $\alpha=0,5$ and $\beta=0$. Comparando a média dos exponentes de escala para o set de sinais embaralhados com o sinal original, a diferença entre os exponentes de escala foi bem maior que 3 desvios padrões, para cada um dos dez sujeitos e para ambos os métodos. Por conseguinte, a hipótese de correlação de longo alcance foi aceita.

Para testar se a observada correlação de longo alcance foi um efeito de correlações de curto alcance acumuladas, os sinais foram divididos em janelas de $10 \mathrm{~s}$ de comprimento e cada uma 
destas janelas foi embaralharada. Agora, a hipótese foi que os dados embaralhados ainda deveriam apresentar correlações de longo alcance se refletisse a estrutura global dos dados. Para cada um dos dez sujeitos, os dados embaralhados ainda apresentaram correlações de longo alcance com exponentes de escala similares aos originais de ambos os métodos. a hipótese de correlação de longo alcance refletindo uma estrutura global dos dados foi aceita de novo.

Uma preocupação foi que a correlação de longo alcance poderia ter sido induzida pelo aparato experimental (como em equipamentos elétricos, que podem exibir correlações de longo alcance da forma de ruído $1 / f$ (Bak et al., 1987; Weissman, 1988)). A plataforma de força é um equipamento eletromecânico baseado em strain gauges. $O$ sinal de um objeto, com peso similar aos nossos sujeitos, colocado sobre a plataforma de força exibiu o ruído $1 / f \operatorname{com} \alpha=1,05$. No entanto, o comportamento $1 / f$ do arranjo experimental pode ser negligenciado por causa da magnitude da flutuação ser cerca de 3 ordens menor que a flutuação do COP e o espectro de potência foi cerca de 6 ordens de magnitude menor que os espectros de potência do COP dos sujeitos.

A Figura 25a apresenta os ajustes por regressão linear da região de 10 s a 10 min para a mediana dos dados extendido até a região de $1 \mathrm{~s}$ e uma outra regressão linear dos dados na região até $1 \mathrm{~s}$. A interceptação destas 2 linhas apontada na Figura 25a exemplifica a transição na região de $1 \mathrm{~s}$ de um comportamento persistente (correlação positiva numa escala de curto alcance) para um comportamento anti-persistente (correlação negativa numa escala de médio alcance, até $10 \mathrm{~s}$ ) dos deslocamentos do COP (Collins \& De Luca, 1993, 1994, 1995b). Estes resultados observados em todas as tentativas, corroboram os achados de Collins \& De Luca e extendem a descoberta de um comportamento anti-persistente de até $10 \mathrm{~s}$ para até $10 \mathrm{~min}$. Note que no presente estudo, um método mais robusto foi utilizado (DFA versus clássico random walk), as observações foram realizadas em sinais de 30 min de duração (comparado às tentativas de 1 min estudadas por Collins e De Luca (1993)) e uma tarefa diferente foi estudada (postura ereta irrestrita em vez de postura ereta quieta). Contrário às predições para a postura ereta quieta, nenhuma indicação de saturação do comportamento anti-persistente foi encontrada. Nossa hipótese é que a saturação observada durante a postura ereta quieta reflete as restrições biomecânicas dadas pela base de suporte em vez de uma saturação dos possíveis processos neurofisiológicos por trás do comportamento anti-persistente quando as restrições biomecânicas são reduzidas, a saturação não é observada.

Para explorar os possíveis mecanismos de correlação de longo alcance na postura ereta irrestrita, nós propomos um modelo que considera duas fontes de migração do COP: migração estocástica do ponto de referência em respeito ao qual o equilíbrio é mantido e uma oscilação estocástica do corpo em torno da trajetória do ponto de referência. Já que os músculo esqueléticos não são geradores de força perfeitos (De Luca et al., 1982) e devido aos mecanismos de perturbação do batimento cardíaco e respiração, o corpo durante a potura ereta oscila de uma forma aleatória. $\mathrm{O}$ modelo é uma extensão do modelo de dois random walkers proposto por Collins e De Luca (1993). O modelo de Collins e De Luca consiste de um sistema de dois random walkers acoplados e de ação limitada. O modelo foi proposto para explicar as observações experimentais durante a postura ereta quieta para pequenos períodos de tempo: comportamento persistente do deslocamento do COP para intervalos de tempo menores que $1 \mathrm{~s}$ e comportamento anti-persistente do deslocamento do COP para intervalos de tempo entre $1 \mathrm{~s}$ e $10 \mathrm{~s}$. No presente estudo, nós estamos interessados em modelar o deslocamento do COP durante longos intervalos de tempo, de $10 \mathrm{~s}$ a 10 minutos; por conseguinte, o modelo original de Collins e De Luca foi modificado. Na modificação proposta, a migração do COP é dada por $r_{n+1}=r_{n}-F\left(r_{n}-r_{\text {org }}\right)+\xi_{n}$, onde $r_{n}$ e $r_{n+1}$ são as posições do random walker nos tempos $t=n$ e $t=n+1, F\left(r_{n}-r_{\text {org }}\right)$ representa a influência de uma mola restaurativa (a ação muscular líquida) 
localizada em $r_{\text {org }}\left(r_{\text {org }}\right.$ pode migrar refletindo a natureza irrestrita da tarefa) e $\xi_{n}$ representa a influência de uma força que flutua aleatoriamente (perturbações fisiológicas e flutuações da força muscular). A análise das simulações realizadas com diferentes parâmetros produziu curvas de flutuações similares com exponentes DFA próximos aos observados experimentalmente e também passaram pelo teste surrogate descrito anteriormente. Ainda que este simples modelo tenha sido capaz de produzir um comportamento similar ao observado, não é possível apontar nenhuma estrutura que compõem o complexo sistema de controle posturas.

Em conclusão, foi reportado pela primeira vez correlações de longo alcance do tipo ruído $1 / f$ na tarefa de postura ereta irrestrita por longos períodos; uma tarefa similar à postura ereta natural na vida diária. Uma questão é se alterações neste escalonamento fractal podem revelar distúrbios fisiopatológicos como tem sido observado na variabilidade do batimento cardíaco e em intervalos da passada durante o andar (Peng et al., 1993b; Hausdorff et al., 1995, 1997). 


\section{Propriedades fractais da postura ereta humana}

Neste estudo, é descrita uma análise da evolução temporal do deslocamento do COP durante postura ereta irrestrita de longa duração (30 min) em humanos saudáveis. Esta análise mostrou que o deslocamento do COP durante a postura ereta apresenta propriedades fractais que foram quantificadas pelo exponente de Hurst obtido utilizando-se a clássica análise de reajuste da dispersão escalonada. O exponente de Hurst (H) ou exponente

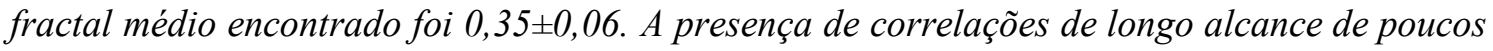
segundos a muitos minutos devido às características fractais do sistema de controle postural tem implicações importantes para a análise do equilíbrio humano. 


\subsection{Introdução}

Os humanos geralmente consideram a habilidade de permanecerem em pé e manter o equilíbrio uma tarefa simples. Somente quando surgem desordens posturais é que reconhecemos a complexidade do controle da postura ereta. Lesões e mesmo perda da vida devido a quedas são um freqüente problema para os idosos (Panzer et al., 1995). A manutenção do equilíbrio durante a postura ereta é uma tarefa complexa desempenhada pelo sistema de controle postural que integra informações do receptor visual, vestibular e somatossensorial, em conjunto com as propriedades passivas do sistema músculo-esquelético. Não obstante, a postura ereta por longos períodos é uma tarefa comum na vida diária. Por exemplo, permanecemos em pé numa fila, ou enquanto conversando com alguém e é comum trabalharmos em pé. Esta forma de postura ereta é caracterizada por repetidas mudanças da posição do corpo, as quais são auto-induzidas e realizadas quase que inconscientemente. Mesmo quando alguém é solicitado a permanecer o mais imóvel possível, seu corpo move continuamente para contrabalançar as pequenas perturbações que agem sobre o corpo. Neste estudo, é reportado que estas flutuações durante a postura ereta natural apresenta propriedades fractais com várias implicações para o estudo da postura ereta humana.

O principal parâmetro registrado em estudos do equilíbrio postural é o COP utilizando uma plataforma de força. A posição do COP é diferente da posição do COG ou de sua projeção no plano horizontal, a linha de gravidade (GL). O COG indica somente a posição global do corpo, o COP inclui componente dinâmica devido à aceleração do corpo. No entanto, em baixas freqüências de oscilação do corpo, abaixo de $0,1 \mathrm{~Hz}$, o COP e GL são similares (Winter, 1995). Tais baixas freqüências são investigadas aqui, e então os dados do COP também se aplicam à oscilação do corpo. A natureza fractal do deslocamento do COP foi idealizada depois que nós observamos componentes de freqüência muito baixas nos dados (Duarte \& Zatsiorsky, 1999), uma evidência de processos de correlação de longo alcance os quais são típicas características de fractais.

\subsection{Materiais e métodos}

Para estudar a natureza fractal dos movimentos do COP durante a postura ereta irrestrita, nós solicitamos à 10 sujeitos saudáveis $(28 \pm 5$ anos de idade, $1,79 \pm 0,09 \mathrm{~m}$ de estatura $\mathrm{e}$ $78 \pm 14 \mathrm{~kg}$ de massa) permanecerem em postura ereta irrestrita em um plataforma de força de $40 \times 90$ $\mathrm{cm}$ por 30 minutos e adquirimos o movimento do COP ao longo do tempo (ver capítulo 3 para mais detalhes). Os sujeitos podiam mover-se conquanto que permanecessem dentro da área da plataforma de força. Em geral, os movimentos observados consistiam de ajustes posturais sem mover a posição dos pés. Usamos o clássico método de amplitude ajustada e reescalada ou estatística R/S proposta por Hurst que foi originalmente desenvolvido em hidrologia para descrever as propriedades fractais de flutuações do nível de rios e outros fenômenos (Beran, 1994, Mandelbrodt, 1983).

Seja $y(k)=\sum_{i=1}^{k} u(i)$ o deslocamento acumulado da variável $u(i)$ depois de $k$ passos. A estatística R/S computa uma amplitude normalizada da variável $y(k)$ (o movimento do COP) para cada $k$ passos (período de tempo); uma medida das flutuações dos dados para diferentes tamanhos de janelas: $R(t, k)=\max _{0 \leq i \leq k}\left[y_{t+i}-y_{t}-\frac{i}{k}\left(y_{t+k}-y_{t}\right)\right]-\min _{0 \leq i \leq k}\left[y_{t+i}-y_{t}-\frac{i}{k}\left(y_{t+k}-y_{t}\right)\right] . R(t, k)$ é a amplitude ajustada e para poder estudar as propriedades independente da escala, , $R(t, k)$ é normalizada por uma medida da dispersão dos dados, $S(t, k)=\sqrt{k^{-1} \sum_{i=t+1}^{t+k}\left(u_{i}-\bar{u}_{t, k}\right)^{2}}$. A razão $R(t, k) / S(t, k)$ é chamada de estatística R/S. Quando o gráfico de logaritmo da estatística R/S versus o logaritmo de $k$ apresenta 
uma relação linear, os dados obedecem a uma função logística do tipo $k^{H}$, onde $H$ é o expoente Hurst ou expoente fractal obtido como a inclinação da regressão linear neste gráfico. Se os dados são completamente randômicos (dados não correlacionados), como ruído branco, a linha de regressão observada é plana e o expoente $H$ é zero. Se os dados representam um puro random walk, ou ruído Browniano (ruído branco acumulado), $\mathrm{H}$ é 0.5 , e é dito que o dado contém correlações de longo alcance triviais. Se $H$ é diferente de 0 e 0,5 , os dados são do tipo ruído $1 / f$, onde $f$ é a freqüência do fenômeno (Beran, 1994, Mandelbrodt, 1983).

\subsection{Resultados}

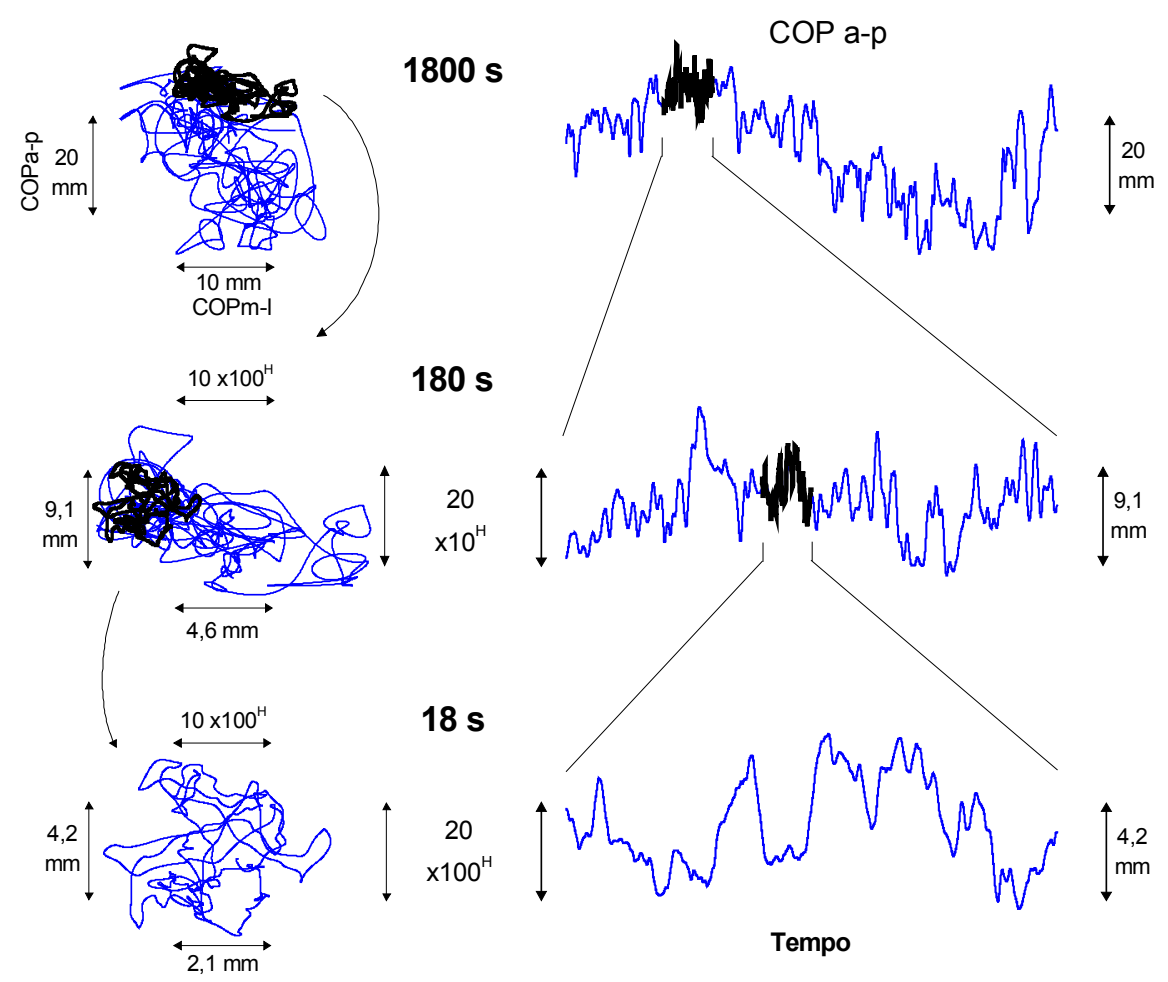

Figura 26. Estabilogramas (esquerda) e séries temporais do COP na direção ânteroposterior (a-p) (direita) para os dados durante a postura ereta natural (1800 s, primeira linha), para 1/10 dos dados (180 s, segunda linha) e para 1/100 dos dados (18 s, terceira linha). $O$ expoente de Hurst $(H)$ para este exemplo é 0,34 , resultando numa redução de 2,2 na escala de amplitude para cada 10 vezes de redução da escala de tempo. Ambos os eixos reais e escalonados são indicados nos gráficos de $180 \mathrm{~s}$ e de $18 \mathrm{~s}$ para ilustração. Note que depois de cada escalonamento (relacionado ao expoente fractal e ao período de tempo), os três estabilogramas e séries temporais apresentam aproximadamente as mesmas amplitudes em espaço. Para melhor claridade, nem todos os pontos são mostrados nos gráficos de $1800 \mathrm{~s}$ e $180 \mathrm{~s}$. A diferença na estrutura fina, observada para s série temporal de 18 s comparada às outras duas séries temporais, $e$ é devido ao fato que os deslocamentos do COP para intervalos de até $1 \mathrm{~s}$ mostram um comportamento diferente. Este comportamento $e ́$ provavelmente devido às características inerciais do corpo ou a diferentes mecanismos de controle do equilíbrio (conhecido como modelo de circuito aberto/fechado (ver Collins e De Luca, 1993)).

A análise dos 30 minutos de dados foi realizada com uma máxima janela de 10 minutos para ambas as direções do movimento do COP, a ântero-posterior $(a-p)$ e a médio-lateral $(m-l)$. O 
resultado da estatística $R / S$ para os 10 sujeitos produziu um expoente Hurst de $0,35 \pm 0,06$ (média $\pm S D, \mathrm{n}=20$ ), variando de 0,25 a 0,50 , com uma dimensão fractal média $D$, de 1,65 $(D=2-H)$. Em geral, não foram observados valores diferentes de $H$ para diferentes partes dos gráficos R/S. Os coeficientes de correlação da regressão linear por mínimos quadrados foram sempre acima de 0,9 e não mostraram qualquer relação com os valores de $H$. Para confirmar a hipótese de presença de correlação de longo alcance, foi aplicado um teste surrogate para os dados (Theiler et al., 1992). O resultado confirmou a hipótese de correlação de longo alcance. Por conseguinte, pode-se concluir que os movimentos do COP têm características estatísticas similares em tempo e amplitude quando propriamente escalonados pelo expoente fractal na região de poucos segundos a 10 minutos.

Não observamos nenhuma relação entre as mudanças posturais e os valores de $H$. Os gráficos à esquerda da Figura 26 mostram exemplos de estabilogramas (gráficos do COP na direção $a-p$ versus COP na direção $m-l)$; os gráficos da direita mostram as respectivas séries temporais do COP na direção a-p $(H=0,34$ para este exemplo). A primeira linha apresenta o completo grupo de dados (1800 s), a segunda linha $1 / 10$ dos dados (180 s) e a terceira linha 1/100 dos dados (18 s). A Figura 27 mostra o gráfico da estatística R/S correspondente para os dados da Figura 26. Os estabilogramas ilustram uma propriedade típica de fractais, a auto-similaridade: quando ambos eixos são escalonados por $10^{-H}$, os dados mantêm as características principais de modo que padrões similares de oscilação são observados a despeito das diferentes amplitudes. A série temporal do COP ilustra a propriedade fractal de auto-afinidade: quando o eixo temporal é escalonado por 10 e a amplitude escalonada por $10^{-\mathrm{H}}$, os dados preservam qualitativamente a estrutura.

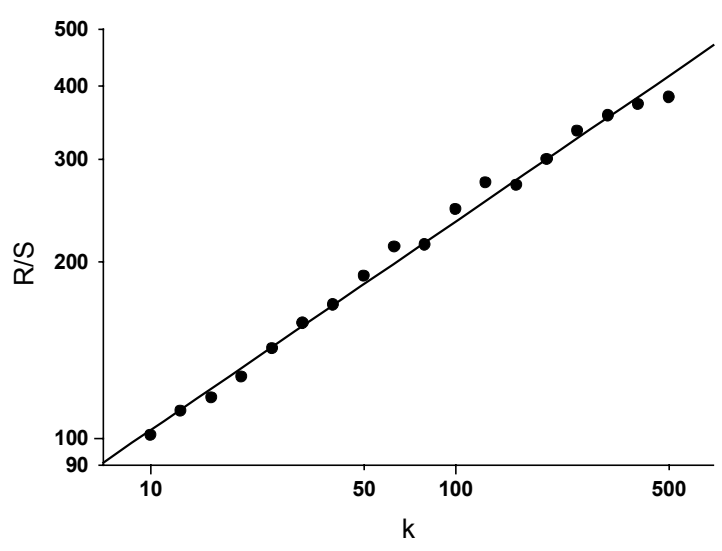

Figura 27. Gráfico R/S em escala log-log para os dados do COP de 1800 s do exemplo da figura anterior (ajuste para $k \equiv 10 \mathrm{~s}$ até $600 \mathrm{~s}$, inclinação $=0,34, r=0,99, p<0,00001$ ).

\subsection{Discussão}

Em estudos similares sobre séries temporais curtas do COP, Collins e De Luca analisaram correlações de até 10 segundos de defasagem e derivaram o modelo de circuito aberto/fechado para o sistema de controle postural agindo em tais períodos curtos de tempo (Collins \& De Luca, 1993, 1995b). Em contraste, o presente estudo analisa uma série temporal mais longa, investigando correlações de $10 \mathrm{~s}$ a $10 \mathrm{~min}$. A presença de correlações de longo alcance nos dados do COP durante a postura ereta natural tem muitas importantes implicações para a análise de dados estabilográficos e são comentadas a seguir.

Uma questão importante em estudos sobre postura é o período de aquisição, isto é, por quanto tempo deve-se adquirir dados para capturar as propriedades essenciais da postura ereta 
humana? Em um artigo constantemente referenciado, Powell e Dzendolet (1984) reportaram baixas freqüências nos dados do COP de $130 \mathrm{~s}$ de duração. Diferentes autores têm citado este artigo como uma referência para justificar a aquisição de dados por não mais que 2 minutos. Nosso estudo sugere que com tempos de aquisição maiores, freqüências do COP ainda menores seriam observadas. Nós mostramos que não há limite para observar baixas freqüências até intervalos de 10 minutos. A conclusão importante é que a escolha do período de aquisição tem que ser baseada em quais períodos (freqüências) são consideradas relevantes para o estudo em questão.

Outra questão importante é que a distinção entre não estacionariedade e correlações de longo alcance é um problema não resolvido na análise de séries temporais e estudos sobre não estacionariedade dos dados de COP têm mostrado resultados discrepantes. Considerando o achado de correlação de longo alcance, tais discrepâncias são conseqüências de que diferentes investigadores têm testado apenas pequenas porções de um processo mais longo. Por causa da presença de correlações de longo alcance, aparentes não estacionariedades em séries temporais curtas do COP podem na verdade representar flutuações de um processo estacionário mais longo. Por conseguinte, a questão sobre estacionariedade não pode ser adequadamente investigada usando-se séries temporais curtas de até poucos minutos. Alternativamente, este problema pode ser parcialmente resolvido aplicando-se um filtro passa-alta nos dados com uma freqüência de corte relacionada ao período de aquisição de dados (Witt et al., 1998). Este método remove as correlações de longo alcance, as quais seriam uma possível fonte de aparente não estacionariedade nos dados.

Por fim, a propriedade de auto-afinidade nos dados do COP dentro dos períodos estudados tem importantes implicações quando da comparação de dados adquiridos com diferentes períodos. Para comparar corretamente as séries temporais de diferentes comprimentos, os dados devem ser escalonados pelos expoentes fractais.

\subsection{Conclusão}

A presença de fractais na natureza tem sido observada em uma larga variedade de diferentes propriedades de sistemas biológicos (Peng et al., 1992; Goldberger \& West, 1987; Hausdorff et al., 1995; Gilden et al., 1995; Chen et al., 1997) e tem sido aplicada para modelar leis de escala alométrica em biologia (West et al., 1997). O fato que o deslocamento do COP durante a postura ereta natural por um longo período segue uma lei de escala fractal está de acordo com estes achados. A manutenção do equilíbrio é executada pelo sistema de controle postural o qual integra informações de diferentes fontes com diferentes latências e respostas em freqüência e controla um sistema mecânico com múltiplos graus de liberdade com atuadores altamente redundantes (vários músculos atravessando a mesma articulação). Perturbações fisiológicas, como por exemplo respiração e batimento cardíaco (o qual também apresenta correlações de longo alcance (Goldberger \& West, 1987)), continuamente perturbam o equilíbrio. Cada uma destas características pode ser responsável pelo processo de correlação de longo alcance (Marinari et al., 1983; Montroll \& Shlesinger, 1982; Per Bak \& Wiesenfeld, 1987; Weissman, 1988). Neste cenário, é improvável que um único fator neurológico ou fisiológico possa ser identificado como a fonte do comportamento fractal. É mais provável que este comportamento seja o resultado de um sistema não linear complexo envolvendo um número de diferentes sistemas em diferentes escalas de tempo e comprimento no corpo humano. 


\section{Acurácia e velocidade de movimento durante a postura ereta}

A lei de Fitts declara que o tempo de movimento (TM) de um movimento voluntário é uma função linear de indice de dificuldade (ID), onde $I D=\log _{2}(2 A / W)$, A é a amplitude de movimento, e $W$ é a largura do alvo. Esta lei considera que TM deve permanecer inalterado enquanto a relação $A / W$ permanece constante (isto é, na ausência de um efeito escala). O objetivo deste estudo foi investigar se, durante a postura ereta, os movimentos recíproco-direcionados com a posição do centro de pressão (COP) seguem a lei de Fitts. Seis sujeitos realizaram a tarefa com seis IDs fatorialmente combinados com quatro As. Os resultados mostraram que para cada A, o TM foi uma função linear de ID. Entretanto, as inclinações das linhas de regressão linear aumentaram com a diminuição da A. Estes resultados indicam a presença de um efeito escala que viola a lei de Fitts. 


\subsection{Introdução}

O estudo sobre o compromisso entre velocidade e acurácia dos movimentos humanos tem focalizado freqüentemente a variação do tempo de movimento (TM) em função da amplitude de movimento (A) e da largura (W) do alvo. A formulação mais conhecida desta relação foi introduzida por Fitts (Fitts, 1954), ele propôs que $\mathrm{TM}=\mathrm{a}+\mathrm{b} \cdot \log _{2}(2 \mathrm{~A} / \mathrm{W})$, onde $\mathrm{a}$ e $\mathrm{b}$ são constantes empíricas, e onde $\log _{2}(2 \mathrm{~A} / \mathrm{W})$ expressa o ID. $1 / \mathrm{b}$ é considerado um índice de performance, quanto maior o seu valor, menos o TM é afetado pelo aumento da dificuldade da tarefa. Como muitas outras formulações da relação entre velocidade e acurácia (Crossman, 1956; Hoffmann, 1992; MacKenzie, 1992; Welford, 1968), esta formulação expressa que quando A/W é constante, o TM deve permanecer inalterado. Portanto, as funções deste tipo rejeitam a presença de um efeito escala, isto é, mudanças no TM com mudanças nas escalas (As e Ws) para um dado ID.

Ainda que existam estudos que apresentam violações desta relação (Chi \& Lin, 1997; Fowler et al., 1991; Kelso et al., 1979; Latash \& Gottlieb, 1990), ela tem sido observada numa ampla variedade de tarefas e, por esta razão, é freqüentemente conhecida como lei de Fitts (para uma revisão veja Plamondon \& Alimi, 1997). A maioria dos estudos sobre a lei de Fitts tem considerado movimentos dos membros superiores (envolvendo braço, punho, ou dedo). Há somente dois trabalhos que reportam a investigação de movimentos voluntários realizados com os membros inferiores (Drury, 1975; Hoffman et al., 1991) e nenhum investigando os movimentos do corpo inteiro. O objetivo deste experimento foi verificar se a lei de Fitts também pode descrever movimentos do corpo inteiro em que os músculos dos membros inferiores são os motores primários.

Movimentos direcionados com o feedback visual da posição do COP são um procedimento comum na reabilitação de pacientes com deterioração do equilíbrio postural (Hamman et al., 1992; Shumway-Cook et al., 1989). Este estudo determinou o quão rápido e acurado as pessoas podem deslocar o seu COP entre alvos com diferentes As e Ws. Esta tarefa é desafiadora já que mesmo quando as pessoas são solicitadas a manter o COP em sua posição preferida, o deslocamento médio do COP é aproximadamente de $1 \mathrm{~cm}$ (veja os resultados a seguir). A presença desta variabilidade no sistema de controle postural pode ser um fator limitante da performance quando $\mathrm{A}$ e $\mathrm{W}$ se aproximam deste valor.

\subsection{Material e métodos}

Seis sujeitos adultos saudáveis ( 5 homens e 1 mulher) realizaram movimentos recíprocodirecionados com a posição do COP. A média de idade dos sujeitos, sua estatura e massa foram de (média e desvio padrão) $28,5 \pm 3,6$ anos, $176 \pm 6 \mathrm{~cm}$, e $71,2 \pm 7,4 \mathrm{~kg}$, respectivamente. Nenhum dos sujeitos tinha qualquer histórico de desordens posturais ou esqueléticas e todos assinaram um termo de consentimento de acordo com o Escritório de Regulamentação de Consentimentos da Universidade Estadual da Pennsylvania.

A tarefa foi baseada no estudo original de Fitts (1954). Os sujeitos ficaram em pé na plataforma de força onde a localização do COP foi adquirida em uma freqüência de $50 \mathrm{~Hz}$. $\mathrm{O}$ feedback visual da posição do COP apresentado em um monitor ajustado para estar na altura da cabeça do sujeito. Dois alvos foram apresentados na tela como janelas delimitadas por duas linhas perpendiculares ao eixo ântero-posterior (a-p), enquanto que a posição do COP foi representada por um cursor. A tarefa dos sujeitos consistiu em realizar os movimentos de balanço com o corpo, gerando deslocamentos para frente e para trás do cursor (COP) entre os dois alvos (para uma 
revisão de estudos utilizando ambientes visuais similares, ver Plamondon e Alimi, 1997). Foi solicitado que os sujeitos realizassem a tarefa o mais rápido e acurado possível. As tentativas contendo mais do que $10 \%$ de erros (acima ou abaixo do alvo) foram rejeitadas e repetidas. A porcentagem média de erros das 24 tentativas foi de $4,6 \pm 0,6 \%$. Durante o teste, os sujeitos estavam com os braços ao lado do corpo. Antes do experimento foi realizada uma sessão de treinamento. Uma análise qualitativa revelou que os sujeitos usaram as estratégias do quadril e do tornozelo (Nashner \& McCollum, 1985) para completar a tarefa.

Cada tentativa foi definida por dois parâmetros, a amplitude entre os centros dos dois alvos (A) e o índice de dificuldade (ID). Quatro As $(3 ; 4,5 ; 6$ e $9 \mathrm{~cm})$ foram fatorialmente combinadas com seis IDs $(1,4 ; 1,7 ; 2,0 ; 2,3 ; 2,6 ;$ e 2,9). Cada sujeito realizou todas as condições (24 tentativas) numa seqüência pseudo-randomizada. A duração de cada tentativa foi de $40 \mathrm{~s}$. As posições dos alvos foram especificadas em relação à posição preferida do COP dos sujeitos. A posição preferida do COP foi determinada durante $60 \mathrm{~s}$ sem feedback visual. Devido às assimetrias conhecidas nos limites de estabilidade ao longo do eixo a-p (Hamman et al., 1992), os alvos foram posicionados 2/3 para frente e $1 / 3$ para trás da localização determinada (nossos sujeitos foram capazes de alcançar $11,1 \pm 1,4 \mathrm{~cm}$ para frente e $6,7 \pm 1,9 \mathrm{~cm}$ para trás sem cair).

O processamento dos dados foi realizado como se segue. Os primeiros $10 \mathrm{~s}$ de cada tentativa foram considerados como um período de adaptação e foram descartados das análises. Durante a permanência de $30 \mathrm{~s}$, nós contamos o número de ciclos de movimentos completos realizados. Então, considerando cada ciclo como a concatenação de dois sub-movimentos, a média do TM foi calculada através desta janela de tempo.

\subsection{Resultados e discussão}

Dentro de cada condição de amplitude, a velocidade esteve relacionada à acurácia de acordo com a lei de Fitts: o TM aumentou linearmente em função do ID (ver Figura 28) (os dados para o $I D=2,9$ e a $A=6 \mathrm{~cm}$ foram considerados outliers e não foram incluídos na regressão linear). Os coeficientes de correlação foram significantes em todas as A ( $r>0,93 p<0,01)$. Entretanto, quando A aumentou, as inclinações (b) das linhas de regressão linear diminuíram $(r=-0,98, p<0,01)$. Os índices de performance correspondentes foram $1 / \mathrm{b}=2,86 ; 3,12 ; 4,69$ e 7,96 ID/s para $A=3 ; 4,5 ; 6$ e $9 \mathrm{~cm}$, respectivamente. Para entender os efeitos do ID e da A, foi realizado um ANOVA de dois fatores para medidas repetidas dos valores de TM. Em concordância com a lei de Fitts, ocorreu um efeito principal do ID $(F(5 ; 25)=26,23, p<0,001)$. Entretanto, ocorreu também um efeito principal da $A(F(3 ; 15)=16,27$; $p<0,001)$, que demonstra a presença de um efeito de escala. Por último, em concordância com os valores que nós obtivemos para $1 / \mathrm{b}$, ocorreu uma significante interação ID $\times A(F(15 ; 75)=5,23$; $p<0,001)$. Este resultado indica que as linhas de regressão para as diferentes $A$ não foram paralelas.

Os resultados mostram que para cada A, o TM comportou-se como uma função linear de ID. Entretanto, as inclinações das linhas de regressão linear aumentaram com a diminuição de A. Isto significa que a razão $\mathrm{A} / \mathrm{W}$ não foi o único fator determinante do rendimento e constitui uma violação da lei de Fitts (Fitts, 1954) bem como para muitas de suas derivadas (Crossman, 1956; Hoffmann, 1992; MacKenzie, 1992; Welford, 1968). Uma possível explicação para este efeito de escala está relacionada à quantidade de variabilidade presente no COP durante a postura ereta. Esta variabilidade foi estimada solicitando aos sujeitos que minimizassem os desvios do seu COP em relação a um alvo estacionário colocado na posição preferida do COP determinada anteriormente. A média do intervalo de confiança de $95 \%$ da posição do COP foi de $0,84 \pm 0,17 \mathrm{~cm}$. Este valor foi 
bastante próximo ao $\mathrm{W}(0,80 \mathrm{~cm})$ com $\mathrm{A}$ de $3 \mathrm{~cm}$ e ID de 2,9, onde o TM foi o mais alto. Este resultado é consistente com a idéia de que a variabilidade inerente do sistema de controle postural foi um fator limitante ao rendimento em escalas pequenas (As e Ws) e IDs altos. Entretanto, permanece a ser explicado se esta explicação pode descrever as mudanças sistemáticas nas inclinações TM/ID com mudanças na escala.

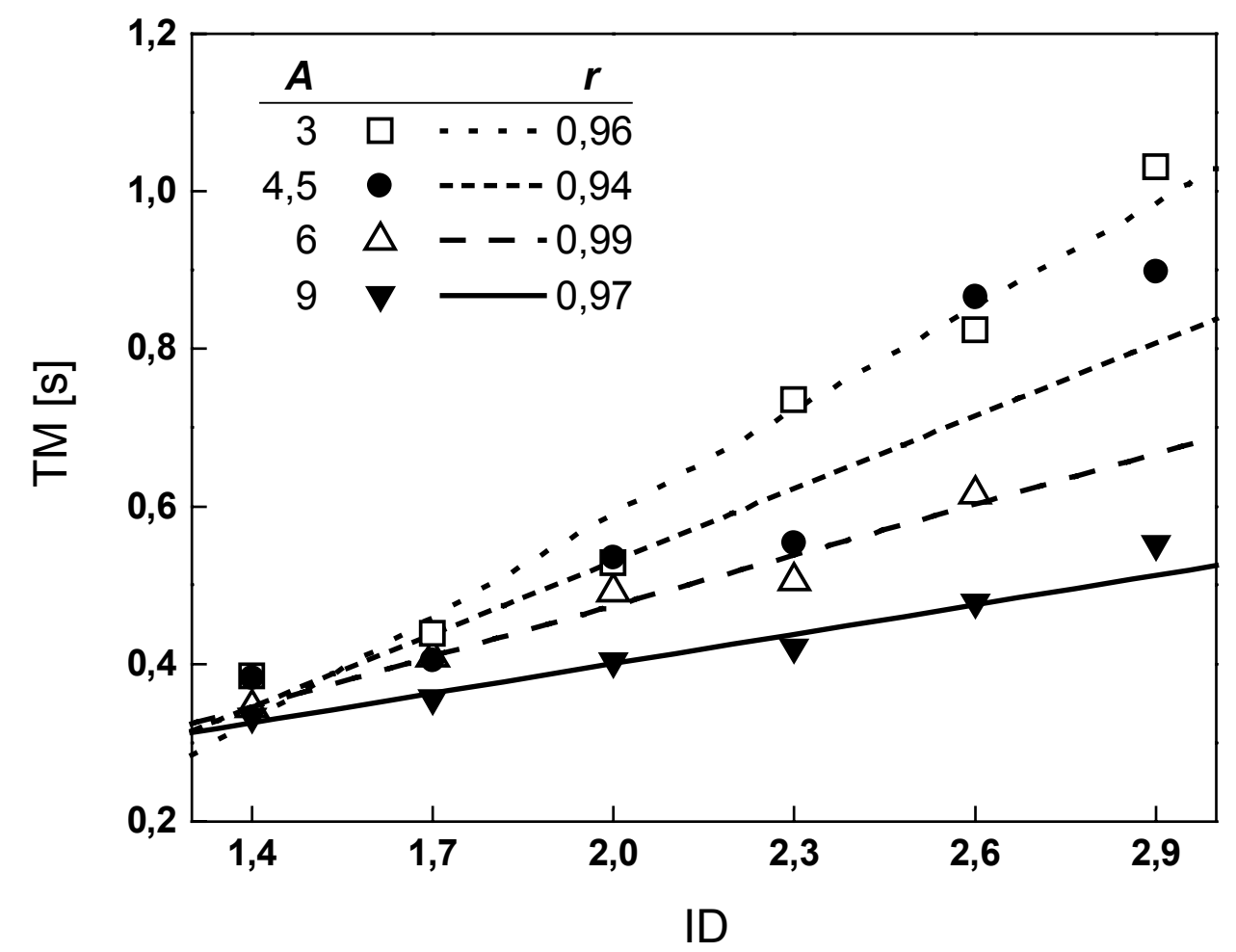

Figura 28. Média do tempo de movimento (TM) em função do índice de dificuldade (ID) para diferentes amplitudes de movimento (A): 3; 4,5; 6 e 9 cm. Regressões lineares e correspondentes coeficientes de correlação (r) são apresentados para cada $A$.

Apesar da presença do efeito de escala, é interessante comparar nossos resultados aos reportados na literatura. Em particular, na maior $\mathrm{A}$, os resultados mostraram que as pessoas podem realizar índices de rendimento que se aproximam do observado em tarefas manuais ( $1 / \mathrm{b} \cong 10 \mathrm{ID} / \mathrm{s}$ para Fitts (Fitts, 1954)). Entretanto, na menor A, os resultados revelaram que, em IDs comparáveis, as pessoas deslocam-se muito mais lentamente o corpo inteiro do que os seus membros superiores (Fitts, 1954; Hoffmann, 1991; Langolf et al., 1976) e do que seus membros inferiores (Drury, 1975; Hoffmann, 1991). Isto foi comprovado num estudo piloto onde os sujeitos apresentaram dificuldades nos IDs acima de 3. Estas limitações são provavelmente devido às restrições biomecânicas, como propriedades inerciais e propriedades músculo-esqueléticas do corpo.

Em conclusão, a lei de Fitts não é válida para movimentos de corpo inteiro, quando medido com o deslocamento do COP. Estudos futuros devem ser focalizados em determinar se o efeito escala que nós observamos está diretamente relacionado à quantidade de variabilidade presente no COP durante a postura ereta quieta. 


\section{Informação visual, limites de estabilidade e variabilidade da postura ereta}

O presente estudo mapeou a variabilidade do COP durante a postura ereta quieta em função de diferentes posições médias de equilibrio relativas à base de suporte e avaliou o papel da informação visual nesta situação. Para tanto, três condições de informação visual foram investigadas: com visão, sem visão e com feedback visual do COP. $O$ comportamento geral da variável área, velocidade média e freqüência mediana indica a existência de um poço de potencial descrito por um parabolóide, onde os valores mínimos de cada variável correspondem à posição de equilíbrio neutro. Para as variáveis área e velocidade média, os poços apresentam valores semelhantes para as condições com visão e com feedback do COP e apresentam paredes mais inclinadas para a condição sem visão, indicando que nesta condição o comportamento do equilibrio é mais afetado pela posição de manutenção da postura. Os resultados indicam que o feedback do COP não foi capaz de diminuir a dispersão espacial do COP, medida pela área do estabilograma, quando comparada à condição com visão. A variável freqüencia mediana do COP mostra um comportamento exatamente inverso ao da variável área do COP para todos os alvos: a condição sem visão apresenta a menor freqüencia mediana, seguida por um valor mais alto para a condição com visão e um valor ainda mais alto para a condição com feedback visual. Os sujeitos utilizaram a informação visual para a correção da posição, mas a maior freqüencia de utilização da informação visual na condição com feedback não foi efetiva para diminuir a dispersão espacial do COP se comparado à condição com visão. A velocidade do COP foi significantemente maior para a condição sem visão do que para as outras duas condições. 


\subsection{Introdução}

A mecânica da postura ereta semi-estática pode ser modelada por um pêndulo invertido onde os torques no tornozelo e no quadril e as forças horizontais na interface pés-solo atuam na restauração do equilíbrio. Para a manutenção deste equilíbrio instável, o objetivo primário é manter a projeção do COG sobre a superfície de suporte, conhecida como linha de gravidade (GL, gravity line), dentro dos limites de estabilidade (LOS, limit of stability) definidos pelos pés. Para a realização desta tarefa, o sistema de controle postural utiliza a variável COP para controlar a posição do COG.

Durante a postura ereta bípede quieta em pessoas normais, ainda que o LOS defina uma base de estabilidade da ordem de algumas centenas de centímetros quadrados, as áreas cobertas pela GL e pelo deslocamento do COP são cerca de cem vezes menores. Esta grande diferença evidencia que o corpo humano procura o estado de menor oscilação possível, o que apresenta duas vantagens diretas. A primeira é que, mantendo-se o corpo o mais próximo da vertical, menores torques restaurativos são necessários, o que implica em menor gasto energético. A segunda vantagem é que, mantendo-se a projeção do COG longe dos LOS, a recuperação do equilíbrio após uma perturbação é mais eficaz. Os LOS reais são menores que os definidos pela superfície delimitada pelos pés porque o corpo humano é incapacitado de gerar certos níveis de torque necessários para restaurar o equilíbrio numa região próxima dos LOS para grandes velocidades de oscilação do corpo (Pai \& Patton, 1997). Essa segunda vantagem apontada indicaria para uma outra teoria de controle do equilíbrio postural: o sistema de controle postural controlaria a distância do COP ao LOS, de modo a maximizar o tempo para o contato do COP com o LOS (Slobounov et al., 1997).

O LOS na direção ântero-posterior é assimétrico em relação à articulação do tornozelo: é maior na parte anterior dos pés do que na parte posterior; o corpo humano durante a postura ereta quieta alinha-se na vertical com uma inclinação média de $4^{\circ}$ para frente fazendo com que a posição horizontal média do COG esteja a cerca de $5 \mathrm{~cm}$ a frente do tornozelo. A máxima capacidade de oscilação do corpo também é influenciada por esta simetria na direção a-p: quando exploravam o LOS, as pessoas deslocam-se em média duas vezes mais para frente do que para trás em relação à posição média de equilíbrio (Danion et al., 1999).

Cerca de metade das quedas em idosos ocorrem durante o andar, tarefa em que a manutenção do equilíbrio dinâmico é crítica. Quedas refletem a incapacidade do sistema de controle postural recuperar-se de uma perturbação (isto é, manter a projeção do COG dentro do LOS). Em situações cotidianas que colocam em risco o equilíbrio e que podem provocar quedas, devemos ser capazes de manter o equilíbrio em diferentes posições da base de suporte e às vezes próximo ao LOS. Em vista disso, diferentes autores têm apontado a pouca significância da posturografia estática (nenhuma perturbação e manutenção do equilíbrio longe dos LOS) para resolver o problema de quedas em seres humanos (Johansson, Magnussson, 1991, Baloh et al., 1994).

O mapeamento do equilíbrio em diferentes posições da base de estabilidade pode ser útil para avaliar a performance do sistema de controle postural em controlar o equilíbrio em situações extremas que o corpo humano possa cair. Schieppati et al. (1994) fizeram tal mapeamento para a direção a-p em sujeitos normais e idosos patológicos e avaliaram o papel da informação visual durante esta tarefa. Estes autores observaram maior oscilação quando o COP estava perto dos limites de estabilidade e concluíram que esta maior oscilação não indicava maior instabilidade mas uma exploração intencional da base de estabilidade para a manutenção da postura naquela posição.

Atividades motoras mais específicas e complexas (que requerem maior demanda do controle postural onde uma variável associada ao equilíbrio postural, geralmente o COP, é fornecida 
como feedback visual em tempo real) têm sido aplicadas em treinamento e reabilitação do equilíbrio postural com diferentes graus de sucesso (Shumway-Cook et al., 1988; Winstein et al., 1989; Clarke et al., 1990; Jobst, 1990; Hamann \& Krausen, 1990; Ledin et al., 1991; Hamman et al., 1992; Lee et al., 1996; Nichols, 1997). De maneira similar, o papel do feedback visual durante a tarefa de manutenção da postura ereta em diferentes posições médias de equilíbrio em relação à base de apoio foi investigada (Hirvonen et al., 1997). Neste estudo foram avaliados parâmetros típicos de experimentos de feedback, como tempo de reação e tempo de permanência em alvos em diferentes lugares da base de suporte para ambas as direções a-p e m-l. O protocolo experimental daquele estudo só permitiu a avaliação do mapeamento para a condição com feedback visual.

O presente estudo pretende mapear a variabilidade do COP durante a postura ereta quieta em função de diferentes posições médias de equilíbrio relativas à base de suporte e avaliar o papel da informação visual nesta situação. Para tanto, três condições de informação visual serão avaliadas: com visão, sem visão e com feedback visual do COP. O que pretende-se investigar é como o corpo humano controla a postura nestas situações e qual é o papel da informação visual para tanto. Busca-se deste modo o entendimento dos mecanismos de controle postural em tarefas próximas a situações de quedas e equilíbrio mais instável.

\subsection{Materiais e métodos}

\subsubsection{A tarefa}

Registramos o COP a partir de uma plataforma de força durante uma tarefa de postura ereta bípede semi-estática. A tarefa consistiu em manter a postura ereta quieta com a posição do COP em 13 diferentes posições da base de suporte do sujeito por $40 \mathrm{~s}$ em cada posição. A apresentação da posição instantânea do COP em falso tempo real na tela de um monitor de computador em conjunto com os um dos 13 alvos de cada vez foi o feedback visual. Primeiro, a base de suporte e a posição de equilíbrio neutro ou de referência do sujeito foram determinados. Então, solicitou-se ao sujeito, com o feedback visual, explorar sua base de suporte para determinar o limite de estabilidade alcançável pelo sujeito, denominado ELOS (explored limits of stability). As 13 posições eram especificadas como frações dos ELOS e relativas ao ponto de equilíbrio médio: $0 \%$, $40 \%$ e $80 \%$ da distância entre o ponto de equilíbrio e o ELOS anterior para a frente; $40 \%$ e $80 \%$ da distância entre o ponto de equilíbrio e o ELOS posterior para trás; $40 \%$ e $80 \%$ da metade entre os ELOS direito e esquerdo para a direita e para a esquerda; e quatro posições correspondentes as quatro diagonais: $40 \%$ à direita e à frente, $40 \%$ à esquerda e à frente, $40 \%$ à esquerda e à trás, $40 \%$ à direita e à trás.

$\mathrm{Na}$ Figura 30 é mostrado um exemplo dos limites de estabilidades físicos (PLOS, physical limits of stability) e limites de estabilidades explorado pelo sujeito (ELOS), posição média e elipse representando $85 \%$ da oscilação do COP nas três condições visuais, visão, sem visão e com feedback para os 13 alvos.

Há três condições para cada um dos 13 alvos: (a) o alvo e o feedback do COP eram vistos (condição feedback, F); (b) somente o alvo era visto e nenhum feedback do COP foi dado (condição visão, V); (c) olhos fechados (condição sem visão, NV). No total foram 39 tentativas que foram pseudo randomizadas em bloco para cada sujeito; foi permitido descansar entre as tentativas e fadiga não foi relevante neste estudo. As tentativas sempre começavam com o sujeito de olhos abertos com o feedback visual. Conforme a localização do alvo apresentado, o sujeito deveria mover o COP para aquela posição e tentar mantê-lo lá. Quando o sujeito anunciava com um comando 
verbal que estava no alvo e pronto para iniciar a tentativa, o feedback era mantido ou removido e era solicitado ao sujeito manter os olhos abertos ou fechados conforme a condição para aquela tentativa. A aquisição durou $40 \mathrm{~s}$. A instrução dada ao sujeito era que deveria minimizar a distância entre o cursor representando o COP e o alvo durante toda a aquisição. Neste experimento, o ganho do feedback do COP (razão entre a distância observada na tela e a real distância na plataforma de força) foi de 2 vezes. Segundo Krizková et al. (1993), o ganho ótimo está na região de 2 a 4 vezes.

\subsubsection{Arranjo experimental}

Para medição do COP, os sujeitos realizaram a tarefa sobre uma plataforma de força de $40 \times 90 \mathrm{~cm}^{2}$ (modelo 4090S Bertec Inc., Worthington, OH, EUA) que fornecia as 3 componentes ortogonais do vetor força e as 3 componentes do vetor torque. Um software escrito em Labview (LabView 5.1, National Instruments Corporation, Dallas, TX, EUA) calculava as duas coordenadas do COP e mostrava-as como feedback em falso tempo real em um monitor de computador a cerca de um metro do sujeito e à altura de sua cabeça. Estas duas coordenadas são identificadas em relação à orientação do sujeito: direção a-p e m-I. A aquisição dos sinais da plataforma e o feedback do COP foram realizados em frequêencia de $50 \mathrm{~Hz}$, implicando num atraso de cerca de $20 \mathrm{~ms}$, considerado desprezível para a presente tarefa. A aquisição dos dados foi feita utilizando-se um computador pessoal (modelo GP6-450, MS Windows NT, Gateway 2000, Inc., N. Sioux City, EUA) com um cartão A/D de 12 bits (modelo AT-MIO-64E-3, National Instruments Corporation, Dallas, TX, EUA) controlados por código desenvolvido em Labview. O contorno da base de suporte foi digitalizado utilizando-se um sistema de digitalização sônica (modelo SAC GP-12XL 3D, Stratford, CT, EUA).

\subsubsection{Amostra}

Onze adultos voluntários (oito homens e 3 mulheres) participaram deste estudo. A idade média dos integrantes do grupo era de $29 \pm 4$ anos de idade, a estatura média era de $173 \pm 13 \mathrm{~cm}$ e massa corporal média era de $68 \pm 12 \mathrm{~kg}$. Nenhum indivíduo apresentava qualquer histórico de desordem músculo-esquelética ou postural e eles deram seu consentimento para particpação no estrudo através de um Termo de Consentimento aprovado de acordo com as regras estabelecidas pelo Escritório de Regulação de Consentimentos da Universidade do Estado da Pennsylvania.

\subsubsection{Análise dos dados}

O intervalo dos primeiros $5 \mathrm{~s}$ da série dos dados foi considerado como um período de adaptação e desconsiderados para a análise após o processo de filtragem. Deste modo, os dados serão citados como uma série temporal de $35 \mathrm{~s}$.

As séries temporais para as condições sem feedback apresentaram uma tendência de longa duração refletindo que os sujeitos tendiam a voltar lentamente para a posição de equilíbrio quando o alvo estava distante da mesma e o sujeito deveria permanecer numa posição inclinada. Para remover essa tendência que é uma não-estacionariedade na série temporal e não representa as oscilações do COP de interesse para o estudo, utilizou-se um filtro passa-alta Butterworth de fase zero e $4 a$ ordem com uma freqüência de corte $2 x$ maior que a menor freqüência possível para a série temporal $(f=2 / 40 s=0,05 \mathrm{~Hz}$ ). Os dados também foram filtrados por um filtro passa baixa do mesmo tipo e com uma freqüência de corte de $10 \mathrm{~Hz}$ para remoção de ruídos. Antes da filtragem, a média 
dos sinais correspondentes aos últimos $35 \mathrm{~s}$ foram calculadas e armazenadas para posterior representação de todas as tentativas no estabilograma como na Figura 30.

O contorno dos limites de estabilidade físico foi calculado a partir dos dados digitalizados achando-se a área convexa que delimita os dados digitalizados por meio de um código escrito em Matlab 5.3 (Mathworks Inc., Natick, MA, EUA). O mesmo se aplica para a tentativa de exploração do dos limites de estabilidade.

As seguintes variáveis foram utilizadas para a análise dos dados: média; área da elipse que cobre os deslocamentos do COP calculada utilizando o método de análise das componentes principais (PCA, principal components analysis) (AREA); a velocidade média do deslocamento do COP (V) e a freqüência mediana do sinal do COP calculada a partir do densidade de potência espectral (PSD, power spectrum density) (Fmed) calculado a partir do periodograma de Welch (módulo processamento de sinal do software Matlab). Exceto a variável área, todas as outras são calculadas separadamente para cada direção. A resultante da velocidade foi calculada como a raiz quadrada da soma dos quadrados das velocidades médias de cada direção. A freqüência resultante foi calculada como a média ponderada entre as duas freqüências para cada direção, com os pesos dados pelas correspondentes potências totais do sinal.

Os resultados destas variáveis em função dos treze alvos diferentes e para cada uma das três condições foram analisados da seguinte forma: Os valores para os 13 alvos foram ajustados por uma função parabolóide por mínimos quadrados segundo o algorítmo de Levenberg-Marquardt (módulo de otimização do software Matlab). Os dados também foram analisados separadamente para os alvos representando deslocamentos em uma única direção, os cinco pontos para cada direção, neste caso os pontos foram ajustados por uma função parábolica por mínimos quadrados.

Para a determinação das diferenças entre os resultados obtidos, um ANOVA de um fator (informação visual) com três níveis (com visão, sem visão e com feedback) para medidas repetidas foi realizado para as medidas de área do estabilograma (AREA), velocidade média resultante do COP $(\mathrm{v})$ e freqüência mediana do COP (Fmed) para os seguintes alvos: neutro $(N)$, extremo anterior $(E A)$, extremo posterior (EP), extremo esquerdo (EE) e extremo direito (ED). Um teste post-hoc de Tukey foi utilizado para análise da diferença intraníveis.

\subsection{Resultados}

O comprimento do LOS físico na direção a-p foi $26,8 \pm 2,3 \mathrm{~cm}$, enquanto que o comprimento do LOS explorado foi $17,7 \pm 2,4 \mathrm{~cm}$. Para a direção m-I, a largura do PLOS foi $36,4 \pm 2,6$ $\mathrm{cm}$ e para o ELOS foi $26,0 \pm 2,4 \mathrm{~cm}$. A área do PLOS foi $82,9 \pm 10,3 \mathrm{~cm}^{2}$ e para o LOS explorado foi $37,2 \pm 7,6 \mathrm{~cm}^{2}$. Há correlação significativa entre o ELOS na direção a-p e a estatura do sujeito, significando que sujeitos mais altos exploraram mais seu LOS, $r=0,79(\mathrm{~N}=11, p<0,005)$, mas não na direção $\mathrm{m}-\mathrm{I}, r=0,32$. Da mesma forma, há correlação significativa entre o PLOS com o ELOS na direção a-p, significando que sujeitos com maiores limites físicos exploraram mais seu LOS, $r=0,76$ $(\mathrm{N}=11, p<0,005)$, mas não na direção $\mathrm{m}-\mathrm{I}, r=0,48$, resultando em uma correlação significativa entre a área do PLOS e a área do ELOS, $r=0,59(\mathrm{~N}=11, p<0,05)$, como mostrado na Figura 29.

A Figura 30 mostra um exemplo representativo dos limites de estabilidade física e limites de estabilidade explorada pelo sujeito, posição média e elipse representando $85 \%$ da oscilação do COP nas três condições visuais, visão, sem visão e com feedback para os 13 alvos. 


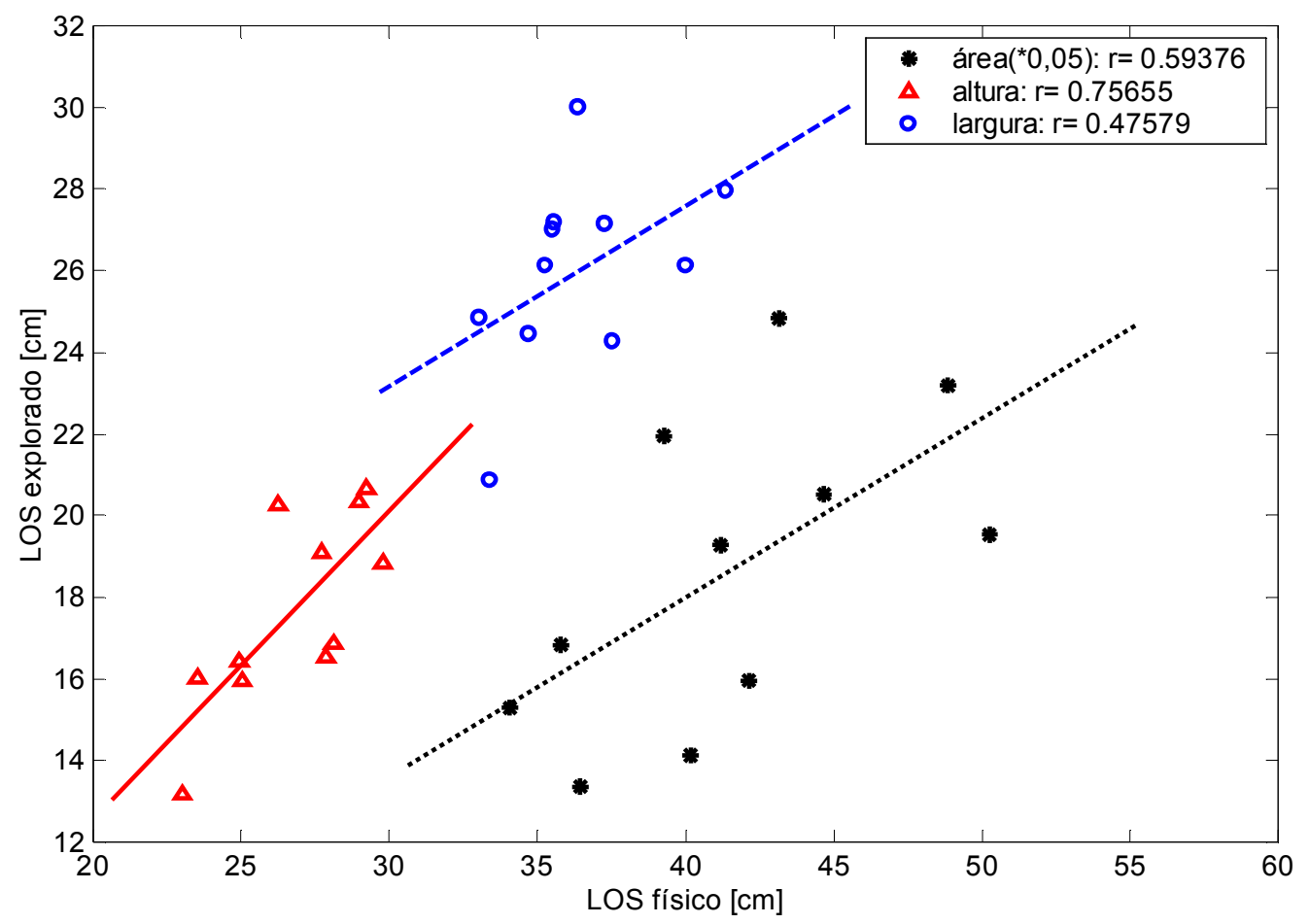

Figura 29. Limites de estabilidade explorada (ELOS) versus limites de estabilidade fisica (PLOS) para a direção a-p (altura), direção m-l (largura) e área. Note que os valores para as áreas foram divididos por $20 \mathrm{~cm}$ para melhor claridade. $N=11$. 

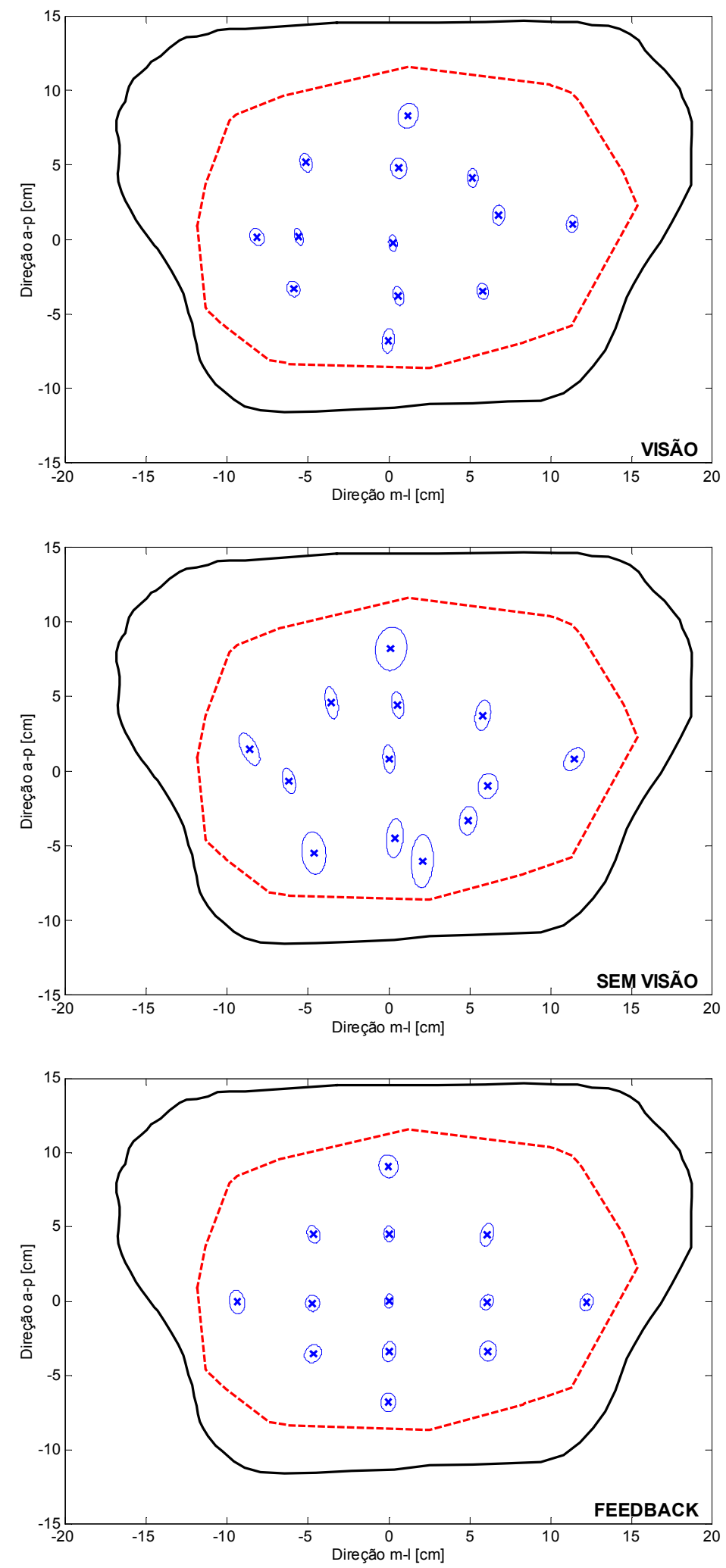

Figura 30. Exemplo representativo dos limites de estabilidade física (PLOS) e limites de estabilidade explorada pelo sujeito (ELOS), posição média e elipse representando 85\% da oscilação do COP nas três condições visuais, visão, sem visão e com feedback para os 13 alvos. Sujeito $A S$. 
A Figura 31 mostra a média da área coberta pelos deslocamentos do COP para as três condições ( $\mathrm{V}, \mathrm{NV}, \mathrm{F})$ em função dos 13 alvos relativos ao ELOS (superior), média e desvio padrão para os 5 alvos na direção $\mathrm{m}$-I (inferior esquerda) e média e desvio padrão para os 5 alvos na direção a-p (inferior direita). Valores positivos da posição dos alvos representam a direita para a direção $\mathrm{m}-\mathrm{l}$ e a frente para a direção a-p.
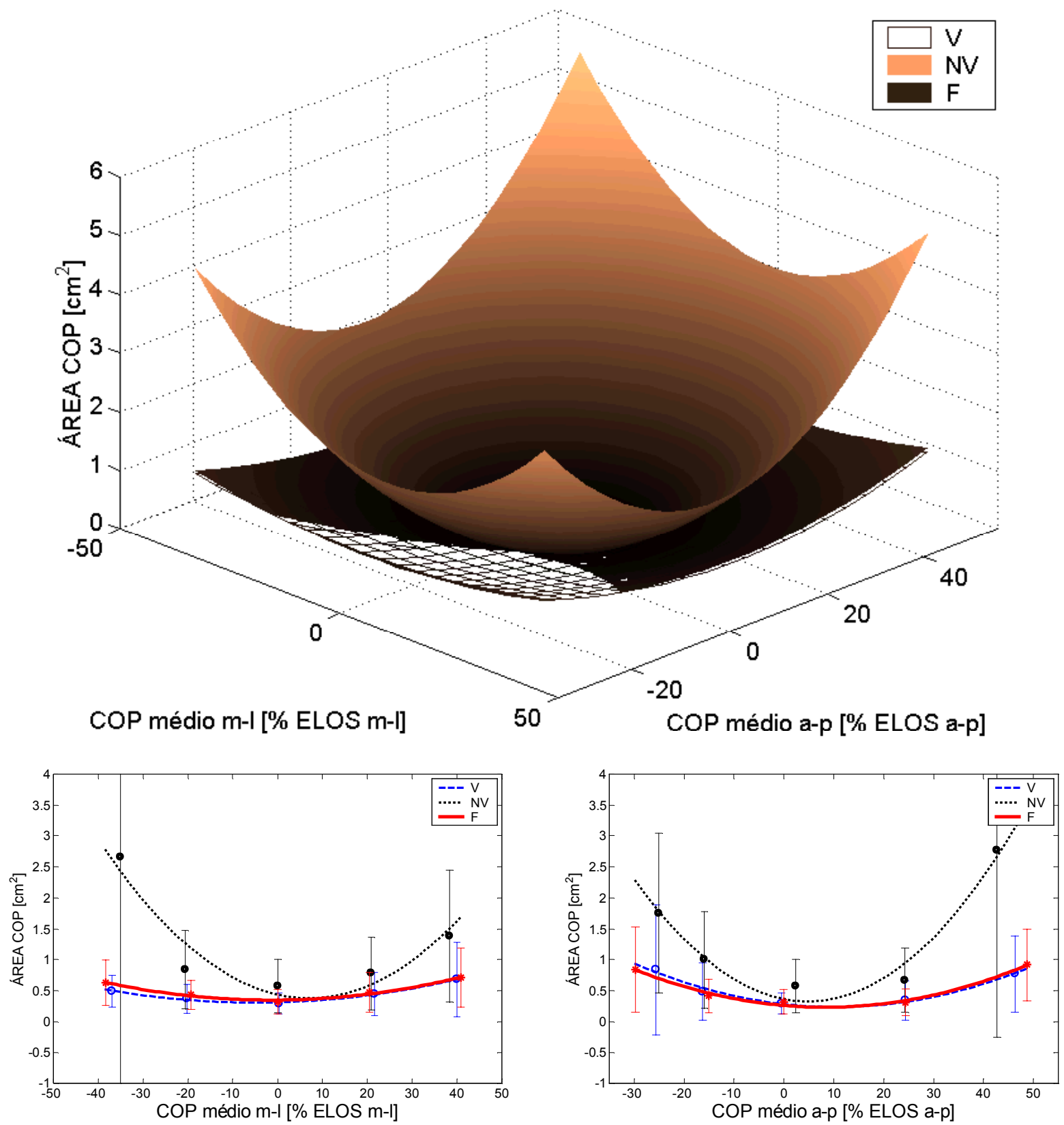

Figura 31. Média da área coberta pelos deslocamentos do COP para as três condições (V, NV, F) em função dos 13 alvos relativos ao ELOS (superior), média e desvio padrão para os 5 alvos na direção m-l (inferior esquerda) e média e desvio padrão para os 5 alvos na direção a-p (inferior direita). Valores positivos da posição dos alvos representam a direita para a direção m-l e a frente para a direção a-p. 
A Figura 32 mostra a média da velocidade média resultante dos deslocamentos do COP para as três condições ( $V, N V, F)$ em função dos 13 alvos relativos ao ELOS (superior), média e desvio padrão para os 5 alvos na direção $\mathrm{m}$-I (inferior esquerda) e média e desvio padrão para os 5 alvos na direção a-p (inferior direita). Valores positivos da posição dos alvos representam a direita para a direção m-l e a frente para a direção a-p.
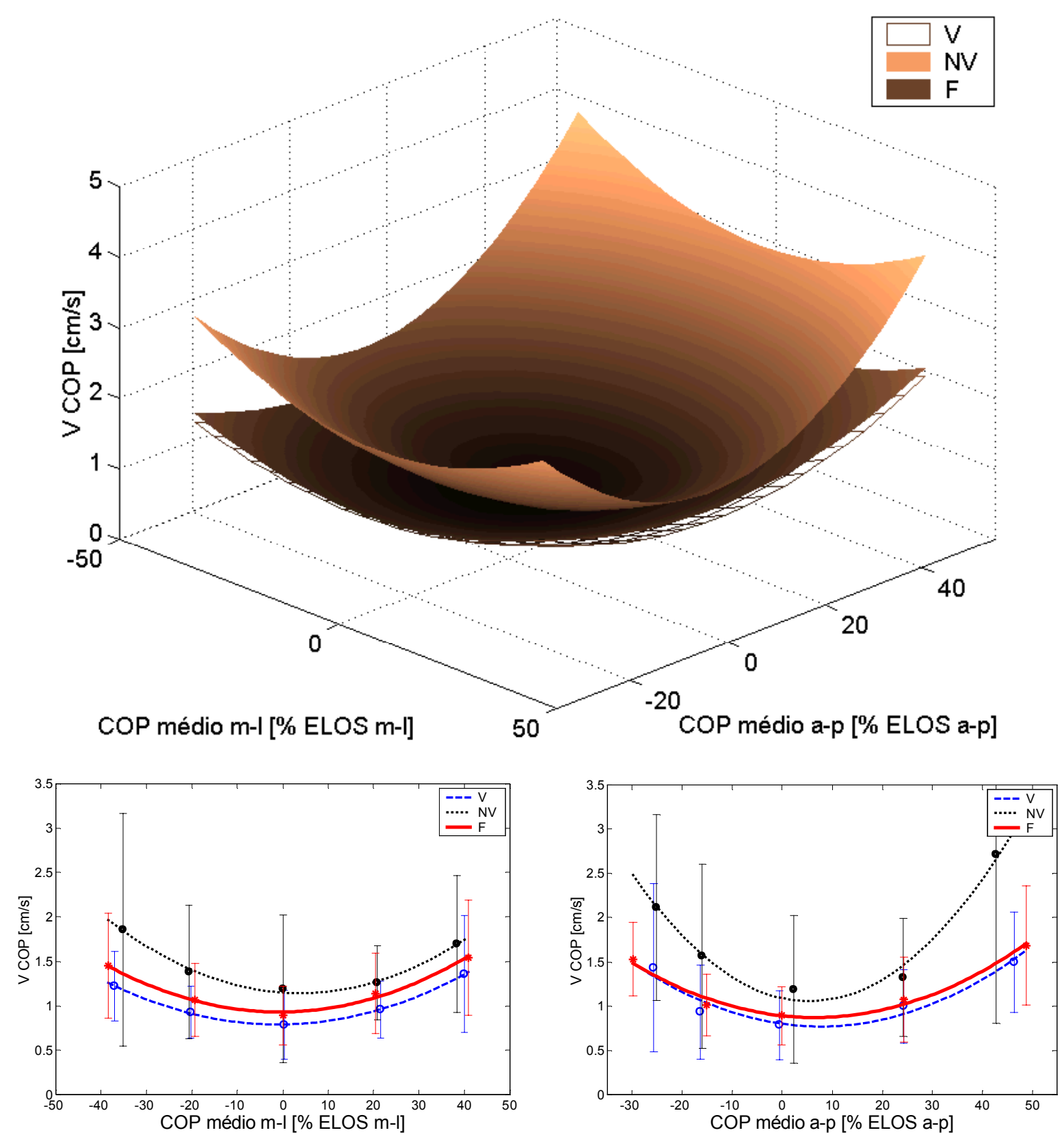

Figura 32. Média da velocidade média resultante dos deslocamentos do COP (V COP) para as três condições $(V, N V, F)$ em função dos 13 alvos relativos ao ELOS (superior), média e desvio padrão para os 5 alvos na direção m-l (inferior esquerda) e média e desvio padrão para os 5 alvos na direção a-p (inferior direita). Valores positivos da posição dos alvos representam a direita para a direção m-l e a frente para a direção ap. 
A Figura 33 mostra a média das freqüências medianas dos deslocamentos do COP para as três condições ( $\mathrm{V}, \mathrm{NV}, \mathrm{F}$ ) em função dos 13 alvos relativos ao ELOS (superior), média e desvio padrão para os 5 alvos na direção $\mathrm{m}-\mathrm{I}$ (inferior esquerda) e média e desvio padrão para os 5 alvos na direção a-p (inferior direita). Valores positivos da posição dos alvos representam a direita para a direção $\mathrm{m}-\mathrm{l}$ e a frente para a direção a-p.
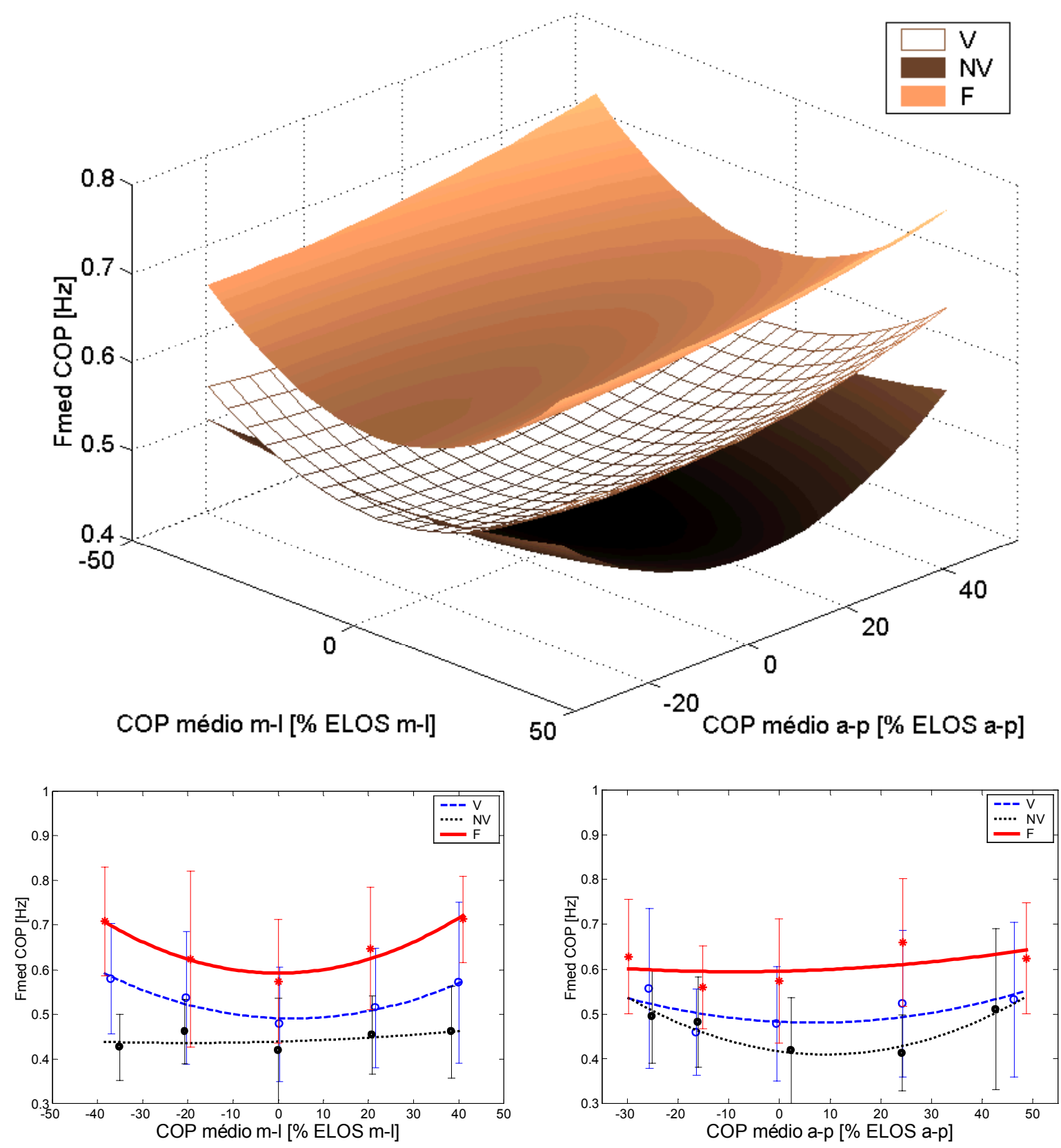

Figura 33. Média da freqüência mediana dos deslocamentos do COP para as três condições $(V, N V, F)$ em função dos 13 alvos relativos ao ELOS (superior), média e desvio padrão para os 5 alvos na direção m-l (inferior esquerda) e média e desvio padrão para os 5 alvos na direção a-p (inferior direita). Valores positivos da posição dos alvos representam a direita para a direção m-l e a frente para a direção a-p. 
As diferenças entre os resultados obtidos para as variáveis AREA, V e Fmed (Tabela 4) foram verificadas através de análise de variância (ANOVA de um fator (informação visual) com três níveis (com visão, sem visão e com feedback) para medidas repetidas para os seguintes alvos: neutro $(N)$, extremo anterior $(E A)$, extremo posterior $(E P)$, extremo esquerdo $(E E)$ e extremo direito (ED)). O teste post-hoc de Tukey foi utilizado para análise da diferença intra-níveis.

Tabela 4. Médias, desvios padrões e interações das variáveis área do estabilograma (AREA), velocidade média resultante do COP (v) e freqüência mediana do COP (Fmed) para os alvos: neutro ( $N)$, extremo anterior (EA), extremo posterior (EP), extremo esquerdo (EE) e extremo direito (ED). ANOVA medidas repetidas, teste posthoc de Tukey. Níveis de significância: *<0,05; **<0,01; ***<0,001.

\begin{tabular}{|c|c|c|c|c|c|c|}
\hline \multirow{3}{*}{$\begin{array}{c}\text { ALVO } \\
\mathrm{N}\end{array}$} & \multicolumn{6}{|c|}{ VARIÁVEIS (interação e valores médios) } \\
\hline & \multicolumn{2}{|c|}{ ÁREA $\left[\mathrm{cm}^{2}\right]$} & \multicolumn{2}{|c|}{$\mathrm{v}[\mathrm{cm} / \mathrm{s}]$} & \multicolumn{2}{|c|}{ Fmed [Hz] } \\
\hline & $\mathrm{V}, \mathrm{NV}$ ** & $V=0,29 \pm 0,17$ & $\mathrm{~V}, \mathrm{NV}$ * & $V=0,79 \pm 0,39$ & $N V, F$ * & $V=0,48 \pm 0,13$ \\
\hline & $\mathrm{NV}, \mathrm{F}$ ** & $N V=0,57 \pm 0,43$ & & $N V=1,19 \pm 0,83$ & & $N V=0,42 \pm 0,12$ \\
\hline & & $F=0,32 \pm 0,2$ & & $F=0,89 \pm 0,33$ & & $\mathrm{~F}=0,57 \pm 0,14$ \\
\hline \multirow[t]{3}{*}{ EA } & $\mathrm{V}, \mathrm{NV}$ * & $V=0,77 \pm 0,62$ & $\mathrm{~V}, \mathrm{NV}$ ** & $V=1,49 \pm 0,57$ & & $V=0,53 \pm 0,17$ \\
\hline & $N V, F^{*}$ & $N V=2,77 \pm 3,02$ & $\mathrm{NV}, \mathrm{F}$ * & $\mathrm{NV}=2,71 \pm 1,91$ & & $N V=0,51 \pm 0,18$ \\
\hline & & $F=0,92 \pm 0,58$ & & $F=1,69 \pm 0,68$ & & $F=0,62 \pm 0,12$ \\
\hline \multirow[t]{3}{*}{ EP } & $\mathrm{V}, \mathrm{NV}$ * & $V=0,84 \pm 1,05$ & $\mathrm{~V}, \mathrm{NV}$ * & $V=1,44 \pm 0,95$ & $\mathrm{NV}, \mathrm{F}^{*}$ & $V=0,56 \pm 0,18$ \\
\hline & $N V, F$ * & $N V=1,75 \pm 1,29$ & & $N V=2,11 \pm 1,05$ & & $N V=0,49 \pm 0,1$ \\
\hline & & $F=0,84 \pm 0,69$ & & $F=1,53 \pm 0,41$ & & $F=0,63 \pm 0,13$ \\
\hline \multirow[t]{3}{*}{ EE } & & $V=0,49 \pm 0,26$ & $\mathrm{~V}, \mathrm{NV}$ * & $V=1,22 \pm 0,39$ & $\mathrm{~V}, \mathrm{NV}$ ** & $V=0,58 \pm 0,12$ \\
\hline & & $N V=2,66 \pm 4,69$ & & $N V=1,86 \pm 1,31$ & $\mathrm{~V}, \mathrm{~F}$ * & $N V=0,43 \pm 0,07$ \\
\hline & & $F=0,63 \pm 0,36$ & & $F=1,45 \pm 0,59$ & $\mathrm{NV}, \mathrm{F}^{* * *}$ & $F=0,71 \pm 0,12$ \\
\hline \multirow[t]{3}{*}{ ED } & $\mathrm{V}, \mathrm{NV}$ *** & $V=0,68 \pm 0,6$ & $\mathrm{~V}, \mathrm{NV}{ }^{* * *}$ & $V=1,36 \pm 0,66$ & $\mathrm{~V}, \mathrm{~F}^{*}$ & $V=0,57 \pm 0,18$ \\
\hline & $N V, F * * *$ & $N V=1,38 \pm 1,07$ & $\mathrm{~V}, \mathrm{~F} *$ & $N V=1,7 \pm 0,77$ & $\mathrm{NV}, \mathrm{F} * * *$ & $N V=0,46 \pm 0,1$ \\
\hline & & $F=0,71 \pm 0,47$ & & $F=1,54 \pm 0,64$ & & $F=0,71 \pm 0,1$ \\
\hline
\end{tabular}

\subsection{Discussão}

A Figura 31, Figura 32 e Figura 33 mostram como o equilíbrio postural é afetado pela informação visual em função da manutenção da postura em diferentes posições dentro dos limites de estabilidade do sujeito. Três variáveis foram escolhidas para descrever o equilíbrio postural: a área coberta pelo deslocamento do COP, a velocidade média resultante do COP e a freqüência mediana do COP. Estas descrevem o comportamento do equilíbrio nos domínios de tempo e freqüência.

Observaram-se tendências nas séries temporais brutas para as condições com e sem visão para os alvos próximos aos extremos de equilíbrio. Essas tendências indicam que o sujeito movia-se lentamente em direção à posição neutra (representando um ponto atrator), principalmente na condição sem visão. Estas tendências, do ponto de vista estatístico, comportavam-se como não estacionariedades nos dados e foram removidas utilizando-se um filtro passa alta com freqüência de corte de 0,05 Hz como já descrito. Ao contrário, Schieppati et al. (1994) não observaram tendências nas séries temporais do COP na direção a-p para as condições com e sem visão.

O comportamento geral do variável área, velocidade média e freqüência mediana indica 
a existência de um poço de potencial descrito por um parabolóide, cujos valores mínimos correspondem à posição de equilíbrio neutro. Para as variáveis área e velocidade média, os poços apresentam valores semelhantes para as condições com visão e com feedback do COP e apresentam concavidade maior para a condição sem visão, indicando que nesta condição o comportamento do equilíbrio é mais afetado pela posição de manutenção da postura.

Os resultados indicam que o feedback não foi capaz de diminuir a dispersão espacial do COP, medida pela área do estabilograma, quando comparada à condição com visão. Em um estudo sobre feedback para a posição neutra, Krizková et al. (1993) reportaram a diminuição do desvio padrão do COP para ambas direções na condição com feedback em relação à condição com visão. Estes autores argumentam que a contribuição do feedback visual para a diminuição da oscilação se deu em freqüências bastante baixas (até $0,05 \mathrm{~Hz}$ ). Estas freqüências estão associadas às tendências nos dados do presente estudo e que foram removidas com o filtro passa-alta. Logo, estes dados não estão em desacordo com Krizková et al. (1993). Surpreendentemente, o feedback não reduziu a dispersão, mesmo em condições extremas de equilíbrio, onde a área do COP foi de duas a três vezes maior que a área na posição de equilíbrio neutro com apenas a informação visual ou com o feedback.

É interessante notar que a freqüência mediana mostra um comportamento inverso ao da área para todos os alvos. A condição sem visão apresenta a menor freqüência mediana, seguida por um valor maior para a condição com visão e um valor ainda maior para a condição com feedback visual. Isto evidencia como a informação visual foi utilizada para a manutenção do equilíbrio nas diferentes posições. Os sujeitos utilizaram a informação visual para a correção da posição, mas a maior freqüência de utilização da informação visual na condição com feedback não foi efetiva para diminuir a dispersão espacial do COP se comparado à condição com visão.

A maior velocidade média do COP foi para a condição sem visão. Isto se deveu a maior oscilação do COP, como indicado pela variável área, que levou a um maior deslocamento do COP. Na maioria dos alvos, a velocidade do COP durante a condição com feedback visual foi maior durante a condição de visão normal. Ainda que não foram encontradas diferenças significativas entre a área do COP para estas duas condições, as maiores freqüências do COP na condição com feedback contribuíram para a maior velocidade.

Há duas possíveis explicações para a ausência de efeito do feedback na tentativa de minimizar a dispersão do COP. A primeira explicação é que, apesar do feedback visual do COP, sujeitos simplesmente não conseguiriam controlar de forma efetiva os pequenos desvios do COP devido à inércia do sistema e ao tempo de reação para o feedback ser processado e resultar numa ação motora. A segunda explicação está relacionada à natureza mecânica do feedback do COP. Quando surge o feedback, a reação do sujeito é aproximar o COP do alvo, i.é, mover-se em direção ao alvo. Esta reação gera em um primeiro instante um movimento do COP para a direção contrária e só depois o COP move-se em direção ao alvo. O movimento do COG na horizontal, a GL, este sim, move-se sempre em direção ao alvo. Isto significa que qualquer tentativa de controlar o COP para minimizar a distância entre a posição do ponto de feedback e o alvo resultará inicialmente no aumento da distância devido à natureza das variáveis COP e COG, como comentado na Sessão 2.4.

Os presentes resultados suportam que o papel do sistema visual no controle da postura ereta é principalmente gerar correções da posição do COG em longos períodos, atuando de forma descontínua, como um gatilho para estratégias posturais programadas e padrões de ativação muscular (Paulus et al., 1987). 
Estes resultados e interpretações dos dados mostram como a informação visual é utilizada em função de diferentes posições médias para a manutenção da postura. As mesmas análises podem ser repetidas para a GL com o intuito de aprofundar este entendimento. Análises posteriores da forma da trajetória do COP podem ser conduzidas para entender como as diferentes posições médias afetam o controle da postura nas direções a-p e m-l separadamente. 


\section{Conclusões gerais}

Para a análise das oscilações observadas durante a postura ereta, um método numérico mais eficiente e preciso para a estimação do centro de gravidade a partir do centro de pressão e da força horizontal foi implementado neste trabalho e é descrito na Sessão 2.6.

O estudo da postura ereta irrestrita de longa duração descrito no Capitulo 3 revelou que existem padrões especificos e consistentes da migração do centro de pressão, que podem ser reconhecidos por meio de um algoritmo computacional. No Capitulo 4, estes padrões denominados shift, fidget e drift foram analisados em função da carga que o sujeito carregava presa em sua cintura, da condição de visão, superfície e calçado durante a postura ereta. Inesperadamente, não houve nenhum efeito significativo sobre o número de padrões do centro de pressão associado às mudanças posturais. Em média, foram observados dois padrões por minuto do centro de pressão em todas as condições. Estes resultados questionam os beneficios divulgados comercialmente dos tapetes anti-fadiga e solados de sola macia para a postura ereta irrestrita sob o ponto ponto de vista biomecânico, pelo menos até 30 minutos de duração da tarefa.

Foi reportado pela primeira vez a correlação de longo alcance do tipo ruído $1 /$ f na tarefa de postura ereta irrestrita de longos periodos, evidenciando as propriedades fractais do sinal do centro de pressão. A presença de correlação de longo alcance e de características fractais do sistema de controle postural em grupos de dados com intervalos de poucos segundos até muitos minutos de duração tem implicações importantes para a análise do equilíbrio humano.

O estudo sobre o compromisso entre velocidade e acurácia dos movimentos humanos utilizando-se o paradigma da lei de Fitts revelou a presença de um efeito escala e a relação linear entre o tempo de movimento e o grau de dificuldade da tarefa não é observada.

A variabilidade do COP durante a postura ereta quieta foi mapeada em função de diferentes posições médias de equilíbrio relativas à base de suporte e avaliou o papel da informação visual nesta situação. Para tanto, três condições de informação visual foram investigadas: com visão, sem visão e com feedback visual do COP. O comportamento geral da variável área, velocidade média e freqüência mediana indica a existência de um poço de potencial descrito por um parabolóide, onde os valores mínimos de cada variável correspondem à posição de equilíbrio neutro. 


\section{0 comenturios frinais}

O presente trabalho relata pesquisas em que estive envolvido nos últimos três anos sobre o controle postural e equilibrio. Algumas destas pesquisas, embora sobre o mesmo tema, são bastante diversificadas, evidenciando minha postura exploratória sobre o tema. Vejo estas pesquisas como o início da consolidação de meus estudos sobre o controle postural; sem dúvida, há muito por se estudar e aplicar. Acredito que a principal aplicação dos estudos sobre controle postural está envolvida com os idosos. O declínio da capacidade de controle do equilibrio é um problema muito sério e comum em idosos, com graves efeitos sobre sua qualidade de vida e um elevado custo social à sociedade. Infelizmente, lesões e fatalidades devido à quedas por causa do debilitado controle postural acometem grande parcela dos idosos.

A avaliação do rendimento do sistema de controle postural é fundamental para o acompanhamento e diagnóstico de possíveis deteriorações do controle postural de indivíduos. $O$ estudo sobre o rendimento de movimentos do corpo inteiro de adultos utilizando-se a relação entre velocidade e acurácia do movimento para descrever a performance de movimentos do corpo inteiro, como descrito no capítulo 7 , pode ser aplicado como método de avaliação do sistema de controle postural. Este paradigma experimental é especialmente atrativo para se estudar o controle postural em seres humanos porque avalia o rendimento do controle do centro de pressão (COP) durante a postura ereta numa situação dinâmica onde o movimento do COP aproxima-se dos limites de estabilidade do individuo. Este paradigma também seria atrativo para o treinamento do controle postural, pois apresenta a capacidade de recrutar $e$ avaliar seletivamente diferentes estratégias de equilíbrio, como as estratégias do quadril e do tornozelo. Este fato é vantajoso para reabilitação postural dado que estudos indicam que idosos apresentam uma maior diminuição da capacidade de desenvolver a estratégia do tornozelo do que a estratégia do quadril (Shumway-Cook \& Woollacott, 1995). Outras possibilidades seriam fornecer como feedback visual o centro de gravidade (COG) ou os ângulos articulares (do tornozelo e quadril) em vez do COP. Estes diferentes tipos de feedback podem ser mais vantajosos para a avaliação de estratégias de manutenção postural e para seu treinamento porque o COG indica realmente o movimento global do corpo e porque os ângulos articulares são uma medida direta destas estratégias.

Num futuro próximo, pretendo investigar algumas destas idéias para a população de idosos. 


\section{Referências}

Aggashyan, R.V., Gurfinkel, V.S., Fomin, S.V. (1973a) Correlation and spectral analysis of the fluctuations of the human body during standing. Biofizika, 18, 1105-1108.

Aggashyan, R.V., Gurfinkel, V.S., Mamasakhlisov, G.V., Elner, A.M. (1973b) Changes in spectral and correlation characteristics of human stabilograms at muscle afferentation disturbance. Agressologie, 14, 5-9.

Alexander, R. M. (1992) The Human Machine. New York: Columbia University Press.

Amblard, B., Crémieux, J., Marchand, A.R.; Carblanc, A. (1985) Lateral orientation and stabilization of human stance: static versus dynamic visual cues. Experimental Brain Research, 61, 21-37.

Bak, P., Tang, C., Wiesenfeld, K. (1987) Self-organized criticality: An explanation of 1/f noise. Phys. Rev. Let., 59, 381-384.

Baloh, R. W., Fife, T. D., Zwerling, L., Scotch, T., Jacobson, K., Bill, T., Beykirch, K. (1994) Comparison of static and dynamic posturography in young and older normal people. J. American Geriatrics Society, 42, 405-412.

Basmajian, J. V. (1979) Muscles Alive, (Williams \& Wilkins Co, Baltimore).

Benda, B.J., Riley, P.O., and Krebs, D.E. (1994) Biomechanical relationship between the center of gravity and center of pressure during standing. IEEE Transactions on Rehabilitation Engineering, 2, 3-10.

Bensel, C.K., Dzendolet, F. (1968) Power spectral density analysis of the standing sway of males. Perception \& Psychophysics, 4, 285-288.

Beran, J. (1994) Statistics for Long-Memory Processes. Chapman \& Hall, New York.

Bhatnager, V., Drury, C.G., Schiro, S.G. (1984) The effect of time-at-task on posture and performance in inspection. In Attwood, D.A., McCann, C. (Eds.), Proceedings of the 1984 International Conference on Occupational Ergonomics, 1, 289-293. Toronto, Ontario, Canada.

Bhatnager, V., Drury, C.G., Schiro, S.G. (1985) Posture, postural discomfort, and performance. Human Factors, 27, 189-199.

Brantingham, C.P., Beekman, B.E., Moss, C.N., Gordon, R. (1970) Enhanced venous pump activity as a result of standing on a varied terrain floor surface. J. Occupational Medicine, 12, 164-169.

Bräuer, D., Seidel, H. (1981) The autoregressive structure of postural sway. In Morecki, A., Fidelius, K., Kedzior, K., and Wit, A. (Eds.), Biomechanics VII-A, 1550-1560. Baltimore, MD: University Park Press.

Bridger, R.S. (1991) Some fundamental aspects of posture related to ergonomics, International J. Industrial Ergonomics, 8, 3-15.

Caron, O., Faure, B., Breniere, Y. (1997) Estimating the centre of gravity of the body on the basis of the centre of pressure in standing posture. J. Biomechanics, 30, 1169-1171.

Cavanagh, P.R., Rodgers, M.M., liboshi, A. (1987) Pressure distribution under symptom-free feet during barefoot standing. Foot \& Ankle, 7, 262-276.

Chen, Y., Ding, M., Kelso, J.A.S. (1997) Long memory processes $\left(1 / f^{\alpha}\right.$ type) in human coordination. Phys. Rev. Let., 79, 4501-4504.

Chi, C.F., Lin, C.L. (1997) Speed and accuracy of eye-gaze pointing. Percept. Mot. Skills, 85, 705718.

Clarke, A.H., Krzok, W., Scherer, H. (1990) Posturography with sensory feedback - a useful approach to vestibular training? In: Brandt, T.; Paulus, W.; Bles, W.; Dieterish, M.; Krafcyk, S.; Straube, A. (eds.). Disorders of posture and gait. Stuttgart, NY: George Thieme Verlag, 281-284.

Collins, J.J., De Luca, C.J. (1993) Open-loop and closed-loop control of posture: A random walk analysis of center-of-pressure trajectories. Experimental Brain Research, 95, 308-318.

Collins, J.J., De Luca, C.J. (1994) Random walk during quiet standing. Physical Review Letters, 73, 764-767.

Collins, J.J., De Luca, C.J. (1995a) The effects of visual input on open-loop and closed- loop postural control mechanisms. Experimental Brain Research, 103, 151-163. 
Collins, J.J., De Luca, C.J. (1995b) Upright, correlated random walks: A statistical-biomechanics approach to the human postural control system. Chaos, 5, 57-63.

Crémieux, J., Mesure, S. (1994) Differential sensitivity to static visual cues in the control of postural equilibrium in man. Percept Mot Skills, 78, 67-74.

Crossman, E.R.F.W. (1956) The measurement of perceptual load. Ph.D. thesis, University of Birmingham, England

Crowe, A., Schiereck, P., Boer, R. Keessen, W. (1993) Characterization of gait of young adult females by means of body centre of mass oscillations derived from ground reaction forces. Gait \& Posture, 1, 61-68.

Danion, F., Duarte, M., Grosjean, M. (1999) Fitts' law in human standing: the effect of scaling. Neuroscience Letters, 277, 131-133.

De Luca, C.J. LeFever, R.S., McCue, M.P., Xenakis, A.P. (1982) Control scheme governing cocnurrently active human motor units during voluntary contractions. J. Physiology, 329, 129-142.

Diener, H. C.. Dichgans, J. (1988) On the role of vestibular, visual and somatosensory information for dynamic postural control in humans. Progress in Brain Research, 76, 253-262.

Drury, C.G. (1975) Application of Fitts' law to foot-pedal design. Hum. Fact., 17, 368-373.

Duarte, M., Zatsiorsky, V.M. (1999) Patterns of center of pressure migration during prolonged unconstrained standing, Motor Control, 3, 12-27.

Duarte, M., Zatsiorsky, V.M. (2000) On the fractal properties of natural human standing. Neuroscience Letters, 283, 173-176.

Duarte, M., Zatsiorsky, V.M. (2000) Stabilographic Analysis of Prolonged Unconstrained Standing. Ergonomics. IN PRESS.

Duarte, M., Zatsiorsky, V.M. Long-range correlations in human standing. Submetido a Physical Review E.

Duarte, M., Zatsiorsky, V.M. Visual information, limits of variability, and variability of the human standing. Manuscrito em preparação.

Eng, J.J., Winter, D.A. (1993) Estimations of the horizontal displacement of the total body centre of mass: considerations during standing activities. Gait \& Posture, 1, 141-144.

Feder, J. (1988) Fractals. Plenum Press, New York, NJ.

Firsov, V.I., Rosenbum, M.G. (1990) Chaotic dynamics of the upright human posture control. In Proceedings of First World Congress on Biomechanics. La Jolla, CA.

Fitts, P.M. (1954) The information capacity of the human motor system in controlling the amplitude of movement. J. Exp. Psychol. (HPP), 47, 381-391.

Fowler, B., Duck, T., Mosher, M., and Mathieson, B. (1991) The coordination of bimanual aiming movements: evidence for progressive desynchronization. Quat. J. Exp. Psychol., 43, 205-221.

Furman, J. M. R., Baloh, R. W., Barin, K., Hain, T. C., Herdman, S., Konrad, H. R., Parker, S. W. (1993) Assessment: Posturography, Report of the Therapeutics and Technology Assessment Subcommittee of the American Academy of Neurology, Neurology, 43, 1261-1264.

Gard, S.A., Childress, D.S. (1997) Investigation of vertical motion of the human body during normal walking. Gait \& Posture, 5, 161.

Gilden, D.L. Thornton, T. Mallon, M.W. (1995) 1/f noise in human cognition. Science, 267, 1837-1839.

Goldberger, A.L., West, B.J. (1987) Fractals in physiology and medicine. The Yale J. Biol. Med., 60, 421-435.

Goldstein, H. (1980) Classical mechanics. 2a ed., Addison-Wesley, USA.

Gurfinkel, E.V. (1973) Physical foundations of stabilography. Agressologie, 14, 9-14.

Gurfinkel, V.S. et al. (1968) Regulation of human posture (em Russo). Nauka, Mocow.

Gurfinkel, V.S., Ivanenko, Yu.P., Levik, YU.S., Babakova, I.A. (1995) Kinesthetic reference for human orthograde posture. Neuroscience, 68, 229-243.

Gurfinkel, V.S., Lipshits, M.I., Popov, K.Ye. (1974) Is the stretch reflex the main mechanism in the system of regulation of the vertical posture of man? Biophysics, 19, 761-766.

Hamann, K.F.; Krausen, C.H. (1990) Clinical application of posturography: body tracking and biofeedback training. In: Brandt, T.; Paulus, W.; Bles, W.; Dieterish, M.; Krafcyk, S.; Straube, A. (eds.). Disorders of posture and gait. Stuttgart, NY: George Thieme Verlag, 295-298.

Hamman, R.G., Mekjavic, I., Mallinson, A.I.; Longridge, N.S. (1992) Training effects during repeated therapy sessions of balance training using visual feedback. Arch. Phys. Med. Rehabil., 73, 738744.

Hasan, S.S., Lichtenstein, M.J., Shiavi, R.G. (1990) Effect of loss of balance on biomechanics platform measures of sway: influence of stance and a method for adjustment. J. Biomechanics, 23, 783789.

Hasan, S.S., Robin, D.W., Szurkus, D.C., Ashmed, D.H., Peterson, S.W., Shiavi, R.G. (1996) Simultaneous measurement of body center of pressure and center of gravity during upright stance. 
Part I: Methods. Gait \& Posture, 4, 1-10.

Hausdorff, J. M., Mitchell, S. L., Firtion, R., Peng, C.-K., Cudkowicz, M. E., Wei, J. Y., Goldberger, A. L. (1997). J. Appl. Physiol. 82, 262.

Hausdorff, J.M., Peng, C.-K., Ladin, Z., Wei, J.Y., Goldberger, A.L. (1995) Is walking a random walk? Evidence for long-range correlations in stride interval of human gait. J. Appl., Physiol., 78, 349-358. Havlin, S., Selinger, R. B., Schwartz, M., Stanley, H. E., Bunde, A. (1988). Phys. Rev. Let., 13, 1438. Hayes, K.C. (1982) Biomechanics of postural control. Ex. Sp. Sci. Rev., 10, 363-392.

Hellebrandt, F.A. (1938) Standing as a geotropic reflex. American J. Physiology, 121, 471-474.

Hirvonen, T.P., Aalto, H., Pyykkö, I. (1997) Stability limits for visual feedback posturography in vestibular rehabilitation. Acta Otolaryngol., S529, 104-107.

Hoffmann, E.R. (1991) A comparison of hand and foot movement times. Ergonomics, 34, 397-406.

Hoffmann, E.R. (1992) Fitts' law with transmission delay. Ergonomics, 35, 37-48.

Hogan, N. (1984) An organizing principle for a class of voluntary movements. J. Neuroscience, 4, 2745-2754.

Horak, F. B. (1997) Clinical assessment of balance disorders. Gait \& Posture, 6, 76-84.

Hufschmidt, A., Dichgans, J., Mauritz, K.H., Hufschmidt, M. (1980) Some methods and parameters of body sway quantification and their neurological application. Arch. Psychiat. Nervenkr., 228, 135-150.

Jobst, U. (1990) Patterns and strategies in posturographic biofeedback training. In: Brandt, T.; Paulus, W.; Bles, W.; Dieterish, M.; Krafcyk, S.; Straube, A. (eds.). Disorders of posture and gait. Stuttgart, NY: George Thieme Verlag, 277-280.

Johansson, R., Magnussson, M. (1991) Human postural dynamics. Critical Reviews in Biomedical Engineering, 18, 413-437.

Kandel, E.R., Schwartz, J.H., Jessell, T.M. (1991) Principles of neural science. Appleton \& Lange, East Norwalk, Connecticut, $3^{\text {a }}$ ed.

Kapteyn, T.S., Bles, W., Njiokiktjien, Ch.J., Kodde, L., Massen, C.H., Mol, J.M.F. (1983) Standardizationin platform stabilometry being a part of posturography. Agressologie, 24, 321-326.

Keane, F. X. (1979) The minimum physiological mobility requirement for man supported on a soft surface. Paraplegia, 16, 383-389.

Kelso, J.A., Southard, D.L., Goodman, D. (1979) On the nature of human interlimb coordination. Science, 203, 1029-1031.

Kim, J.Y., Stuart-Buttle, C., Marras, W. S. (1994) The effects of mats on back and leg fatigue. Applied Ergonomics, 25, 29-34.

King, D.L., Zatsiorsky, V.M. (1997) Extracting gravity line displacement from stabilographic recordings. Gait and Posture, 6, 27-38.

Kingma, I., Toussaint, H.M., Comissaris, D.A.C.M., Hoozemans, M.J.M., Ober, M.J. (1995) Optimizing the determination of the body center of mass. J. Biomechanics, 28, 1137-1142.

Krizková, M., Hlavacka, F., Gatev, P. (1993) Visual control of human stance on a narrow and soft support surface. Physiol. Res., 42, 267-272.

Koozekanani, S.H., Duerk, J. (1985) Determination of body segment parameters and their effect in the calculation of the position of center of pressure during postural sway. IEEE Transactions on Biomedical Engineering, 32, 67-69.

Langolf, G.D., Chaffin, D.B., Foulke, J.A. (1976) An investigation of Fitts' law using a wide range of movement amplitudes, J. Mot. Behav., 8, 113-128.

Latash, M., Gottlieb, G. (1990) Hypothesis on the equilibrium point and variability of amplitude, speed and time of single-joint movement (in Russian). Biofizika, 35, 870-874.

Latash, M.L. (1993) Control of human movement. Human Kinetics, Champaign, IL, USA.

Latash, M.L. (1997) Neurophysiological basis of human movement. Human Kinetics, Champaign, IL, USA.

Lauk, M., Chow, C.C., Pavlik, A.E., Collins, J.J. (1998) Human balance out of equilibrium: nonequilibrium statistical mechanics in posture control. Physical Review Letters, 80, 413-416.

Ledin, T.; Kronbed, A.C.; Moller, C. (1991) Effects of balance training in elderly evaluated by clinical tests and dynamic posturography. J. Vestibular Research, 1, 129-138.

Lee, M.Y., Wong, M.K.; Tang, F.T. (1996) Clinical evaluation of a new biofeedback standing balance training device. J. Medical Engineering \& technology, 20, 60-66.

Lestienne, F.G., Gurfinkel V.S. (1988) Posture as an organizational structure based on a dual process: a formal basis to interpret changes of posture in weightlessness. In Pompeiano, O. \& Allum, J.H.J. (Eds), Progress in Brain Research, 76, 307-313. Amsterdam: Elsevier Science.

Levin, O., Mizrahi, J. (1996) An iterative procedure for estimation of center of pressure from bilateral reactive force measurements in standing sway. Gait and Posture, 4, 89-99. 
MacKenzie, I.S. (1992) Fitts' law as a research and design tool for in human-computer interaction. Hum. Comput. Interaction, 7, 91-113.

Madeleine, P., Voigt, M., Arendt-Nielsen, L. (1998) Subjective, physiological and biomechanical responses to prolonged manual work performed standing on hard and soft surfaces. European $\mathrm{J}$. Applied Physiology, 77, 1-9.

Mandelbrot, B.B. (1983) The Fractal Geometry of Nature. Freeman, San Francisco.

Marinari, E., Parisi, G., Ruelle, D., Windey, P. (1983) On the interpretation of $1 / f$ noise. Commun. Math. Phys., 89, 1-12.

Massion, J. (1998) Postural control systems in developmental perspective. Neuroscience Behav Rev, 22, 465-472.

MathWorks, Inc., The (1996) Signal Processing Toolbox User's Guide. Natick, MA, USA

Montroll, E.W., Shlesinger, M.F. (1982) On 1/f noise and other distributions with long tails, Proc. Natl. Acad. Sci., USA, 79, 3380-3383.

Murray, M.P., Seireg, A., Scholz, R.C. (1967) Center of gravity, center of pressure, and supportive forces during human activities. J. Applied Physiology, 23, 831-838.

Murray, M.P., Seireg, A., Sepic, S.B. (1975) Normal postural stability and steadiness: quantitative assessment. J. Bone and Joint Surgery, 57, 510-516.

Nashner, L.M. (1981) Analysis of stance posture in humans. In A.L. Towe, A. and E.S. Luschei, E. (Eds.), Handbook of Behavioral Neurobiology, Motor Coordination, 5, 521-561. New York: Plenum Press.

Nashner, L.M., McCollum, G. (1985) The organization of human postural movements: a formal basis and experimental synthesis. Behav. Br. Sc., 8, 135-172.

Newell, K.M., Slobounov, S.M., Slobounova, E.S., Molenaar, P.C. (1997) Stochastic processes in postural center-of-pressure profiles. Experimental Brain Research, 113, 158-164.

Newell, K.M., van Emmerik, R.E.A., Lee, D., Sprague, R.L. (1993) On postural stability and variability. Gait \& Posture, 4, 225-230.

Nichols, D.S. (1997) Balance retraining after stroke using force platform biofeedback. Physical Therapy, 77, 553-558.

Norre, M., Forrez, G., Beckers, A. (1987a) Posturography measuring instability in vestibular dysfunction in the elderly. Age \& Aging, 16, 89-93.

Norre, M., Forrez, G., Beckers, A. (1987b) Posturographic findings in two common peripheral vestibular disorders. J. Otolaryngology, 16, 340-344.

Oliveira, L. F., Simpson, D. M., Nadal, J. (1994) Calculation of area of stabilometric signals using principal component analysis. Physiological Measurement, 17, 305-312.

Pai, Yi-C., Patton, J. (1997) Center of mass velocity-position predictions for balance control. J. Biomechanics, 4, 347-354.

Panzer, V.P., Bandinelli, S.; Hallett, M. (1995) Biomechanical assessment of quiet standing changes associated with aging. Arch. Phys. Med. Rehabil., 76, 151-157.

Paulus, W.M., Straube, A., Brandt, T. (1984) Visual stabilization of posture. Brain, 107, 1143-1163.

Paulus, W.M., Straube, A., Brandt, T.H. (1987) Visual postural peformance after loss of somatosensory and vestibular function. J. Neurol. Neurosurg. Psychiat., 50, 1542-1545.

Peeters, H.P.M., Caberg, C.H., Mol, J.M.F. (1985) Evaluation of biomechanical models in posturography. Medical \& Biological Engineering and Computing, 23, 469-473.

Peng, C.-K., Buldyrev, S.V., Goldberger, A.L., Havlin, S., Sciortino, F., Simons, M., Stanley, H.E. (1993a) Finite-size effects on long-range correlations: Implications for analyzing DNA sequences. Phys. Rev. E, 47, 3730-3733.

Peng, C.-K., Buldyrev, S.V., Goldberger, A.L., Havlin, S., Sciortino, F., Simons, M., Stanley, H.E. (1992) Long-range correlations in nucleotide sequences. Nature, 356, 168-170.

Peng, C.-K., Buldyrev, S.V., Havlin, S., Simons, M., Stanley, H.E., Goldberger, A.L. (1994) Mosaic organization of DNA nucleotides. Phys. Rev. E, 49, 1685-1689.

Peng, C.-K., Mietus, J., Hausdorff, J.M., Havlin, S., Stanley, H.E., Goldberger, A.L. (1993b) Longrange anticorrelations and non-gaussian behavior of the hearbeat. Phys. Rev. Let., 70, 1343-1346.

Per Bak, T.C., Wiesenfeld, K. (1987) Self-organized criticality: and explanation of 1/f noise. Phys. Rev. Let., 59, 381-384.

Plamondon, R.; Alimi, A. (1997) Speed-accuracy trade-off in target directed movements. Behav. Br. Sc., 20, 279-349.

Powell, G.M., Dzendolet, E. (1984) Power spectral density analysis of lateral human standing sway. J. Motor Behavior, 16, 424-441.

Prieto, T.E., Myklebust, J.B., Myklebust, B.M. (1993) Characterization and modeling of postural steadiness in the elderly: a review. IEEE Transactions on Rehabilitation Engineering, 1, 26-34. 
Prieto, T.E., Myklebust, J.B., Myklebust, B.M., Kreis, D.U. (1992) Intergroup sensitivity in measures of postural steadiness. In Woolacott, M. \& F. Horak, F. (Eds.), Posture and Gait: Control Mechanisms (XIth Int. Symp. Postural Gait Research), 122-125. Portland, OR: University of Oregon Books.

Riach, C.L., Starkes, J.L. (1993) Stability limits of quiet standing postural control in children and adults. Gait \& Posture, 1, 105-111.

Riach, C.L., Starkes, J.L. (1994) Velocity of centre of pressure excursions as an indicator of postural control systems in children. Gait \& Posture, 2, 167-172.

Riccio, G. E., McDonald, V. (1998) Methods for investigating adaptive postural control. In Proceedings of the Satellite meeting to the Society for Neuroscience: Identifying control mechanisms for postural behaviors, November 6-7, 1998, (Los Angeles, CA).

Riccio, G.E. (1993) Information in movement variability about the qualitative dynamics of posture and orientation. In Newell, K. and Corcos, D. (Eds.), Variability and Motor Control, 317-358. Champaign, IL: Human Kinetics Publishers.

Riley, P.O., Mann, R.W., Hodge, A.W. (1990) Modeling of the biomechanics of posture and balance. J. Biomechanics, 23, 503-506.

Riley, M.A., Mitra, S., Stoffregen, T.A., Turvey, M.T. (1997) Influences of body lean and vision on unperturbed postural sway. Motor Control, 1, 229-246.

Riley, P.O., Benda, B.J., Gill-Body, K.M., Krebs, D.E. (1995) Phase plane analysis of stability in quiet standing. J. Rehabilitation Research Development, 32, 227-235.

Rothwell, J. (1994) Control of human voluntary movement. $2^{\mathrm{a}}$ ed., Chapman \& Hall, London, UK.

Roy, S.H., Ladin, Z., De Luca, C.J. (1987) Experimental evidence for a random process model of postural sway. In Proceedings of 9th Ann. Int. Conf. IEEE Engineering in Medicine and Biology Society, 9, 759 .

Rys, M., Konz, S. (1994) Standing. Ergonomics, 37, 677-687.

Schieppati, M., Hugon, M., Grasso, M., Nardone, A., Galante, M. (1994) The limits of equilibrium in young and elderly normal subjects and in parkinsonians. Electroencephalography and Clinical Neurophysiology, 93, 286-298.

Schumann, T., Redfern, M.S., Furman, J.M., El-Jaroudi, A., Chaparro, L.F. (1995) Time-frequency analysis of postural sway. J. Biomechanics, 28, 603-607.

Scott, D.E., Dzendolet, E. (1972) Quantification of sway in humans. Agressologie, 13, 35-40.

Shimba, T. (1984) An estimation of center of gravity from force platform data. J. Biomechanics, 17, 53-60.

Shumway-Cook, A., Anson, D., Haller, S. (1989) Postural sway biofeedback: its effect on reestablishing stance stability in hemiplegic patients, Arch. Phys. Med. Rehabil., 70, 755-762.

Shumway-Cook, A., Anson, D.; Haller, S. (1988) Postural sway biofeedback: its effect on reestablishing stance stability in hemiplegic patients, Arch. Phys. Med. Rehabil., 69, 395-400.

Shumway-Cook, A., Woollacott, M. (1995) Motor Control: Theory and pratical applications. Baltimore, Williams \& Wilkins.

Slobounov, S.M., Newell, K.M. (1994) Postural dynamics as a function of skill level and task constraints. Gait \& Posture, 2, 85-93.

Slobounov, S.M., Slobounov, E.S., Newell, K.M. (1997) Virtual time-to-collision and human postural control. J. Motor Behavior, 28, 263-281.

Soames, R.W., Atha, J., Harding, R.H. (1976) Temporal changes in the pattern of sway as reflected in power spectral density analysis. Agressologie, 17, 15-20.

Spaepen, A. J., Vranken, M., Willems, E.J. (1977) Comparison of the movements of the center of gravity and of the center of pressure in stabilometric studies. Agressologie, 18, 109-113.

Spaepen, A. J., Peeraer, L., Willems, E.J. (1979) Center of gravity and center of pressure in stabilometric studies. A comparison with film analysis. Agressologie, 20, 117-118.

Starkes, J.L., Riach, J.C., Clarke, B. (1992) The effect of eye closure on postural sway: Converging evidence from children and a parksonian patient. In L. Proteau, L. and D. Elliott, D. (Eds.), Vision and Motor Control, 353-373. Elsevier Science Publishers B.V.

Takata, K., Kakeno, H., Watanabe, Y. (1983a) Time series analysis of postural sway and respiration using an autoregressive model. In Matsui, H. and Kobayashi, K. (Eds.), Biomechanics VIII-A, 591596. Champaign, IL: Human Kinetics Publishers.

Takata, K.; Kakeno, H., Watanabe, Y. (1983b) Time series analysis os postural sway and respiration using an autoregressive model. Biomechanics VIIIA, Human Kinetics Pub., Champaign, 591-596.

Terekhov, Y. (1976) Stabilometry and some aspects of its applications - a review. Biomed. Eng., 6, 1115, 1976.

Terekhov, Y. (1976) Stabilometry as a diagnostic tool in clinical medicine. CMA J., 115, 631-633, 1976. 
Theiler, J., Eubank, S., Longtin, A., Galdrikian, B. Farmer, J.D. (1992) Testing for nonlinearity in time series: the method of surrogate data. Physica D, 58, 77-94.

Thomas, D.P., Whitney, R.J. (1959) Postural movements during normal standing in man. J. Anatomy, 93, 524-539.

Tokumasu, K., Ikegami, A., Tashiro, N., Bre, M., Yoneda, S. (1983) Frequency analysis of the body sway in different standing postures. Agressologie, 24, 89-90.

Weissman, M.B. (1988) $1 / \mathrm{f}$ noise and other slow, nonexponential kinetics in condensed matter. Rev. Mod. Phys., 60, 537-571.

Welford, A.T. (1968) Fundamentals of skills. Barnes \& Noble, New York.

West, G.B., Brown, J.H., Enquist, B.J. (1997) A general model for the origin of allometric scaling laws in biology. Science, 276, 122-126.

Whistance, R. S., Adams, L. P., van Geems, B. A., Bridger, R. S. (1995) Postural adaptations to workbench modifications in standing workers. Ergonomics, 38, 2485-2503.

Williams, H.G., McClenaghan, B.A., Dickerson, J. (1997) Spectral characteristics of postural control in eldery individuals. Archives of Physical Medicine and Rehabilitation, 78, 737-744.

Winstein, C.J., Gardner, E.R., McNeal, D.R., Barto, P.S. (1989) Standing balnce training: effect on balance and locomotion in hemiparetic adults. Arch. Phys. Med. Rehabil., 70, 755-762.

Winter, D.A. (1990) Biomechanics and motor control of human movement. $2^{\mathrm{a}}$ ed., John Wiley \& Sons, New York.

Winter, D.A. (1995) A.B.C. (Anatomy, Biomechanics, and Control) of Balance during Standing and Walking, (Waterloo Biomechanics, Waterloo, Ontario).

Winter, D.A., Patla, A.E., Frank, J.S. (1990) Assessment of balance control in humans. Medical Progress through Technology, 16, 31-51.

Winter, D.A., Patla, A.E., Prince, F., Ishac, M., Gielo-Perczak, F (1998) Stiffness control of balance in quiet standing. J. Neurophysiology, 80, 1211-1221.

Witt, A., Kurths, J., Pikovsky A. (1998) Testing stationarity in time series. Phys. Rev. E, 58, 18001810.

Woolacott, M.H., Shumway-Cook, A. (1990) Changes in posture control across the life span - A systems approach. Physical Therapy, 70, 799-807.

Yoneda, S., Tokumasu, K. (1986) Frequency analysis of body sway in the upright posture. Statistical study in cases of peripheral vestibular disease. Acta Otolaryngologica, 102, 87-92.

Zacharkow, D. (1988) Posture: Sitting, Standing, Chair Design and Exercise, (Charles C. Thomas, Springfield).

Zatsiorsky, V.M., Duarte, M. (1999) Instant equilibrium point and its migration in standing tasks: rambling and trembling components of the stabilogram. Motor Control, 3, 28-38.

Zatsiorsky, V.M., Duarte, M. (2000) Rambling and trembling in quiet standing. Motor Control, IN PRESS.

Zatsiorsky, V.M., King, D.L. (1998) An alghoritm for estimating the center of gravity migration from stabilographic recording. J. Biomechanics, 31, 161-164.

Zhang, L., Drury, C.G., Wooley, S.M. (1991) Constrained standing: evaluating the foot/floor interface. Ergonomics, 34, 175-192. 